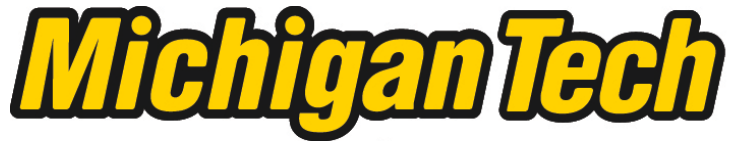 \\ Michigan Technological University Create the Future Digital Commons @ Michigan Tech
}

Dissertations, Master's Theses and Master's Reports - Open

Dissertations, Master's Theses and Master's

Reports

2011

\section{Effects of hibernation on bone in yellow-bellied marmots}

Samantha J. Wojda

Michigan Technological University

Follow this and additional works at: https://digitalcommons.mtu.edu/etds

Part of the Mechanical Engineering Commons

Copyright 2011 Samantha J. Wojda

\section{Recommended Citation}

Wojda, Samantha J., "Effects of hibernation on bone in yellow-bellied marmots", Master's Thesis, Michigan Technological University, 2011.

https://doi.org/10.37099/mtu.dc.etds/424

Follow this and additional works at: https://digitalcommons.mtu.edu/etds

Part of the Mechanical Engineering Commons 
THE EFFECTS OF HIBERNATION ON BONE IN YELLOW-BELLIED MARMOTS

By

Samantha J. Wojda

\begin{abstract}
A THESIS
Submitted in partial fulfillment of the requirements for the degree of MASTER OF SCIENCE

Mechanical Engineering
\end{abstract}

MICHIGAN TECHNOLOGICAL UNIVERSITY

2011

(C) 2011 Samantha J. Wojda 
This thesis "The Effects of Hibernation on Bone in Yellow-Bellied Marmots," is hereby approved in partial fulfillment of the requirements for the Degree of MASTER OF SCIENCE IN MECHANICAL ENGINEERING.

Department of Mechanical Engineering-Engineering Mechanics

Signatures:

Thesis Advisor

Seth W. Donahue, $\mathrm{PhD}$

Committee Member

Rupak Rajachar, $\mathrm{PhD}$

Committee Member

Gopal Jayaraman, $\mathrm{PhD}$

Department Chair

William W. Predebon, PhD

Date 


\section{Table of Contents}

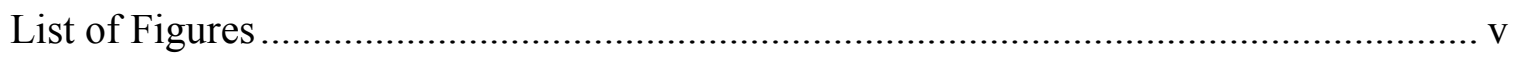

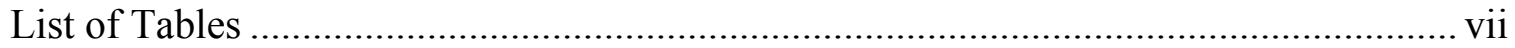

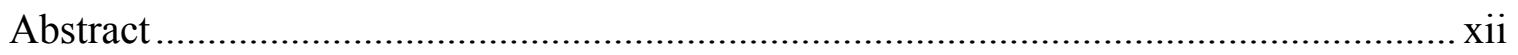

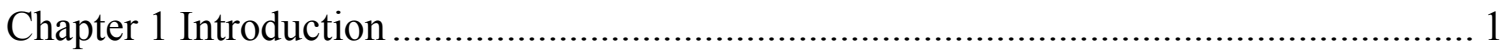

1.1 Osteoporosis Overview ………….................................................................... 1

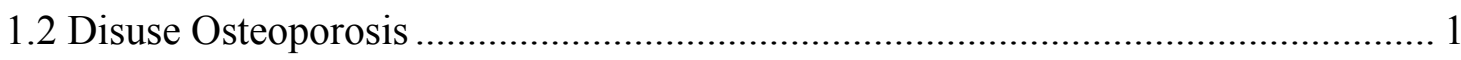

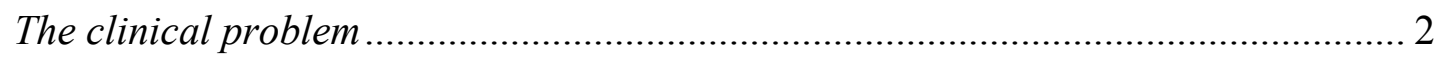

Effects of disuse on cortical bone in mammals........................................................ 3

Effects of disuse on trabecular bone in mammals ..................................................... 3

Recovery of disuse induced bone loss....................................................................... 4

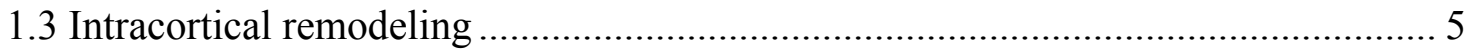

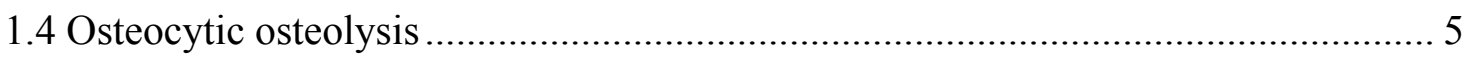

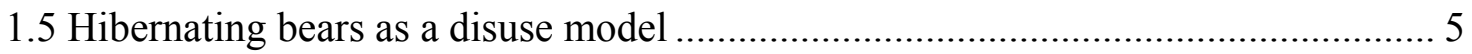

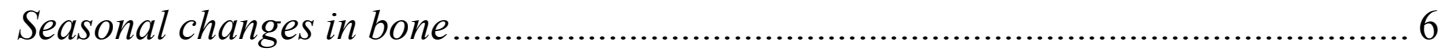

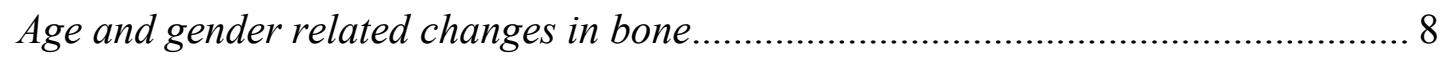

1.6 Small hibernators as a disuse model ................................................................... 9

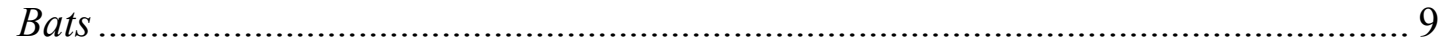

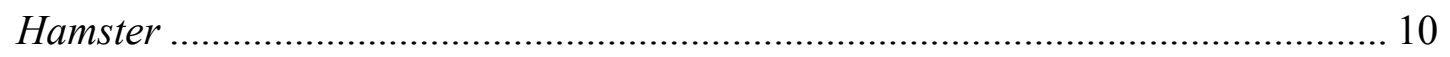

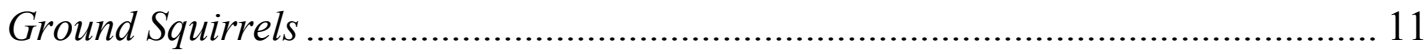

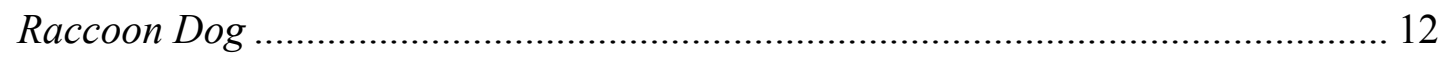

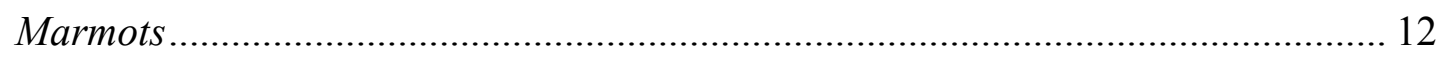

1.7 Hibernating marmots as a disuse model......................................................... 12

1.8 Hypothesis and Specific Aims ....................................................................... 13

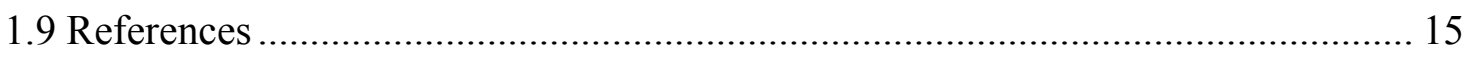

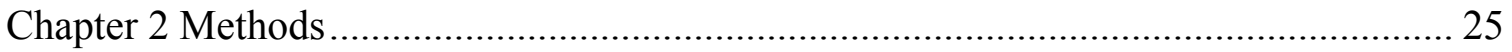

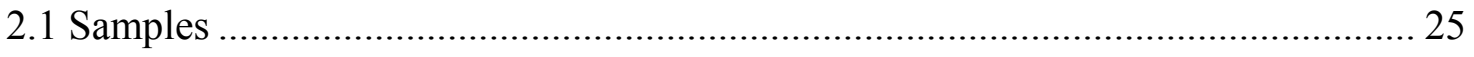

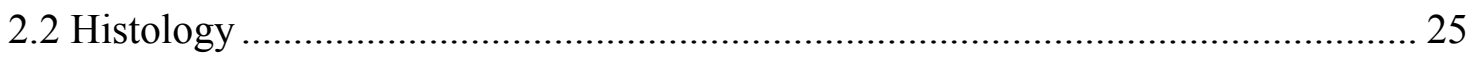

Lacunar properties ……………………………………………………….... 26 
Resorption and Refilling Cavities...................................................................... 28

Intracortical Porosity ....................................................................................... 28

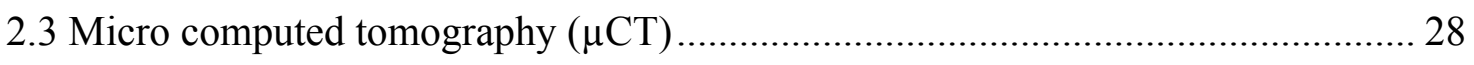

2.4 Geometrical properties .................................................................................. 31

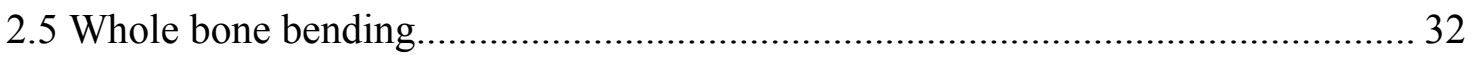

Whole bone mechanical properties ..................................................................... 33

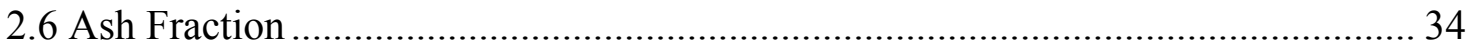

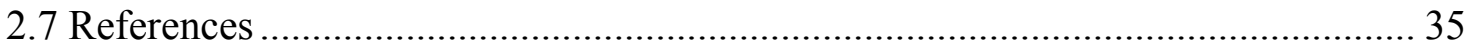

Chapter 3 Results and Conclusions............................................................................ 37

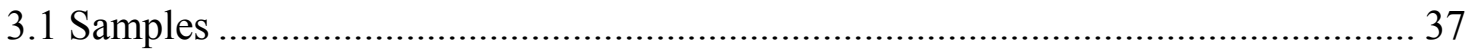

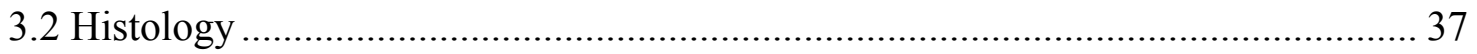

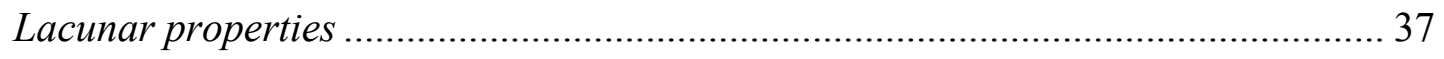

Resorption and Refilling Cavities.......................................................................... 39

Intracortical Porosity ................................................................................... 42

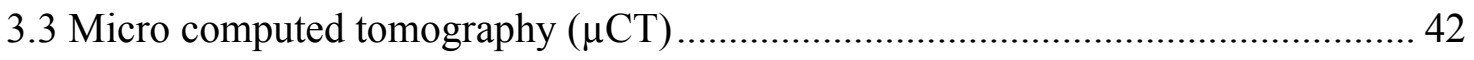

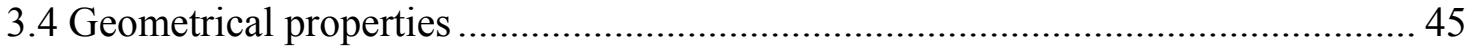

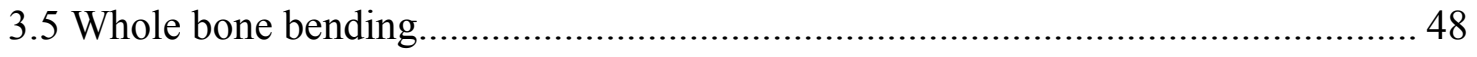

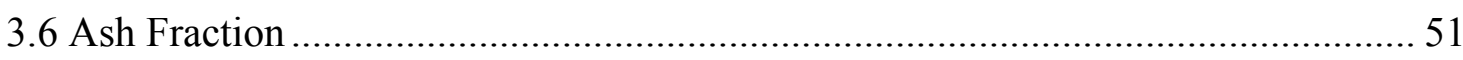

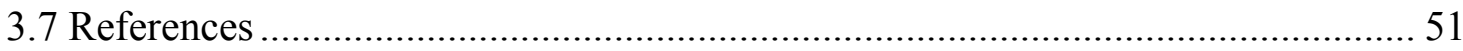

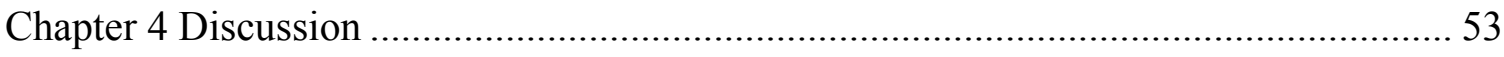

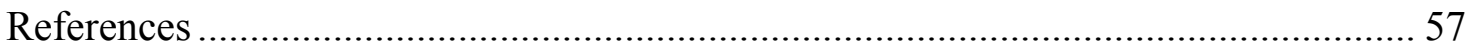

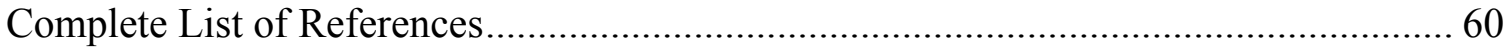

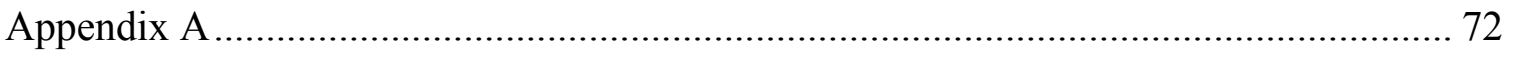




\section{List of Figures}

Figure 2.1: The gray highlighted on this femur outline is the region used for histology. After embedding, sections were cut perpendicular to the long axis of the bone. Sections were cut starting at the midshaft............................... 26

Figure 2.2: Femur cross section, where the grey lines represent the location of anatomical octants. Red boxes indicate location of images obtained from each octant for analysis of osteocyte lacunar properties. Note: size representation of images in comparison to cross section size may vary............................. 26

Figure 2.3: Osteocyte lacunae data was collected in three groups. Lacunae with a partial halo (left), lacunae with no halo (middle), and lacunae with a halo (right). 27

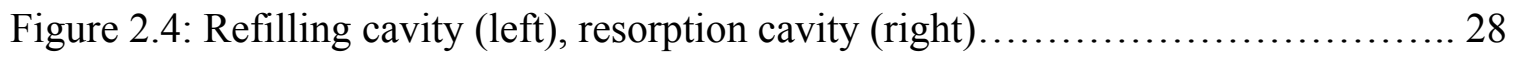

Figure 2.5: Marmot tibia next to the fixture used for micro-CT .................... 29

Figure 2.6: Micro-CT scout view of a marmot tibia with evaluation region highlighted.

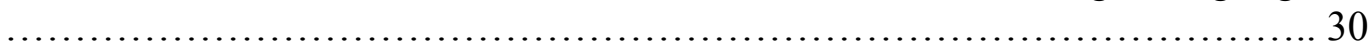

Figure 2.7: 3-D reconstruction of the region of a marmot tibia scanned with $\mu \mathrm{CT} \ldots \ldots 30$

Figure 2.8: Example of a digitized femoral cross section used to calculate cross sectional properties. The neutral axis and point furthest from the neutral axis, as well as the $\mathrm{x}$ and $\mathrm{y}$ distances from the centroidal axis to the point furthest from the neutral axis and moments of inertia were determined by the macro.................... 32

Figure 2.9: Typical load-deformation curve, red X marks the failure point. Stiffness is denoted as $\mathrm{S}$ on the curve and yield force is denoted as $\mathrm{F}_{\mathrm{y}}$. Yield was found by $0.2 \%$ offset method on the stress strain curve. Failure energy $\left(U_{f}\right)$ is the sum of

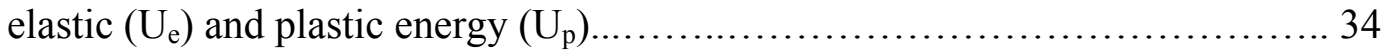

Figure 2.10: The segment of cortical bone used for determination of ash fraction is highlighted in gray.................................................... 35

Figure 3.1: Lacunar porosity was $21 \%$ lower in post-hibernation samples $(\mathrm{p}<0.0001)$. 38

Figure 3.2: Remodeling cavity density was not different between groups $(\mathrm{p}=0.843)$.

Figure 3.3: Intracortical porosity was not different between pre- and post-hibernation samples. However, pre-hibernation samples appeared to have increased periosteal bone formation. The red circle highlights one of these forming primary osteons. 
Figure 3.4: Trabecular thickness was $19.6 \%$ greater in post-hibernation samples $(\mathrm{p}=$

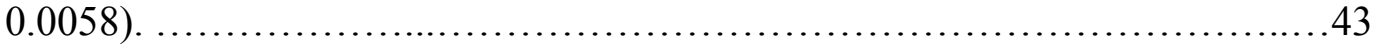

Figure 3.5: Material mineral density was $3.5 \%$ higher in post-hibernation samples $(\mathrm{p}=$

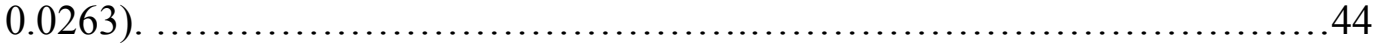

Figure 3.6: After normalization cortical area was higher in post-hibernation samples...48

Figure 3.7: Ash fraction was higher in post-hibernation samples...................51

Figure A.1: Representative images of lacunae with a halo, partial halo or no halo...... 72 


\section{List of Tables}

Table 2.1: Span and length-diameter (L/D) ratio information for pre- and post-hibernation samples.

Table 3.1: Weight and femur length information for pre- and post-hibernation samples with $\%$ differences in post hibernation samples relative to pre-hibernation samples 37

Table 3.2: Osteocyte lacunar property results for all lacunae in the field of view, with \% differences in post hibernation samples relative to pre-hibernation samples. 38

Table 3.3: Data from paired t-test ( $\mathrm{n}=11$ per group) of lacunar properties with $\%$ differences in post hibernation samples relative to pre-hibernation samples. Lacunar properties are lower in post hibernation samples. 39

Table 3.4: Samples were divided into 4 groups based on femur length and remodeling cavity density for each quartile was examined to determine whether or not there was remodeling present in smaller samples. Avg.RC.Dn stands for average remodeling cavity density.

Table 3.5: Results of one-way ANOVA comparing pre-hibernation vs. post-hibernation samples for all properties measured by $\mu \mathrm{CT}$ with $\%$ differences in post hibernation samples relative to pre-hibernation samples.

Table 3.6: Trabecular bone properties normalized by (femur length) ${ }^{3}$ with $\%$ differences in post hibernation samples relative to pre-hibernation samples.............. 45

Table 3.7: Geometrical properties compared between pre- and post-hibernation groups with $\%$ differences in post hibernation samples relative to pre-hibernation samples 46

Table 3.8: Normalized geometrical properties with \% differences in post hibernation samples relative to pre-hibernation samples. Cross-sectional areas were normalized by (femur length) ${ }^{2}$ and moments of inertia were normalized by (femur length) ${ }^{4}$ according to known scaling relationships (Ruff 1984; Casinos et al. 1993; Heinrich and Biknevicius 1998). Endosteal area/periosteal area was not normalized for this table since it is a ratio.

Table 3.9: Mechanical properties calculated from three-point bending test with \% differences in post hibernation samples relative to pre-hibernation samples 49 
Table 3.10: Mechanical properties calculated from three-point bend tests for select samples. Twelve samples from each group were paired by femur length and compared using paired t-test to better assess the effects of hibernation on these properties by eliminating effects due to post-hibernation samples being larger than pre-hibernation samples. Data is presented with \% differences in post hibernation samples relative to pre-hibernation samples...............................5 50

Table A.1: Summary of how results compare for each measurement type...............73

Table A.2: All lacunae-Average lacunar area, porosity, and density are lower in post-

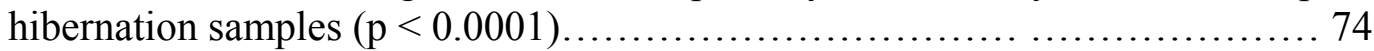

Table A.3: All lacunae-Average lacunar area for each octant, area is different by octant ( $p$ $<0.0001)$. Octants with the same letters are not significantly different from each other. Data presented is for all samples (spring and fall groups

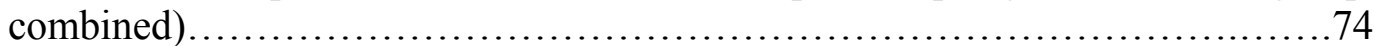

Table A.4: All lacunae-Lacunar porosity data for each octant, porosity is different by octant $(\mathrm{p}=0.0162)$. Octants with the same letters are not significantly different from each other. Data presented is for all samples (spring and fall groups

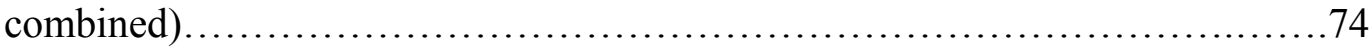

Table A.5: All lacunae-Lacunar density data for each octant, lacunar density is different by octant $(\mathrm{p}<0.0001)$. Octants with the same letters are not significantly different from each other. Data presented is for all samples (spring and fall groups combined). .75

Table A.6: All lacunae-Average lacunar area is lower in the endosteal region. Lacunar density is higher in endosteal regions. Lacunar porosity is not different between sampling areas. Data presented is for all samples (spring and fall groups

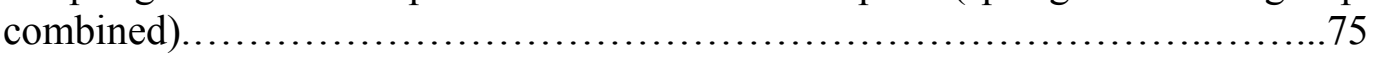

Table A.7: Lacunae with full halos-Average lacunar area and lacunar density are lower in post-hibernation samples $(\mathrm{p}<0.0001)$. Lacunar porosity tends to be lower in post-

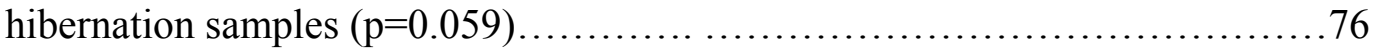

Table A.8: Lacunae with full halos-Average lacunar area is different between octants $(\mathrm{p}<$ 0.0001). Octants with the same letters are not significantly different from each other. Data presented is for all samples (spring and fall groups combined).

Table A.9: Lacunae with full halos-Lacunar porosity is not different between octants ( $\mathrm{p}=$ 0.2462). (Octants with the same letters are not significantly different from each other). Data presented is for all samples (spring and fall groups combined).

Table A.10: Lacunae with full halos-Lacunar density is not different between octants ( $\mathrm{p}$ $=0.358$ ). (Octants with the same letters are not significantly different from each 
other). Data presented is for all samples (spring and fall groups combined)

Table A.11: Lacunae with full halos-Average lacunar area is lower in the endosteal region. Lacunar density and porosity are higher in endosteal regions. Data presented is for all samples (spring and fall groups combined).................77

Table A.12: Lacunae with full halo or partial halo-Average lacunar area, lacunar porosity, and lacunar density are lower in post-hibernation samples $(\mathrm{p}<0.0001)$.

Table A.13: Average lacunar area is different between octants $(\mathrm{p}<0.0001)$. Octants with the same letters are not significantly different from each other. Data presented is for all samples (spring and fall groups combined) $\ldots \ldots \ldots \ldots \ldots \ldots \ldots \ldots \ldots \ldots . \ldots \ldots$

Table A.14: Lacunae with full halo or partial halo-Lacunar porosity is not different between octants $(p=0.4206)$. (Octants with the same letters are not significantly different from each other). Data presented is for all samples (spring and fall

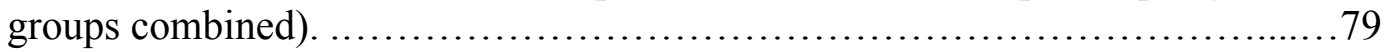

Table A.15: Lacunae with full halo or partial halo-Lacunar density varies between octants $(\mathrm{p}=0.0027)$. (Octants with the same letters are not significantly different from each other). Data presented is for all samples (spring and fall groups combined).

Table A.16: Lacunae with full halo or partial halo-Average lacunar area is lower in the endosteal region. Lacunar density is higher in endosteal regions. And there is no difference between endosteal and periosteal locations for lacunar porosity. Data presented is for all samples (spring and fall groups combined).

Table A.17: Lacunae with no halo-Average lacunar area, lacunar porosity, and lacunar density are lower in post-hibernation samples $(\mathrm{p}<0.0002) \ldots \ldots \ldots \ldots \ldots \ldots \ldots . . .60$

Table A.18: Lacunae with no halo-Average lacunar area is not different between octants $(\mathrm{p}<0.3751)$. Octants with the same letters are not significantly different from each other. Data presented is for all samples (spring and fall groups combined).

Table A.19: Lacunae with no halo-Lacunar porosity varies between octants $(p=0.0123)$. (Octants with the same letters are not significantly different from each other). Data presented is for all samples (spring and fall groups combined).

Table A.20: Lacunae with no halo-Lacunar density varies between octants $(\mathrm{p}<0.0001)$. (Octants with the same letters are not significantly different from each other). Data presented is for all samples (spring and fall groups combined). 
Table A.21: Lacunae with no halo-Average lacunar area is lower in the endosteal region $(p<0.0001)$. Lacunar density is higher in endosteal regions $(p<0.0001)$. Lacunar porosity is not different between regions $(\mathrm{p}=0.1267)$. Data presented is for all samples (spring and fall groups combined) .................................. 81 


\section{Acknowledgements}

I would like to thank the following people for everything they have done to help make this project a success:

Dr. Seth Donahue

Dr. Hal Black

Dr. Janene Auger

Dr. Meghan McGee-Lawrence

Adam Abraham

Richie Gridley 
Disuse osteoporosis is a problem for people with spinal cord injury or stroke, patients confined to bed rest, and astronauts exposed to microgravity. Unlike most mammals however, bears have been shown to prevent bone loss during hibernation, a seasonal period of disuse. Similarly, studies in ground squirrels indicate preservation of whole bone strength during hibernation, though evidence suggests there may be some increased osteocytic osteolysis. Uncovering the mechanism by which these animals prevent bone loss during hibernation could lead to an improved treatment for osteoporosis in humans. Marmots are a good animal model for these studies because they are small enough to easily house in an animal facility yet still utilize intracortical remodeling like humans and bears, and unlike smaller rodents like squirrels. Marmots preserve bone mechanical and microstructural properties during hibernation. Bone mechanical and geometrical properties are not diminished in post-hibernation samples compared to pre-hibernation samples. Mineral content, measured by ash fraction, was higher in post-hibernation samples $(\mathrm{p}=0.0003)$. Haversian porosity as well as remodeling cavity density were not different $(p>0.38)$ between pre- and post-hibernation samples. Similarly, average lacunar area, lacunar density, and lacunar porosity were all lower $(\mathrm{p}<0.0001)$ in post-hibernation samples. Trabecular thickness was larger in posthibernation samples $(\mathrm{p}=0.0058)$. Bone volume fraction was not different between groups, but approached significance $(\mathrm{p}=0.0725)$. Further studies in marmots and other hibernators could help uncover the mechanism that allows hibernators to prevent disuse osteoporosis during hibernation. 


\section{Chapter 1 \\ Introduction}

\subsection{Osteoporosis Overview}

Osteoporosis is a worldwide problem affecting both men and women, most commonly of the elderly population. A widely accepted definition of osteoporosis is the World Health Organization's definition, which is bone mineral density (BMD) levels being more than 2.5 standards of deviation below the normal young adult mean for the given population (Kanis et al. 1994; Organization 1994). There are various factors that can affect bone mineral density including, but not limited to, smoking, nutrition, and physical activity (Law and Hackshaw 1997; Compston 2000; Takata and Yasui 2001; Gerdhem and Obrant 2002; Christodoulou and Cooper 2003; Ducher et al. 2006). Gender and race also appear to have an effect on osteoporosis. From data collected in 1995, the National Osteoporosis Foundation reported that $78.9 \%$ of all hospitalizations for osteoporotic fractures were for women; only 6.4\% of these cases were for non-white women (Ray et al. 1997). As a result of lower bone mineral density, people with osteoporosis are at a greater risk of fracture. An epidemiological study done in Rochester, MN produced data that, when extrapolated, estimates 1.5 million fractures occur every year due to osteoporosis in the United States alone (Riggs and Melton 1995). Estimated health care costs in 1995 for the treatment of osteoporotic fractures in people age 45 or older was \$13.76 billion (Ray et al. 1997). Bisphosphonates including ibandronate, alendronate, zoledronic acid and risedronate have been shown to reduce risk of vertebral fracture and increase BMD in post-menopausal women (Reginster et al. 2000; Bone et al. 2004; Chesnut et al. 2004; Black et al. 2007). Some other treatments include calcitonin, parathyroid hormone $(\mathrm{PTH})$, and hormone replacement therapy using estrogen and progesterone (Epstein 2006). There are various options for treatment, however, all have their drawbacks and there is room for improvement. For example PTH and bisphosphonates are currently used as treatments for osteoporosis; however, effectiveness is limited under disuse conditions ( $\mathrm{Li}$ et al. 2005; R. T. Turner et al. 2006).

\subsection{Disuse Osteoporosis}

Disuse osteoporosis, or bone loss caused by a decrease in physiological levels of mechanical loading, is a problem for astronauts exposed to microgravity, patients confined to bed rest, or patients with spinal cord injury (SCI) (Takata and Yasui 2001). During periods of reduced skeletal loading, the bones of humans and many other animals undergo a process which degrades bone (e.g., increased porosity, decreased bone mineralization, decreased geometrical properties, decreased mechanical properties). For example, astronauts lose both cortical and trabecular bone during spaceflight at a rate of approximately $0.8-1.5 \%$ per month (Lang et al. 2004). Bone loss is also observed in 
human bed rest, rats with sciatic neurectomy, and canine models of limb immobilization among many other disuse models (Jaworski and Uhthoff 1986; Kaneps et al. 1997; Zerwekh et al. 1998; Yonezu et al. 2004; Spector et al. 2009). This bone loss can be due to increased resorption and decreased formation, an unbalanced increase in both resorption and formation, or a decrease in formation alone (observed in small animals) (Wronski et al. 1987; Caillot-Augusseau et al. 1998; Zerwekh et al. 1998; Li et al. 2005).

\section{The clinical problem}

Three of the most prevalent conditions resulting in disuse osteoporosis clinically are bed rest, spinal cord injury, and stroke. Patients subject to bed rest for 12 weeks experienced a decrease in BMD in the lumbar spine, femoral neck, and greater trochanter. An increase in osteoclast and eroded surface within both cortical and trabecular bone was also observed. ICTP, (the cross-linked carboxy-terminal telopeptide of type I collagen) a serum marker of bone resorption, was increased during bed rest (Zerwekh et al. 1998). Countermeasures such as flywheel exercise or drug therapy during bed rest have only been shown to be partially effective in preventing bone loss during periods of disuse (Rittweger et al. 2005). However, a regimen of side-alternating resistive vibration exercise appeared to be effective in maintaining BMC and bone area in the tibia epiphysis (Rittweger et al.). Though this may prove useful for situations like spaceflight, these measures may not be possible in situations like spinal cord injury or stroke.

Bone mineral content was $21 \%$ lower in SCI group and areal bone mineral density (aBMD) was 25\% lower (Modlesky et al. 2005). Within the first 5-7 years after injury, a decrease in shaft bone mass of $35 \%$ in the femur and $25 \%$ in the tibia can be expected. Fifty and sixty percent losses in bone mass were observed in the femur epiphysis, and tibia epiphysis respectively (Eser et al. 2004). Cross sectional and mechanical properties of bone are also affected. In men at least 2 years post SCI at the C6-L1 level showed a $27-47 \%$ decrease in cortical thickness at the midfemur as well as a $50 \%$ increase in volume of the medullary cavity (Modlesky et al. 2005). Within 5-7 years post SCI, a 30\% decrease in cross sectional area at the femur midshaft is lost through endosteal resorption at a rate of $0.25 \mathrm{~mm} /$ year (Eser et al. 2004). Apparent shear modulus of tibias from SCI patients is significantly lower than that of controls (Lee et al. 1997). Flexural modulus of elasticity of bone samples machined from the tibia of SCI patients was also lower than that of controls, indicating micro-structural changes in the cortical bone (Lee et al. 1997). MRI analyses have also shown micro-structural losses in trabecular bone in the distal femur and proximal tibia (Modlesky et al. 2004). Apparent bone volume fraction (app BV/TV) decreased by $27 \%$ and $20 \%$ and apparent trabecular number (app Tb.N) decreased by $21 \%$ and 20\% in the femur and tibia, respectively (Modlesky et al. 2004). Even though bone geometrical properties and bone mineral density achieve a new steadystate in the femur and tibia between 3-8 years after injury (Frotzler et al. 2008), the initial bone loss can still negatively affect daily life for people with spinal cord injury. Even after bone is no longer being progressively lost, fractures may occur with seemingly minor trauma like a fall out of a wheelchair (Ragnarsson and Sell 1981). Low energy fractures are more prevalent in spinal cord injury subjects than in healthy individuals (Vestergaard et al. 1998). 
Stroke patients have problems similar to those of SCI patients. Fracture rates in stroke patients are 2-4 times that of the general population (Ramnemark et al. 1998) which may be a result of loss of BMD on the hemiplegic side as well as impaired mobility (Jorgensen et al. 2000b). Stroke patients who were initially wheelchair bound showed a $10 \%$ reduction in BMD as measured in the femoral neck and trochanteric area on the paretic side and $5 \%$ on the non-paretic side, depending on whether or not the patient re-learned to walk. After one year losses were $13 \%$ and $8 \%$ respectively for patients who did not re-learn to walk and those who relearned to walk within the first 2 months of the study (Jorgensen et al. 2000a; Jorgensen et al. 2000b). Whereas patients initially ambulatory experienced a 3\% reduction of BMD in the paretic leg and no change in the other (Jorgensen et al. 2000b). Losses are more prominent in the lower femoral neck as opposed to the upper femoral neck (Jorgensen et al. 2000a). Bone loss as a result of skeletal disuse is not unique to humans; it is common in many mammals.

\section{Effects of disuse on cortical bone in mammals}

Disuse results in a decrease in mechanical properties and BMD and an increase in porosity in cortical bone. For example, in turkeys subject to four weeks of disuse, an increase in porosity and thinning of the cortex through endosteal resorption was observed in the ulna (C. Rubin et al. 1996). Likewise, disuse resulted in an increase in porosity in turkey radii although the increase was not uniform throughout the cross section (Gross and Rubin 1995). Outcomes of disuse osteoporosis are not only complex in the way that bone loss may not be uniform, but the period of disuse can also affect both the amount of bone loss and how bone is being. During the first 12 weeks of 40 weeks of cast immobilization in beagles, resorption at the periosteal and endosteal surfaces as well as intracortical porosity all contributed to bone loss in the ulna, radius, humerus, and third metacarpal. Whereas at 40 weeks, bone loss in the radius and ulna was mostly periosteal (Jaworski et al. 1980). End results included a decrease in bone density and widening of the the medullary canal (and therefore a decrease in cortical thickness) (Jaworski et al. 1980). Sixteen weeks of forelimb immobilization resulted in reduced mechanical properties in dogs (Kaneps et al. 1997). Rats subject to sciatic neurectomy experienced a decrease in BMC at the femur diaphysis and cortical bone area as well as a decrease in periosteal circumference at the femur metaphysis and diaphysis (Yonezu et al. 2004). A study in adult rhesus monkeys and pigtail monkeys showed endosteal resorption, subtle periosteal loss, and tunneling in the tibia cortex. Tibia stiffness declined during immobilization, within one month of restraint resorption cavities become more prevalent (D. R. Young et al. 1986).

\section{Effects of disuse on trabecular bone in mammals}

Trabecular bone is more metabolically active than cortical bone due to the fact that trabecular bone has considerably more surface area (Takata and Yasui 2001). Thus it is generally expected that bone loss as a result of disuse will be recognizable in trabecular bone possibly even prior to significant losses in cortical bone. Ten days of spaceflight results in decreased mineral apposition rate and bone formation in trabecular bone in rats (R. T. Turner et al. 1995). In long term human spaceflight, trabecular volumetric BMD in 
the femur was lost at a rate of 2.2-2.7\% per month (Lang et al. 2004). Decreased trabecular bone formation and mineral apposition rate were also observed juvenile rhesus monkeys subject to immobilization for two weeks (Wronski and Morey 1983). Similarly, 10 days after tenotomy growing rats demonstrated a $40 \%$ reduction in mineral apposition rate (Weinreb et al. 1989). After 14 days of tail suspension, rats showed a decrease in bone volume fraction (BV/TV), trabecular number (Tb.N) and trabecular thickness (Tb.Th) were observed as well as an increase in trabecular separation (Tb.Sp) (Ju et al. 2008). Hind limb immobilization via sciatic neurectomy in rats resulted in a decrease in trabecular BMC and BMD in the femoral metaphysis (Yonezu et al. 2004). Thirty and seventy-two hours after tenotomy, growing rats displayed an increase in the number of osteoclasts/mm (two fold increase in osteoclast surface at 72 hours) in the tibial metaphysis and after 10 days, a 59\% reduction of trabecular bone (Weinreb et al. 1989). However, at later time points, the number of osteoclasts $/ \mathrm{mm}$ and osteoclast surface returned to values similar to those of the control leg. Twenty six days post tenotomy, osteoblast surface was shown to be reduced and bone formation rate was reduced (Weinreb et al. 1989).

\section{Recovery of disuse induced bone loss}

Canine models of limb immobilization have demonstrated the recovery of bone lost during disuse can take 2-3 times longer than the disuse period (Jaworski and Uhthoff 1986; Kaneps et al. 1997). This has also been observed in humans; astronauts still demonstrate reduced bone mass (compared to pre-flight values) several years after 6 months in space. Six months of reambulation after 17 weeks of bed rest did not fully restore BMD to pre-bed rest values in healthy adult humans (Tilton et al. 1980; Leblanc et al. 1990). Similarly, when osteopenia was induced in young (still growing) rats via hind limb suspension, recovery of lost bone took approximately twice the length of time it took to lose the bone and trabecular bone was recovered more rapidly than cortical (Weinreb et al. 1997). Where hind limb immobilization (2 weeks) was followed by remobilization (4 weeks) in rats, mechanical properties actually continued to worsen during the start of the remobilization period thus recovery of bone mass was limited (Trebacz 2001). Monkeys subjected to 6 months of restraint required approximately 8.5 months of recovery to restore normal bending properties but after 15 months BMC was still not completely back to initial values (D. R. Young et al. 1986). Histologically, after 15 months the cortex consisted mainly of newly formed bone with little remodeling activity. After 40 months the cortex contained numerous secondary/tertiary osteons, as you would expect to see in bone of a normally active monkey (D. R. Young et al. 1986). If disuse affected animals that hibernate similarly the active period would not be long enough to recover bone lost during hibernation and their skeletal system would become progressively weaker each year. Studies in bears and squirrels have shown they are able to preserve bone strength during hibernation, which is different from what is seen with 6 months of disuse in other animals (McGee-Lawrence et al. 2009a). 


\subsection{Intracortical remodeling}

Intracortical remodeling is an important mechanism for bone maintenance and calcium homeostasis in humans and many other mammals (Rauch et al. 2007). Increased cortical bone porosity is a consequence of disuse osteoporosis in humans and many mammals. However, small mammals like rats and mice do not typically demonstrate intracortical remodeling. However, it can be induced with external stimuli like microdamage from fatigue loading (Jee et al. 1990; Bentolila et al. 1998). Because Haversian remodeling is such an important process in human disuse osteoporosis and maintenance of cortical bone strength, when studying an animal model of osteoporosis it can be beneficial for the chosen animal to show intracortical remodeling (Mosekilde 1995). Sheep, dogs, rabbits, and ferrets show Haversian remodeling and therefore have potential for use as an animal model in osteoporosis research (Mackey et al. 1995; Mosekilde 1995; Kaneps et al. 1997). Of these animals, ferrets are the smallest known animal to exhibit intracortical remodeling, ranging in weight from $0.7-3 \mathrm{~kg}$. It is reasonable to expect animals of a similar size or larger than ferrets would also utilize intracortical remodeling. Because hibernators like bears and squirrels preserve whole bone mechanical properties they could also be a very useful animal model for studying disuse osteoporosis. Like humans bears demonstrate intracortical remodeling. However, smaller hibernators like squirrels or bats, which would be easy to handle in the lab due to their size, do not demonstrate intracortical remodeling.

\subsection{Osteocytic osteolysis}

Osteocytic osteolysis is a proposed resorptive process within the lacunar canalicular system that aids in systemic mineral homeostasis, though the concept has been disputed (Teti and Zallone 2009). Though one might expect to see an increase in lacunar area with osteoporosis it has been proposed that osteocytes may be able to aid in mineral homeostasis without it being microscopically apparent (Teti and Zallone 2009). Thus some mineral could be being removed from the lacunar-canalicular system without being noticeable under bright field microscopy. For example, a study examined differences in lacunar size and number with respect to osteoporotic fracture. No differences between the osteoporotic fracture group and control were found in either lacunar number or in the size of lacunae (McCreadie et al. 2004). However, enlarged osteocyte lacunae have been observed in pathological conditions like hyperparathyroidsim, renal disease, and osteoporosis (Wright et al. 1978). Continuous administration of parathyroid hormone (PTH 1-34) resulted in increased lacunar area in rats (Tazawa et al. 2004). Thus if osteocytic osteolysis were occurring to a great extent it would be expected that changes in osteocyte lacunar properties would be quantifiable.

\subsection{Hibernating bears as a disuse model}

Hibernating bears are of interest because they are a relatively unique groundbased model of disuse. Previous research suggests that their bones respond differently to disuse compared to humans and other animals. During hibernation, bears are inactive for approximately 6 months and would be expected to lose bone during this time. However, bears prevent bone loss during hibernation and with age. This has not only been 
demonstrated via preservation of mechanical properties, porosity, and trabecular architecture (Pardy et al. 2004; McGee et al. 2007b; McGee et al. 2008a; McGee et al. $2008 \mathrm{~b}$ ) but has also been implicated by the maintenance of serum calcium levels during hibernation (Floyd et al. 1990). Bears do not eat, drink, urinate or defecate during their hibernation period. Bears accumulate fat reserves prior to hibernation and metabolize this fat for energy while denning. The American black bear (ursus americanus) loses $15-33 \%$ of its body mass during hibernation (Lundberg et al. 1976; Hellgren et al. 1990; Tinker et al. 1998). Even in reproductive black bears it has been shown that fat can provide about $92 \%$ of required energy throughout the winter (Harlow et al. 2002). Though the majority of body mass lost is from fat reserves, a small amount of protein is lost during hibernation (Lohuis et al. 2007). Research by Lundberg et al (1976) indicated preservation of lean body mass during the hibernation period. However, other studies have demonstrated small losses in protein. Female black bears (6 with cubs, 1 without) demonstrated a decrease in skeletal protein during hibernation in the gastrocnemius and biceps femoris muscles. Assuming these decreases are a good estimator for all skeletal muscle, this indicates approximately $13.3 \%$ of the weight lost during hibernation could be due to protein loss (Tinker et al. 1998). A study in six adult bears (5 female, 1 male) showed $20 \%$ lower muscle protein content in winter denning bears as compared to their active summer state. A balanced but decreased rate of protein synthesis and breakdown was also observed (Lohuis et al. 2007). This protein preservation is partially possible because bears effectively recycle nitrogen from urea during hibernation (Barboza et al. 1997). Bears are not traditional hibernators in the sense of entrance into deep torpor and periodic arousal. Bears maintain a body temperature that is not drastically reduced like that which is typically observed in "true hibernation". Though they do not arouse without provocation, bears maintain the ability to arouse and flee or defend themselves upon indication of danger (Matson 1946; Nelson 1973). Black bears reduce their body temperature from $37-39^{\circ} \mathrm{C}$ to about $34^{\circ} \mathrm{C}$ (Nelson 1973). Heart rate in black bears decreases from 40 beats per minute to 8 beats per minute (Hellgren 1998). The metabolic rate of grizzly bears decreases to $73 \%$ of the interspecific basal rate (Farley and Robbins 1995).

\section{Seasonal changes in bone}

Bone mineral density (determined by dual energy X-ray absorptiometry, DEXA) of the radius and ulna of black bears showed no change between autumn and spring bears (Pardy et al. 2004). A study of 8 grizzly bears showed no change cortical thickness, cortical area, periosteal area or mineralization when comparing bears that had hibernated for 16-18 weeks and bears that had been active for 14 weeks (McGee et al. 2008b). Likewise, no change in mechanical properties, moments of inertia or section modulus were observed between active and hibernating bears (McGee et al. 2008b). Another study used black bears killed during Utah's hunting seasons. The two seasons take place before hibernation and after hibernation allowing samples from bears preparing for entrance into hibernation and samples from bears arousing from hibernation. Femurs broken in threepoint bending demonstrated no differences in ultimate stress, modulus of toughness and failure energy between pre- and post-hibernation bears. Ash fraction of the femoral diaphysis and bone geometrical properties (periosteal area, cortical area, endosteal area, 
section modulus, and moments of inertia) at the femur midshaft were also not different between groups (McGee-Lawrence et al. 2009a).

Microstructural changes in bone of bears provide further evidence of bone preservation during hibernation in bears. Intracortical porosity in the femoral diaphysis was 30\% lower in hibernating grizzly bears when compared to active bears. There was also a decreasing trend in resorption and refilling cavity density, 68\% lower in hibernating bears and 55\% lower in hibernating bears, respectively (McGee et al. 2008b). Labeled osteon density was $64 \%$ lower in hibernation and activation frequency was $75 \%$ lower, indicating a decrease in cortical bone turnover during the hibernation period. Normalized osteonal mineral apposition rate and refilling period were not different between hibernating and active bears indicating fewer osteons were remodeling during hibernation, but active osteons were refilling at a "normal" rate. Though hibernation resulted in a decrease in cortical bone turnover, resorption and formation remained balanced (McGee et al. 2008b).

Even though changes were not observed in hibernating bear cortical bone, changes might still be observed in trabecular bone properties. Trabecular bone typically shows greater changes during periods of decreased mechanical loading than cortical bone (Kaneps et al. 1997; Lang et al. 2004). However, micro-computed tomography ( $\mu$ CT) of the trabecular bone of the distal radius demonstrated a lack of change in trabecular architecture between spring and fall bears (Pardy et al. 2004). Trabecular bone samples collected from the distal femoral metaphysis of black bears collected during hunting seasons in Utah, one prior to entrance into hibernation and one after emergence from hibernation, were analyzed by $\mu \mathrm{CT}$. There were no differences in trabecular bone architecture or mineralization between pre- and post-hibernation bears (McGee-Lawrence et al. 2009b). Trabecular cores from the ilium, distal femoral metaphysis, distal femoral epiphysis, and calcaneus of grizzly bears were evaluated using $\mu \mathrm{CT}$ to determine if there were site-specific changes that occurred during hibernation. No differences were found in bone volume fraction or trabecular number between active and hibernating bears at any of the four sites. Trabecular thickeness was decreased in the ilium of hibernating bears as compared to active bears; however, there were no seasonal differences at any other site. Trabecular separation was lower in the calcaneus of hibernating compared to active bears but not different between seasons when looking at other sites. Trabecular tissue mineral density was higher in the ilium of hibernating compared to active but not different for other sites. When data from all sites were grouped together, no seasonal differences were found for bone volume fraction, mineral density or architectural properties (McGeeLawrence et al. 2009b). Similarly, another study used trabecular bone cores from the ilium and distal femoral epiphysis of 16 grizzly bears sacrificed after either 16-18 weeks of hibernation or after at least 14 weeks of activity. Upon histological analysis, osteoid and eroded surface was not different between active and hibernating bears at either location or when grouped together and analyzed as a combined data set. The ratio of osteoid surface to eroded surface, an indicator of balance between bone formation and resorption, was not different between active and hibernating bears. Osteoid thickness decreased in the distal femur of hibernating compared to active bears and in combined data, but not for the ilium data. Mineral apposition rate as well as adjusted apposition rate 
(which represents mineral apposition rate over the entire osteoid surface) were decreased in hibernating bears in at both sites. Mineralizing surface was lower in the distal femur in hibernating bears and approached significance in ilium. When data from the two sites were combined mineralizing surface was lower during hibernation (McGee-Lawrence et al. 2009b). Unlike the results of disuse in many mammals, bears are able to preserve trabecular bone architectural properties and demonstrate balanced remodeling during hibernation.

\section{Age and gender related changes in bone}

Further supporting the lack of observable bone loss during hibernation in bears is the preservation of bone with age. In order to preserve bone with age the bear would have to regain all bone lost in a period of activity approximately equal to that of disuse, which does not occur in other mammals. Ultimate stress, bending modulus and ash fraction significantly increased with age in black bears (Harvey and Donahue 2004). A similar study demonstrated preservation of tensile strength with age; yield stress increased with age and ultimate strain and fracture energy decreased with age (Harvey et al. 2005). Whole bone 3-point bending of femurs from black bears from Utah showed ultimate stress increasing with age and modulus of toughness decreased with age. Geometrical properties (periosteal area, cortical area, endosteal area, section modulus, and moments of inertia) also significantly increased with age (McGee-Lawrence et al. 2009a). Similarly, testing of black bear femurs from the Upper Peninsula of Michigan showed an age related increase in cross-sectional moments of inertia $\left(\mathrm{I}_{\mathrm{ML}}, \mathrm{I}_{\mathrm{AP}}, \mathrm{I}_{\max }\right)$ in male bears (McGee et al. 2007a). Femurs obtained from black bears in Utah and Alaska also showed periosteal area, cortical area, section modulus, maximum moment of inertia $\left(\mathrm{I}_{\max }\right)$, mediolateral moment of inertia $\left(\mathrm{I}_{\mathrm{ML}}\right)$, and anteroposterior moment of inertia $\left(\mathrm{I}_{\mathrm{AP}}\right)$ all increased with age in skeletally immature male bears. Results were similar for skeletally immature female bears, however cortical thickness did not change with age (McGee et al. 2007b). Ash fraction of bone from the femur of black bears from Michigan was also shown to increase with age for both male and female bears which is consistent with the findings in the tibia. Ultimate stress, yield stress, and elastic modulus increased with age, though modulus of toughness decreased with age (McGee et al. 2007a).

No age related changes were observed in cortical bone porosity of the tibia in black bears (Harvey and Donahue 2004). Cross-sectional porosity quantified in black bears from Utah and Alaska did not change with age in skeletally immature bears for male or female groups (McGee et al. 2007b). However, when quantified in the femur diaphysis with a larger sample size, porosity was shown to decrease with age (McGeeLawrence et al. 2009a). Bone volume fraction and trabecular number decreased with age and trabecular separation and trabecular tissue mineral density increased with age in black bears from Utah (McGee-Lawrence et al. 2009b).

Since humans experience bone loss with age and during periods of disuse (such as spinal cord injury) it would be useful to understand how bears prevent bone loss during their hibernation period. This information could be useful in the development of new therapies to prevent or treat disuse osteoporosis. 


\subsection{Small hibernators as a disuse model}

If small hibernators (i.e. bats, squirrels, marmots etc) were to show a similar ability to preserve bone as bears do, they could provide a very useful disuse model. Smaller animals would allow studies to happen in laboratories that cannot house bears. It would also make it possible to study calcium regulatory hormone changes during hibernation in various hibernators and compare across species to see if there is a common change among hibernators that may lead to uncovering the mechanism behind the ability to preserve bone during these periods of disuse. Small hibernators would allow a much more practical laboratory specimen compared to bears due to size and relative availability. Thus, having a convenient hibernator to study could greatly improve the progress on understanding the mechanism bears and possibly other hibernators use to preserve bone during their disuse period of hibernation. However, it is very important to understand the effects of hibernation on the bones of small hibernators first; it is not safe to assume they do not lose bone simply because bears do not. The hibernation period for many rodents consists of a series of torpor bouts (characterized by decreased body temperature and metabolic rate) which last 4-25 days interrupted by arousal followed by a period of euthermia (increased in body temperature) for approximately 1-3 days (Bailey and Davis 1965; P. J. Young 1990; Armitage et al. 2003). Thus, small hibernators follow a different hibernation pattern than bears, i.e. they arouse periodically (which bears do not do) and may urinate or defecate during arousal. Urination or defacation allows a method for ridding the body of systemic calcium. Since small hibernators have a method for liberating this calcium, calcium homeostasis may be controlled in such a way that calcium is just pulled from the skeletal system as needed and excreted as needed to maintain a proper balance, potentially resulting in bone loss. Bears do not excrete waste during hibernation and are therefore forced to recycle the calcium in their system. The effects of hibernation on bone in small hibernators is not currently well defined, some studies suggest evidence of bone loss while others suggest evidence of bone maintenance.

Bats

Bats hibernate for 3-6 months of the year (depending on species, location, etc.), and have been the subject of a number of studies in the past (Thomas et al. 1990). Bats maintain a body temperature close to the ambient temperature and arouse periodically during their hibernation period (Park et al. 2000). Bats lose 25-30\% of their prehibernation body weight over the winter period (Thomas et al. 1990). Most studies on bats indicate bone loss during hibernation. However, most of these studies rely on qualitative observations rather than quantitative data. A radiographic study in little brown bats (Myotis lucifugus) demonstrated cortical thinning of the femur during hibernation and a return to apparently normal thickness soon after becoming active again (Krook et al. 1977). A study examining year round skeletal changes in little brown bats resulted showed thinning of the humeral cortex with hibernation. A wider humeral cortex in pregnant females compared to post-lactational females was also observed (Kwiecinski et al. 1987). Microradiographs of the mandible also (qualitatively) showed maximum mineral density in all pre-hibernation bats (September) and minimal mineral density in all 
post-hibernation bats. In female bats maximum mineral density was observed in pregnant bats (May-June) and minimal mineral density in lactating bats. Similar observations were made in ground sections of the mandible (Kwiecinski et al. 1987). Another study showed the mineral content of bone decreasing as hibernation progressed and increasing again in the summer. However, no consistent pattern of mineral changes in plasma calcium levels were observed, though they appeared to be highest in early hibernation (Bruce and Wiebers 1970). Plasma calcium concentrations have been shown to vary throughout the year and levels were different for males and females in a given month. The lowest plasma calcium levels were in May for males and June for females and the highest levels were in February for males and January for females (Kwiecinski et al. 1987). This may be indicative of increased bone resorptoin in January and February.

Evidence of osteocytic osteolysis has been observed in hibernating specimens. In a study where adult male hibernating bats were given daily subcutaneous injections of calcitonin vs. those not given calcitonin, calcitonin injections reduced or eliminated histological evidence of osteocytic osteolysis. In this case, evidence of osteocytic osteolysis was qualitatively identified as enlarged and rounded osteocytes with basophilia or metachromasia around the lacunae (Krook et al. 1977). Resorptive activity was present in bats captured during their approximate emergence from hibernation. Resorptive activity was again identified by enlarged, round osteocytes with basophilic lacunar rims and basophilia of the matrix (Kwiecinski et al. 1987). Enlarged osteocytes have also been observed in the central and medial aspects of the cortex of the femur in early samples collected early in the hibernation period (Whalen et al. 1972). The idea that microstructural bone loss may occur via osteocytic osteolysis as opposed to osteoclastic activity in bats is further corroborated by the disappearance of osteoclasts and structurally differentiated osteoblasts from the long bone surfaces during hibernation and return of these cells following hibernation (Doty and Nunez 1985).

These studies in bats suggest bone loss during the hibernation period as opposed to the preservation of bone that is achieved in hibernating bears. It is possible that since bats and other small hibernators arouse during the hibernation period and can excrete waste there is no need for a mechanism to preserve bone and recycle calcium as is necessary in bears. Further understanding of the impact hibernation has on the skeletal system of both bears and smaller mammals can aid in understanding how hibernators preserve bone. This understanding could be useful in treating human osteoporosis.

\section{Hamster}

Golden hamsters have also been used for hibernation research. When the effects of cold stress and hibernation on bone in golden hamsters (Mesocricetus auratus) were studied, 83 days of cold stress and 7 days of hibernation resulted in an increase in bone diameter and cortical thickness at the femoral midshaft. However, 69 days of cold stress and 21 days of hibernation resulted in a decrease in bone diameter and cortical thickness. A shift from lamellar to Haversian remodeling was also observed (Steinberg et al. 1981). Osteoblastic activity (as determined by H-proline labeling) was decreased during early hibernation in golden hamsters; endosteal osteoblasts were more active but followed a 
similar pattern (of decrease) to that of the periosteal osteoblasts during hibernation (Steinberg et al. 1986). Studies in hamsters further indicate bone preservation during hibernation may be unique to bears.

\section{Ground Squirrels}

Ground squirrels hibernate for approximately 5-6 months and wake intermittently throughout the hibernation period. For example the Columbian ground squirrel (Spermophilus columbianus) is torpid for 2-28 days interrupted by euthermic periods of 12-48 hours (depending on time of season, ie torpor bouts were shorter at the beginning and end of hibernation season) (P. J. Young 1990). They lose $31-34.1 \%$ of prehibernation body mass (P. J. Young 1990). Similar to the bat studies, early studies in 13lined ground squirrels (Ictidomys tridecemlineatus, previous genus name Spermophilus) observed differences in osteocyte lacuna between hibernating and non hibernating animals (Haller and Zimny 1977). A more recent study of captive 13-lined ground squirrels showed that whole bone mechanical properties (ultimate load, failure energy, stiffness, ultimate stress) were not different between active and hibernating animals (McGee-Lawrence et al. 2010). Throughout the course of hibernation, mechanical properties of the femur stayed constant in adult squirrels whereas ultimate load increased and ultimate stress tended to decrease over the course of hibernation in juvenile squirrels. Likewise geometrical properties at the femur midshaft were not different between active and hibernating animals with the exception of the anteroposterior moment of inertia being greater in hibernating adults compared to active adults. No differences were observed in ash fraction of bones from hibernating vs. active squirrels; though ash fraction was higher in adults than juveniles. Ash fraction showed an increasing trend over the course of hibernation for juvenile squirrels. Average lacunar osteocyte area was similar between active and hibernating squirrels. Lacunar porosity was significantly higher in hibernation for juveniles and adults, lacunar density significantly higher in hibernation in juveniles and approached significance in adults. Average lacunar area increased over the course of hibernation for juveniles but lacunar porosity and density did not change. No osteocyte lacunar properties changed for adults over the course of hibernation. Bone volume fraction decreased in hibernating, compared to active adult squirrels but no other trabecular bone architectural properties showed differences (McGee-Lawrence et al. 2010). There has also been evidence to suggest that although 13-lined ground squirrels subjected to a unilateral sciatic nerve section lose bone during the active period, they do not when the same procedure is performed during the hibernation period (Zimmerman et al. 1976). The golden-mantled ground squirrel (Spermophilus lateralis) has also been shown to maintain bone strength, as assessed by three-point bending, after 8 months of hibernation. There was also no change in bone length, mass, mid-point diameter, volume, and apparent bone density between summer active and hibernating groups (Utz et al. 2009).

Studies in squirrels indicate that there may, at the very least, be a preservation of whole bone strength during hibernation. However, the lacunar measurements in 13-lined ground squirrels indicate that mineral homeostasis may be maintained through osteocytic osteolysis. 


\section{Raccoon Dog}

The raccoon dog (Nyctereutes procyonoides) is a canid ranging in weight between $3.5-10.5 \mathrm{~kg}$ that spends $4-5$ months of the winter in a burrow in a hibernation-like state. Unlike the small hibernators previously discussed, the raccoon dog maintains a body temperature close to normal $\left(38^{\circ} \mathrm{C}\right.$ normal decreases to $35.9-36.7^{\circ} \mathrm{C}$ in the winter) (Kitao et al. 2009). However, like small hibernators raccoon dogs arouse periodically and can eat and defecate throughout the period. Fat stores are the primary source of energy during the winter period resulting in a $33-45 \%$ decrease in body weight (Kitao et al. 2009). Recently a study presented raccoon dogs as a potential disuse model. Raccoon dogs were shown to preserve bone mass, BMD, cross-sectional geometry, and biomechanical properties during the overwintering period (Nieminen et al. 2010). However, it is important to note that during the overwintering raccoon dogs do occasionally leave the dens and move around (Kitao et al. 2009).

Similar to squirrels it appears as though the raccoon dog also preserves bone during a period of reduced skeletal loading. The raccoon dog could potentially provide a more ideal disuse model for osteoporosis studies as compared to squirrels and bears due to it being small enough to use as a laboratory specimen but large enough to utilize Haversian remodeling. However, during the overwintering period, raccoon dogs leave the den and are mobile for short periods of time.

\section{Marmots}

Marmots may provide an even better yet model for these studies. Male yellowbellied marmots weigh between 2.95-5.22 $\mathrm{kg}$ (average $3.9 \mathrm{~kg}$ ) and females weigh between 1.59-3.97 kg (average $2.8 \mathrm{~kg}$ ) and would thus be expected to show intracortical remodeling (Armitage et al. 1976). However, they are also small enough to provide a manageable laboratory model, and do not leave the den during hibernation.

\subsection{Hibernating marmots as a disuse model}

Yellow-bellied marmots (Marmota flaviventris) hibernate approximately 8 months of the year (Salsbury and Armitage 1994; Armitage et al. 2003). Like other small hibernators, marmots experience intermittent bouts of arousal during the hibernation period (Bailey and Davis 1965; Heldmaier et al. 2004). Torpor bouts have been observed to last between 10 and 19 days depending on time of year, air temperature and the age of the marmot (Armitage et al. 2003). For example, the duration of continuous torpor bouts for woodchucks (Marmota monax) in a hibernaculum was observed to be 9.8 days, separated by arousal bouts of 2.2 days (Bailey and Davis 1965). Hibernation characteristics can vary slightly depending on species, age, and location (Zervanos et al. 2010). Juvenile marmots have been observed to hibernate longer, likely because of their size and lower fat stores (French 1990). Woodchucks observed at three different latitudes demonstrated differences in hibernation pattern within the species. Marmots at the northernmost latitude, or coldest climate, compared to the southernmost latitude entered 
hibernation sooner and emerged later (Zervanos et al. 2010). They also experienced longer torpor bouts $(184+/-18.9 \mathrm{~h}$ vs. $117.3+/-30.1 \mathrm{~h})$ and shorter euthermic bouts $(28.3$ $+/-2.5$ h vs. $59.4+/-11.8$ h) (Zervanos et al. 2010). However, percent of pre-hibernation body mass lost did not differ between locations (28.6-38.8\%) (Zervanos et al. 2010). Alpine marmots (Marmota marmota) showed the ability to adjust body temperature in deep hibernation to decreasing air temperature. At an air temperature of $5^{\circ} \mathrm{C}$ a minimum body temperature of approximately $9.5^{\circ} \mathrm{C}$ was achieved and maintained (Ortmann and Heldmaier 2000).

Entrance into hibernation is started by suppression of metabolic heat production to below $10 \mathrm{ml} \mathrm{O} /\left(\mathrm{kg}^{*} \mathrm{~h}\right)$. This is maintained for about a day before a smooth decline in body temperature to minimum body temperature and metabolic rate (below $20 \mathrm{ml}$ $\mathrm{O}_{2} /(\mathrm{kg} * \mathrm{~h})$ ) occurs (Ortmann and Heldmaier 2000). During continued hibernation maintenance of a minimum metabolic rate with periodic bursts of heat production remained at a constant frequency but became more pronounced with decreasing air temperature were observed in alpine marmots. As air temperature increased, body temperature passively followed (Ortmann and Heldmaier 2000).

Unlike some other hibernating rodents, marmots do not store food. Like bears, they rely solely on body fat deposits for energy during the hibernation period (Bailey and Davis 1965; Anderson et al. 1976; Davis 1976; Ward and Armitage 1981). As would be expected adult marmots serum triglycerides, cholesterol and urea-nitrogen increase between May to July (during the active period), and decrease between Septemeber and May (inactive). Serum calcium and phosphate did not change throughout the year (Sartorelli et al. 2004). Alpine marmots have been shown to lose $32.5+/-2.5 \%$ of prehibernation body mass, which is similar to the seasonal weight loss observed in bears (Lundberg et al. 1976; Ortmann and Heldmaier 2000; Zervanos et al. 2010). A study by Zatzman and South indicates renal function in hibernating marmots is maintained at approximately $10 \%$ of the level in euthermia. During hibernation, an increase in renal vascular resistance, indicated by increased filtration fraction, was observed. In other words, the amount of filtrate removed from the blood being filtered by the kidney per minute increases; this has also been seen in hibernating bears (Brown et al. 1971; Zatzman and South 1972). Though marmots do not drink during hibernation, below 15$20^{\circ} \mathrm{C}$ metabolic water production in the yellow-bellied marmot exceeds evaporative water loss (Armitage et al. 1990). Renal function in the marmot has been further demonstrated by the ability to collect urine samples that were measureable and hypertonic. Studies have also shown that filtration of the blood in association with water reabsorption occurred during the hibernation period (Zatzman and South 1975).

\subsection{Hypothesis and Specific Aims}

An estimated 1.5 million osteoporotic fractures occur yearly, resulting in health care costs of over $\$ 13$ billion. Disuse osteoporosis is a problem for people with spinal cord injury or stroke, patients confined to bed rest, and astronauts exposed to microgravity. Reduction in skeletal loading results in a decrease in bone mineralization as well as an increase in porosity and therefore a decrease in bone strength. Some 
countermeasures for osteoporosis do exist. For example, drugs like bisphosphonates or hormone treatments have been used to reduce osteoporotic fracture risk. Similarly, for patients that are able, certain exercise regimens have been shown to be effective in curbing the progression of osteoporosis. However, no current countermeasures to osteoporosis are entirely effective in reversing or preventing osteoporosis. Unlike most mammals however, bears have been shown to prevent bone loss during hibernation, a seasonal period of disuse. Uncovering the mechanism by which these animals prevent bone loss during hibernation could lead to an improved treatment for osteoporosis in humans. Small hibernators have been investigated to some degree in the past. However, until more recent studies in ground squirrels, the effect of hibernation on their bone was not well defined. Studies in ground squirrels are indicative of preservation of whole bone strength during hibernation, though evidence suggests there may be some increased osteocytic osteolysis. This is particularly interesting since small hibernators like squirrels experience a different hibernation pattern than bears; bears are torpid for the entire winter whereas smaller hibernators wake intermittently throughout the winter and can move around and urinate or defecate which would allow for removal of calcium from their system. Squirrels differ from both bears and humans in bone microstructure; squirrels do not experience Haversian remodeling under normal circumstances. Yellow-bellied marmots (Marmota flaviventris) follow a similar hibernation pattern to that of squirrels in that they wake intermittently throughout the winter. However, marmots are also large enough to experience Haversian remodeling which is similar to bears and humans. Understanding the effects of hibernation on bone in marmots can help progress the understanding of bone maintenance in hibernators. For example, if both bears and marmots prevent bone loss during hibernation, further studies examining and comparing gene expression or hormone patterns during hibernation in marmots versus bears could aid in the discovery of the mechanism.

Central Hypothesis: Yellow-bellied marmots (Marmota flaviventris) will experience losses in bone structure, strength, and mineralization during hibernation due to physical inactivity paired with the ability to excrete calcium, released from bone by bone resorption, during interbout arousals.

Aim: Assess bone structure, strength, and mineralization in yellow-bellied marmots collected in either the fall (pre-hibernation) or spring (post-hibernation) to assess changes due to hibernation.

Task 1: Assess bone structure.

a.) Quantify cortical bone microstructural properties histologically (lacunar area, lacunar porosity, lacunar density, intracortical porosity, and intracortical remodeling cavity density).

b.) Assess trabecular bone architectural properties using micro-computed tomography.

c.) Calculate geometrical properties at the femur midshaft.

Task 2: Assess bone strength. Test femurs to failure in 3-point bending.

Task 3: Assess mineral content via ash fraction. 


\subsection{References}

Anderson DC, Armitage KB, Hoffman RS. 1976. Socioecology of marmots: female reproductive strategies. Ecology 57(3):552-560.

Armitage KB, Downhower JF, Svendsen GE. 1976. Seasonal-Changes in Weights of Marmots. American Midland Naturalist 96(1):36-51.

Armitage KB, Melcher JC, Ward JM. 1990. Oxygen-Consumption and BodyTemperature in Yellow-Bellied Marmot Populations from Montane-Mesic and Lowland-Xeric Environments. Journal of Comparative Physiology B-Biochemical Systemic and Environmental Physiology 160(5):491-502.

Armitage KB, Blumstein DT, Woods BC. 2003. Energetics of hibernating yellow-bellied marmots (Marmota flaviventris). Comparative Biochemistry and Physiology Part A: Molecular and Integrative Physiology 134(1):101-14.

Bailey ED, Davis DE. 1965. The utilization of body fat during hibernation in woodchucks. Canadian Journal of Zoology 43(5):701-7.

Barboza PS, Farley SD, Robbins CT. 1997. Whole-body urea cycling and protein turnover during hyperphagia and dormancy in growing bears (Ursus americanus and U-arctos). Canadian Journal of Zoology-Revue Canadienne De Zoologie 75(12):2129-2136.

Bentolila V, Boyce TM, Fyhrie DP, Drumb R, Skerry TM, Schaffler MB. 1998. Intracortical remodeling in adult rat long bones after fatigue loading. Bone 23(3):275-81.

Black DM, Delmas PD, Eastell R, Reid IR, Boonen S, Cauley JA, Cosman F, Lakatos P, Leung PC, Man Z et al. . 2007. Once-yearly zoledronic acid for treatment of postmenopausal osteoporosis. New England Journal of Medicine 356(18):180922.

Bone HG, Hosking D, Devogelaer JP, Tucci JR, Emkey RD, Tonino RP, RodriguezPortales JA, Downs RW, Gupta J, Santora AC et al. . 2004. Ten years' experience with alendronate for osteoporosis in postmenopausal women. New England Journal of Medicine 350(12):1189-99.

Brown DC, Mulhausen RO, Andrew DJ, Seal US. 1971. Renal function in anesthetized dormant and active bears. American Journal of Physiology 220(1):293-8.

Bruce DS, Wiebers JE. 1970. Calcium and phosphate levels in bats (Myotis lucifugus) as function of season and activity. Experientia 26(6):625-7. 
Caillot-Augusseau A, Lafage-Proust MH, Soler C, Pernod J, Dubois F, Alexandre C. 1998. Bone formation and resorption biological markers in cosmonauts during and after a 180-day space flight (Euromir 95). Clinical Chemistry 44(3):578-85.

Chesnut IC, Skag A, Christiansen C, Recker R, Stakkestad JA, Hoiseth A, Felsenberg D, Huss H, Gilbride J, Schimmer RC et al. . 2004. Effects of oral ibandronate administered daily or intermittently on fracture risk in postmenopausal osteoporosis. Journal of Bone and Mineral Research 19(8):1241-9.

Christodoulou C, Cooper C. 2003. What is osteoporosis? Postgrad Medical Journal 79(929):133-8.

Compston J. 2000. Prevention of osteoporotic fractures in post-menopausal women. Baillieres Best Practice and Research Clinical Endocrinology and Metabolism 14(2):251-64.

Davis DE. 1976. Hibernation and circannual rhythms of food consumption in marmots and ground squirrels. Quarterly Review of Biology 51(4):477-514.

Doty SB, Nunez EA. 1985. Activation of osteoclasts and the repopulation of bone surfaces following hibernation in the bat, Myotis lucifugus. Anatomical Record 213(4):481-95.

Ducher G, Tournaire N, Meddahi-Pelle A, Benhamou CL, Courteix D. 2006. Short-term and long-term site-specific effects of tennis playing on trabecular and cortical bone at the distal radius. Journal of Bone and Mineral Metabolism 24(6):484-490.

Epstein S. 2006. Update of current therapeutic options for the treatment of postmenopausal osteoporosis. Clinical Therapeutics 28(2):151-73.

Eser P, Frotzler A, Zehnder Y, Wick L, Knecht H, Denoth J, Schiessl H. 2004. Relationship between the duration of paralysis and bone structure: a pQCT study of spinal cord injured individuals. Bone 34(5):869-80.

Farley SD, Robbins CT. 1995. Lactation, hibernation, and mass dynamics of American black bears and grizzly bears. Canadian Journal of Zoology-Revue Canadienne De Zoologie 73(12):2216-2222.

Floyd T, Nelson RA, Wynne GF. 1990. Calcium and bone metabolic homeostasis in active and denning black bears (Ursus americanus). Clinical Orthopaedics and Related Research(255):301-9.

French AR. 1990. Age-class differences in the pattern of hibernation in yellow-bellied marmots, Marmota flaviventris. Oecologia 82(1):93-96. 
Frotzler A, Berger M, Knecht H, Eser P. 2008. Bone steady-state is established at reduced bone strength after spinal cord injury: a longitudinal study using peripheral quantitative computed tomography (pQCT). Bone 43(3):549-55.

Gerdhem P, Obrant KJ. 2002. Effects of cigarette-smoking on bone mass as assessed by dual-energy X-ray absorptiometry and ultrasound. Osteoporos International 13(12):932-6.

Gross TS, Rubin CT. 1995. Uniformity of resorptive bone loss induced by disuse. Journal of Orthopaedic Research 13(5):708-14.

Haller AC, Zimny ML. 1977. Effects of hibernation on interradicular alveolar bone. Journal of Dental Research 56(12):1552-7.

Harlow HJ, Lohuis T, Grogan RG, Beck TDI. 2002. Body mass and lipid changes by hibernating reproductive and nonreproductive black bears (Ursus americanus). Journal of Mammalogy 83(4):1020-1025.

Harvey KB, Donahue SW. 2004. Bending properties, porosity, and ash fraction of black bear (Ursus americanus) cortical bone are not compromised with aging despite annual periods of disuse. Journal of Biomechanics 37(10):1513-20.

Harvey KB, Drummer TD, Donahue SW. 2005. The tensile strength of black bear (Ursus americanus) cortical bone is not compromised with aging despite annual periods of hibernation. Journal of Biomechanics 38(11):2143-50.

Heldmaier G, Ortmann S, Elvert R. 2004. Natural hypometabolism during hibernation and daily torpor in mammals. Respiratory Physiology and Neurobiology 141(3):317-29.

Hellgren EC, Vaughan MR, Kirkpatrick RL, Scanlon PF. 1990. Serial Changes in Metabolic Correlates of Hibernation in Female Black Bears. Journal of Mammalogy 71(3):291-300.

Hellgren EC. 1998. Physiology of Hibernation in Bears. Ursus 10:467-477.

Jaworski ZF, Liskova-Kiar M, Uhthoff HK. 1980. Effect of Long-Term Immobilisation on the Pattern of Bone Loss in Older Dogs. Journal of Bone and Joint Surgery 62$\mathrm{B}(1): 104-110$.

Jaworski ZF, Uhthoff HK. 1986. Reversibility of nontraumatic disuse osteoporosis during its active phase. Bone 7(6):431-9.

Jee WS, Mori S, Li XJ, Chan S. 1990. Prostaglandin E2 enhances cortical bone mass and activates intracortical bone remodeling in intact and ovariectomized female rats. Bone 11(4):253-66. 
Jorgensen L, Crabtree NJ, Reeve J, Jacobsen BK. 2000a. Ambulatory level and asymmetrical weight bearing after stroke affects bone loss in the upper and lower part of the femoral neck differently: bone adaptation after decreased mechanical loading. Bone 27(5):701-7.

Jorgensen L, Jacobsen BK, Wilsgaard T, Magnus JH. 2000b. Walking after stroke: does it matter? Changes in bone mineral density within the first 12 months after stroke. A longitudinal study. Osteoporosis International 11(5):381-7.

Ju YI, Sone T, Okamoto T, Fukunaga M. 2008. Jump exercise during remobilization restores integrity of the trabecular architecture after tail suspension in young rats. Journal of Applied Physiology 104(6):1594-600.

Kaneps AJ, Stover SM, Lane NE. 1997. Changes in canine cortical and cancellous bone mechanical properties following immobilization and remobilization with exercise. Bone 21(5):419-23.

Kanis JA, Melton LJ, 3rd, Christiansen C, Johnston CC, Khaltaev N. 1994. The diagnosis of osteoporosis. Journal of Bone and Mineral Research 9(8):1137-41.

Kitao N, Fukui D, Hashimoto M, Osborne PG. 2009. Overwintering strategy of wild freeranging and enclosure-housed Japanese raccoon dogs (Nyctereutes procyonoides albus). International Journal of Biometeorology 53(2):159-165.

Krook L, Wimsatt WA, Whalen JP, MacIntyre I, Nunez EA. 1977. Calcitonin and hibernation bone loss in the bat (Myotis lucifugus). Cornell Vet 67(2):265-71.

Kwiecinski GG, Krook L, Wimsatt WA. 1987. Annual skeletal changes in the little brown bat, Myotis lucifugus lucifugus, with particular reference to pregnancy and lactation. American Journal of Anatomy 178(4):410-20.

Lang T, LeBlanc A, Evans H, Lu Y, Genant H, Yu A. 2004. Cortical and Trabecular Bone Mineral Loss From the Spine and Hip in Long-Duration Spaceflight. Journal of Bone and Mineral Research 19:1006-1012.

Law MR, Hackshaw AK. 1997. A meta-analysis of cigarette smoking, bone mineral density and risk of hip fracture: recognition of a major effect. British Medical Journal 315(7112):841-6.

Leblanc AD, Schneider VS, Evans HJ, Engelbretson DA, Krebs JM. 1990. Bone mineral loss and recovery after 17 weeks of bed rest. Journal of Bone and Mineral Research 5(8):843-50.

Lee TQ, Shapiro TA, Bell DM. 1997. Biomechanical properties of human tibias in longterm spinal cord injury. Journal of Rehabilitation Research and Development 34(3):295-302. 
Li CY, Price C, Delisser K, Nasser P, Laudier D, Clement M, Jepsen KJ, Schaffler MB. 2005. Long-term disuse osteoporosis seems less sensitive to bisphosphonate treatment than other osteoporosis. Journal of Bone and Mineral Research 20(1):117-24.

Lohuis TD, Harlow HJ, Beck TD. 2007. Hibernating black bears (Ursus americanus) experience skeletal muscle protein balance during winter anorexia. Comparative Biochemistry and Physiology Part B Biochemistry and Molecular Biology 147(1):20-8.

Lundberg DA, Nelson RA, Wahner HW, Jones JD. 1976. Protein-Metabolism in Black Bear before and during Hibernation. Mayo Clinic Proceedings 51(11):716-722.

Mackey MS, Stevens ML, Ebert DC, Tressler DL, Combs KS, Lowry CK, Smith PN, Mcosker JE. 1995. The Ferret as a Small Animal-Model with Bmu-Based Remodeling for Skeletal Research. Bone 17(4):S191-S196.

Matson J. 1946. Notes on Dormancy in the Black Bear. Journal of Mammalogy 27(3):203-212.

McCreadie BR, Hollister SJ, Schaffler MB, Goldstein SA. 2004. Osteocyte lacuna size and shape in women with and without osteoporotic fracture. Journal of Biomechanics 37(4):563-572.

McGee-Lawrence ME, Wojda SJ, Barlow LN, Drummer TD, Bunnell K, Auger J, Black HL, Donahue SW. 2009a. Six months of disuse during hibernation does not increase intracortical porosity or decrease cortical bone geometry, strength, or mineralization in black bear (Ursus americanus) femurs. Journal of Biomechanics 42(10):1378-83.

McGee-Lawrence ME, Wojda SJ, Barlow LN, Drummer TD, Castillo AB, Kennedy O, Condon KW, Auger J, Black HL, Nelson OL et al. . 2009b. Grizzly bears (Ursus arctos horribilis) and black bears (Ursus americanus) prevent trabecular bone loss during disuse (hibernation). Bone 45(6):1186-91.

McGee-Lawrence ME, Stoll DM, Mantila ER, Fahrner BK, Carey HV, Donahue SW. 2010. 13-lined ground squirrels (Ictidomys tridecemlineatus) show microstructural bone loss during hibernation but preserve bone macrostructural geometry and strength. Journal of Experimental Biology.

McGee ME, Magic KW, Miller DL, Maki AJ, Donahue SW. 2007a. Black bear femoral porosity decreases and mechanical properties increase with age despite annual periods of disuse (hibernation). Engineering Fracture Mechanics 74(12):19421952 . 
McGee ME, Miller DL, Auger J, Black HL, Donahue SW. 2007b. Black bear femoral geometry and cortical porosity are not adversely affected by ageing despite annual periods of disuse (hibernation). Journal of Anatomy 210(2):160-9.

McGee ME, Barlow LN, Simoni KJ, Wojda SJ, Auger J, Black HL, Donahue SW. 2008a. Post-hibernation black bears (Ursus americanus) do not demonstrate cortical bone loss compared to pre-hibernation bears despite 6 months of disuse.

McGee ME, Maki AJ, Johnson SE, Nelson OL, Robbins CT, Donahue SW. 2008b. Decreased bone turnover with balanced resorption and formation prevent cortical bone loss during disuse (hibernation) in grizzly bears (Ursus arctos horribilis). Bone 42(2):396-404.

Modlesky CM, Majumdar S, Narasimhan A, Dudley GA. 2004. Trabecular bone microarchitecture is deteriorated in men with spinal cord injury. Journal of Bone and Mineral Research 19(1):48-55.

Modlesky CM, Slade JM, Bickel CS, Meyer RA, Dudley GA. 2005. Deteriorated geometric structure and strength of the midfemur in men with complete spinal cord injury. Bone 36(2):331-9.

Mosekilde L. 1995. Assessing bone quality--animal models in preclinical osteoporosis research. Bone 17(4 Suppl):343S-352S.

Nelson RA. 1973. Winter sleep in the black bear. A physiologic and metabolic marvel. Mayo Clinic Proceedings 48(10):733-7.

Nieminen P, Finnila MA, Tuukkanen J, Jamsa T, Mustonen AM. 2010. Preservation of bone mass and biomechanical properties during winter sleep-the raccoon dog (Nyctereutes procyonoides) as a novel model species. Bone.

Organization WH. 1994. Assessment of fracture risk and its application to screening for postmenopausal osteoporosis. Report of a WHO Study Group. Geneva: World Health Organization.

Ortmann S, Heldmaier G. 2000. Regulation of body temperature and energy requirements of hibernating Alpine marmots (Marmota marmota). American Journal of Physiology-Regulatory Integrative and Comparative Physiology 278(3):R698R704.

Pardy CK, Wohl GR, Ukrainetz PJ, Sawers A, Boyd SK, Zernicke RF. 2004. Maintenance of bone mass and architecture in denning black bears (ursus americanus). Journal of Zoology, London 263:359-364.

Park KJ, Jones G, Ransome RD. 2000. Torpor, arousal and activity of hibernating Greater Horseshoe Bats (Rhinolophus ferrumequinum). Functional Ecology 14(5):580588 . 
Ragnarsson KT, Sell GH. 1981. Lower extremity fractures after spinal cord injury: a retrospective study. Archives of Physical Medicine amd Rehabilitation 62(9):41823.

Ramnemark A, Nyberg L, Borssen B, Olsson T, Gustafson Y. 1998. Fractures after stroke. Osteoporos International 8(1):92-5.

Rauch F, Travers R, Glorieux FH. 2007. Intracortical remodeling during human bone development--a histomorphometric study. Bone 40(2):274-80.

Ray NF, Chan JK, Thamer M, Melton LJ, 3rd. 1997. Medical expenditures for the treatment of osteoporotic fractures in the United States in 1995: report from the National Osteoporosis Foundation. Journal of Bone and Mineral Research 12(1):24-35.

Reginster J, Minne HW, Sorensen OH, Hooper M, Roux C, Brandi ML, Lund B, Ethgen D, Pack S, Roumagnac I et al. . 2000. Randomized trial of the effects of risedronate on vertebral fractures in women with established postmenopausal osteoporosis. Vertebral Efficacy with Risedronate Therapy (VERT) Study Group. Osteoporos International 11(1):83-91.

Riggs BL, Melton LJ, 3rd. 1995. The worldwide problem of osteoporosis: insights afforded by epidemiology. Bone 17(5 Suppl):505S-511S.

Rittweger J, Beller G, Armbrecht G, Mulder E, Buehring B, Gast U, Dimeo F, Schubert H, de Haan A, Stegeman DF et al. . Prevention of bone loss during 56 days of strict bed rest by side-alternating resistive vibration exercise. Bone 46(1):137-47.

Rittweger J, Frost HM, Schiessl H, Ohshima H, Alkner B, Tesch P, Felsenberg D. 2005. Muscle atrophy and bone loss after 90 days' bed rest and the effects of flywheel resistive exercise and pamidronate: results from the LTBR study. Bone 36(6):1019-29.

Rubin C, Gross T, Qin YX, Fritton S, Guilak F, McLeod K. 1996. Differentiation of the bone-tissue remodeling response to axial and torsional loading in the turkey ulna. Journal of Bone and Joint Surgery 78(10):1523-33.

Salsbury CM, Armitage KB. 1994. Resting and field metabolic rates of adult male yellow-bellied marmots, Marmota flaviventris. Comparative Biochemistry and Physiology 108(4):579-88.

Sartorelli P, Calderola S, Sala M, Citterio C, Lanfranchi P. 2004. Seasonal changes in serum metabolites in free-ranging alpine marmots (Marmota marmota). Journal of Comparative Physiology B-Biochemical Systemic and Environmental Physiology 174(4):355-61. 
Spector ER, Smith SM, Sibonga JD. 2009. Skeletal effects of long-duration head-down bed rest. Aviation Space and Environmental Medicine 80(5 Suppl):A23-8.

Steinberg B, Singh IJ, Mitchell OG. 1981. The effects of cold-stress. Hibernation, and prolonged inactivity on bone dynamics in the golden hamster, Mesocricetus auratus. Journal of Morphology 167(1):43-51.

Steinberg B, Singh IJ, Mitchell OG. 1986. An autoradiographic study of the uptake of tritiated proline by osteoblasts during hibernation. Histology and Histopathology $1(2): 155-60$.

Takata S, Yasui N. 2001. Disuse osteoporosis. Journal of Medical Investigation 48(34):147-56.

Tazawa K, Hoshi K, Kawamoto S, Tanaka M, Ejiri S, Ozawa H. 2004. Osteocytic osteolysis observed in rats to which parathyroid hormone was continuously administered. Journal of Bone and Mineral Metabolism 22(6):524-529.

Teti A, Zallone A. 2009. Do osteocytes contribute to bone mineral homeostasis? Osteocytic osteolysis revisited. Bone 44(1):11-6.

Thomas DW, Dorais M, Bergeron JM. 1990. Winter Energy Budgets and Cost of Arousals for Hibernating Little Brown Bats, Myotis-Lucifugus. Journal of Mammalogy 71(3):475-479.

Tilton FE, Degioanni JJ, Schneider VS. 1980. Long-term follow-up of Skylab bone demineralization. Aviation Space and Environmental Medicine 51(11):1209-13.

Tinker DB, Harlow HJ, Beck TD. 1998. Protein use and muscle-fiber changes in freeranging, hibernating black bears. Physiological Zoology 71(4):414-24.

Trebacz H. 2001. Disuse-induced deterioration of bone strength is not stopped after free remobilization in young adult rats. Journal of Biomechanics 34(12):1631-1636.

Turner RT, Evans GL, Wakley GK. 1995. Spaceflight results in depressed cancellous bone formation in rat humeri. Aviation Space and Environmental Medicine 66(8):770-4.

Turner RT, Lotinun S, Hefferan TE, Morey-Holton E. 2006. Disuse in adult male rats attenuates the bone anabolic response to a therapeutic dose of parathyroid hormone. J Appl Physiol 101(3):881-6.

Utz JC, Nelson S, O'Toole BJ, van Breukelen F. 2009. Bone strength is maintained after 8 months of inactivity in hibernating golden-mantled ground squirrels, Spermophilus lateralis. Journal of Experimental Biology 212(17):2746-52. 
Vestergaard P, Krogh K, Rejnmark L, Mosekilde L. 1998. Fracture rates and risk factors for fractures in patients with spinal cord injury. Spinal Cord 36(11):790-6.

Ward JM, Armitage KB. 1981. Circannual rhythms of food consumption, body mass, and metabolism in yellow-bellied marmots. Comparative Biochemistry and Physiology, A. Comparative Physiology 69A:621-626.

Weinreb M, Rodan GA, Thompson DD. 1989. Osteopenia in the immobilized rat hind limb is associated with increased bone resorption and decreased bone formation. Bone 10(3):187-94.

Weinreb M, Patael H, Preisler O, Ben-Shemen S. 1997. Short-term healing kinetics of cortical and cancellous bone osteopenia induced by unloading during the reloading period in young rats. Virchows Archive 431(6):449-52.

Whalen JP, Krook L, Nunez EA. 1972. A radiographic and histologic study of bone in the active and hibernating bat (Myotis lucifugus). Anatomical Record 172(1):97108 .

Wright PH, Jowsey JO, Robb RA. 1978. Osteocyte Lacunar Area in Normal Bone, Hyper-Parathyroidism, Renal-Disease, and Osteoporosis. Surgical Forum 29:558559.

Wronski TJ, Morey ER. 1983. Inhibition of cortical and trabecular bone formation in the long bones of immobilized monkeys. Clinical Orthopaedics and Related Research(181):269-76.

Wronski TJ, Moreyholton ER, Doty SB, Maese AC, Walsh CC. 1987. Histomorphometric Analysis of Rat Skeleton Following Spaceflight. American Journal of Physiology 252(2):R252-R255.

Yonezu H, Takata S, Shibata A. 2004. Effects of unilateral sciatic neurectomy on growing rat femur as assessed by peripheral quantitative computed tomography, Fourier transform infrared spectroscopy and bending test. Journal of Medical Investigation 51(1-2):96-102.

Young DR, Niklowitz WJ, Brown RJ, Jee WS. 1986. Immobilization-associated osteoporosis in primates. Bone 7(2):109-17.

Young PJ. 1990. Hibernating Patterns of Free-Ranging Columbian Ground-Squirrels. Oecologia 83(4):504-511.

Zatzman ML, South FE. 1972. Renal function of the awake and hibernating marmot Marmota flaviventris. American Journal of Physiology 222(4):1035-9.

Zatzman ML, South FE. 1975. Concentration of urine by the hibernating marmot. American Journal of Physiology 228(5):1336-40. 
Zervanos SM, Maher CR, Waldvogel JA, Florant GL. 2010. Latitudinal Differences in the Hibernation Characteristics of Woodchucks (Marmota monax). Physiological and Biochemical Zoology 83(1):135-141.

Zerwekh JE, Ruml LA, Gottschalk F, Pak CY. 1998. The effects of twelve weeks of bed rest on bone histology, biochemical markers of bone turnover, and calcium homeostasis in eleven normal subjects. Journal of Bone and Mineral Research 13(10):1594-601.

Zimmerman GD, McKean TA, Hardt AB. 1976. Hibernation and disuse osteoporosis. Cryobiology 13(1):84-94. 


\section{Chapter 2 Methods}

\subsection{Samples}

Sixty six yellow-bellied marmots (Marmota flaviventris) collected between March 2009 and September 2010 were used for this study. There were 34 pre-hibernation samples (collected between August $5^{\text {th }}$ and September $2^{\text {nd }}$ ) and 32 post-hibernation samples (collected from March $22^{\text {nd }}$ through the beginning of June). Exact dates of capture varied depending on when entrance into hibernation and emergence from hibernation occurred that year. Age data was not available for samples. Gender (posthibernation: 12 Female, 10 Male and pre-hibernation: 20 Female, 12 Male) and weight were only available for some samples (post-hibernation: 10 Female, 9 Male and prehibernation: 15 Female, 12 Male). Bones were removed post mortem, cleaned of soft tissue and stored at $-20^{\circ} \mathrm{C}$. All procedures were approved by the Institutional Animal Care and Use Committee (L0119).

\subsection{Histology}

The distal $1 / 2$ of the left femur (as shown in Figure 2.1) from each marmot was removed and cleaned of marrow. Each segment was fixed in $70 \%$ ethanol for a minimum of 48 hours then histologically prepared. Segments were bulk stained in Villanueva osteochrome bone stain as follows: bones were placed in stain for 72 hours then moved to $70 \%$ ethanol for 1 hour, 95\% ethanol for 1.5 hours, fresh $95 \%$ ethanol for 1.5 hours, $100 \%$ ethanol for 1.5 hours, fresh $100 \%$ ethanol for 1.5 hours, $100 \%$ acetone for 1.5 hours and removed and let air dray. Stained segments were then embedded in methylmethacrylate (Ortho-jet, Lang Dental Manufacturing Co, Inc) anterior side up with the distal end in the center of the block. Embedded segments were cut perpendicular to the longitudinal axis on an Isomet 1000 diamond saw (Buehler LTD). The first section was saved for quantification of bone geometrical properties. Subsequent sections were ground to $<90$ microns and made into slides, three slides per marmot were made (three consecutive sections were used when possible, however due to processing there were occasions where samples were lost/destroyed and exceptions had to be made). One slide was used for quantification of lacunar properties and Haversian porosity. Remodeling cavities were quantified for all three slides. 


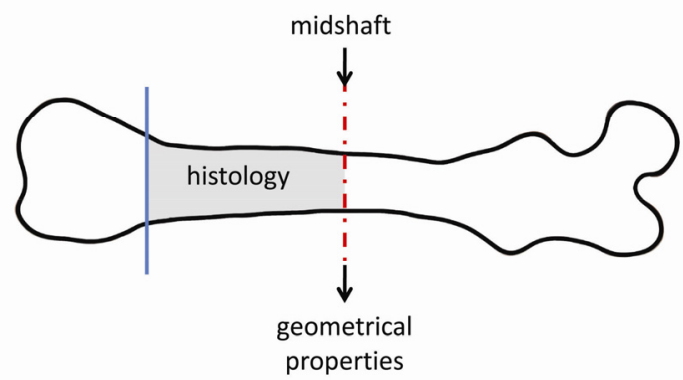

Figure 2.1: The gray highlighted on this femur outline is the region used for histology. After embedding, sections were cut perpendicular to the long axis of the bone. Sections were cut starting at the midshaft.

\section{Lacunar properties}

Osteocyte lacunar properties were quantified for one femoral cross section per marmot. The entire cross section was not imaged/analyzed, rather the cross section was divided into octants and two pictures were taken for each octant, one image of the periosteal side and one of the endosteal side (Figure 2.2). Images were taken at $400 \mathrm{X}$ magnification on an Olympus CX41 microscope (Center Valley, PA) and Spot camera (SPOT Insight QE, Diagnostic Instruments, Sterling Heights, MI). Lacunar measurements were made using an image analysis software package, Bioquant Osteo II (Nashville, TN).

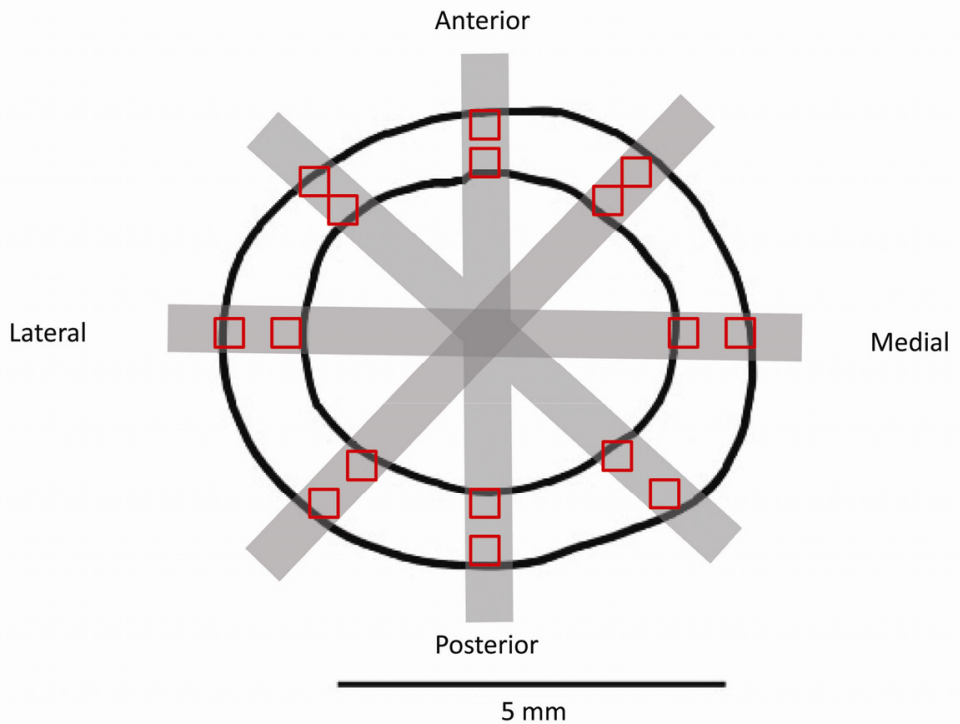

Figure 2.2: Femur cross section, where the grey lines represent the location of anatomical octants. Red boxes indicate location of images obtained from each octant for analysis of osteocyte lacunar properties. Note: size representation of images in comparison to cross section size may vary. 
All lacunae in focus in the field of view for each image were measured. However, lacunae data was collected in three different groups; lacunae with a halo around the entire lacunae, lacunae with a halo around part of the lacunae, and lacunae with no halo (Figure 2.3). Lacunae data was collected in this manner because the term osteocyte halo is used in some literature to describe a demineralized perilacunar area in osteocytes where osteocytic osteolysis is believed to be occuring (Alcobendas et al. 1991; Teti and Zallone 2009). Though the halo noticed in these samples is likely an artifact of the processing/imaging technique, data were separated out to see if the appearance of the lacunae affected the results of data analysis, thus warranting further investigation. Lacunar properties quantified for this study were average lacunar area (Lc.Ar), lacunar density (Lc.Dn), and lacunar porosity (Lc.Por) (total lacunar area divided by bone area) for each image. Data was analyzed using a three-way ANOVA with season, octant, and cortical location (endosteal or periosteal) as factors. A p-value of 0.05 was considered significant. A three-way ANOVA was used on each of the 4 subsets of the data separately; all lacunae in the field of view, only lacunae with a halo all the way around, only lacunae with a halo or partial halo, and only lacunae with no halo.

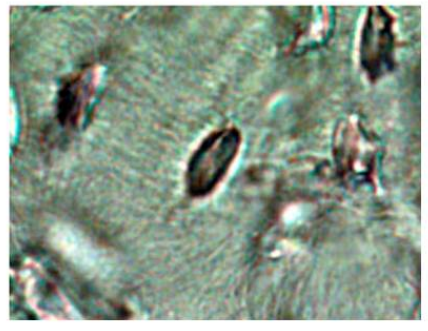

Partial Halo

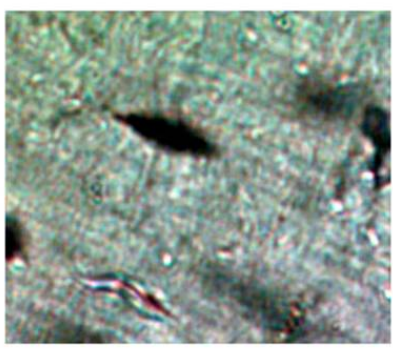

Non Halo

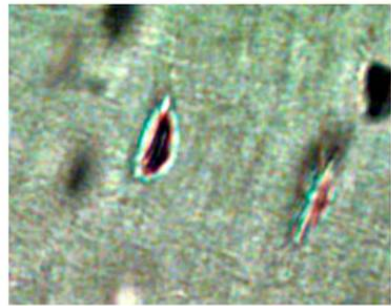

Halo

Figure 2.3: Osteocyte lacunae data was collected in three groups. Lacunae with a partial halo (left), lacunae with no halo (middle), and lacunae with a halo (right).

Because there are no known relationships available to allow for normalization of lacunar properties by bone length to account for changes that may be occurring due to animals being larger or older. Osteocyte lacunar density has been shown to decrease with age in humans (Busse et al. 2010), and average lacunar area and lacunar porosity were lower in adult 13-lined ground squirrels than juveniles (McGee-Lawrence et al. 2011). Therefore, to get an idea of how properties compare pre- versus post-hibernation without the possibility of age affecting the data pre- and post-hibernation samples were paired by femur length. Paired t-tests were used to determine whether or not properties were different between pre- and post-hibernation samples (Note: variation by octant and endosteal/periosteal were not looked at). Since post-hibernation samples were on average longer than pre-hibernation samples some samples did have to be excluded reducing the sample size to $\mathrm{n}=11$ per group. 


\section{Resorption and Refilling Cavities}

Resorption and refilling cavity density (Figure 2.4) was quantified for three consecutive sections starting at the femur midshaft. Remodeling cavities were counted by quadrant. Remodeling cavity density was calculated as remodeling cavities per cross section area. Results were compared between pre- and post-hibernation samples using a one-way ANOVA.
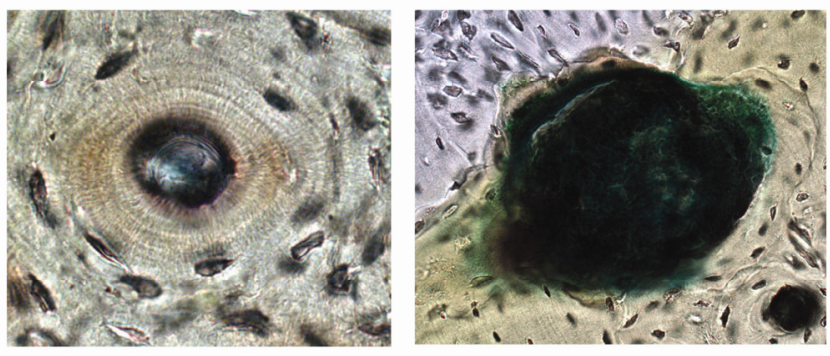

Figure 2.4: Refilling cavity (left), resorption cavity (right).

\section{Intracortical Porosity}

Intracortical porosity was quantified for one cross section per marmot. The cross section for each sample was imaged at 100X magnification on an Olympus CX41 microscope (Center Valley, PA) and Spot camera (SPOT Insight QE, Diagnostic Instruments, Sterling Heights, MI). Images were analyzed in Bioquant Osteo (Nashville, TN). Porosity was calculated as porous area divided by total bone area. Porous area included Haversian canals and Volkmanns canals as well as any resorption or refilling cavities. Porostiy was compared between pre- and post-hibernation samples using a oneway ANOVA. Like lacunar properties, size differences cannot be accounted for by normalization using a known relationship between femur length or body weight with porosity. Thus to provide a check that the results seen in the one-way ANOVA were not confounded by changes in size, paired t-tests were performed for porosity also $(n=11$ per group).

\subsection{Micro computed tomography $(\mu \mathrm{CT})$}

The left tibia from each sample was fixed in $70 \%$ ethanol for 48 hours. Trabecular bone properties were assessed by micro computed tomography $(\mu \mathrm{CT})$. The proximal tibia was scanned at $30 \mu \mathrm{m}$ resolution ( $\mu \mathrm{CT} 35$, Scanco Medical). During scanning bones were held in a $30.5 \mathrm{~mm}$ tube surrounded by ethanol (Figure 2.5 ). The entire scan region was 233 slices and started 3-9.96mm distal to the growth plate depending on the bone $(\mathrm{mm}$ distal to growth plate $=6 \%$ total bone length). However, in order to make sure the same region of each bone was being evaluated due to a wide range of whole bone lengths the 
evaluation region was $5 \%$ of total bone length, so not all 233 slices were evaluated for bone properties. See Figure 2.6 for an example of the scan region. Bone volume (BV), tissue volume (TV), bone volume fraction (BV/TV), trabecular number (Tb.N.), trabecular thickness (Tb.Th.), trabecular separation (Tb.Sp.), apparent mineral density (App.M.Dn) and material mineral density (Mat.M.Dn.) were quantified (Figure 2.7) Properties were compared between pre- and post-hibernation groups using a one-way ANOVA. Due to cost only the first two collection periods were used for $\mu \mathrm{CT}$ analysis, thus sample size was $n=14$ fall, 12 spring.

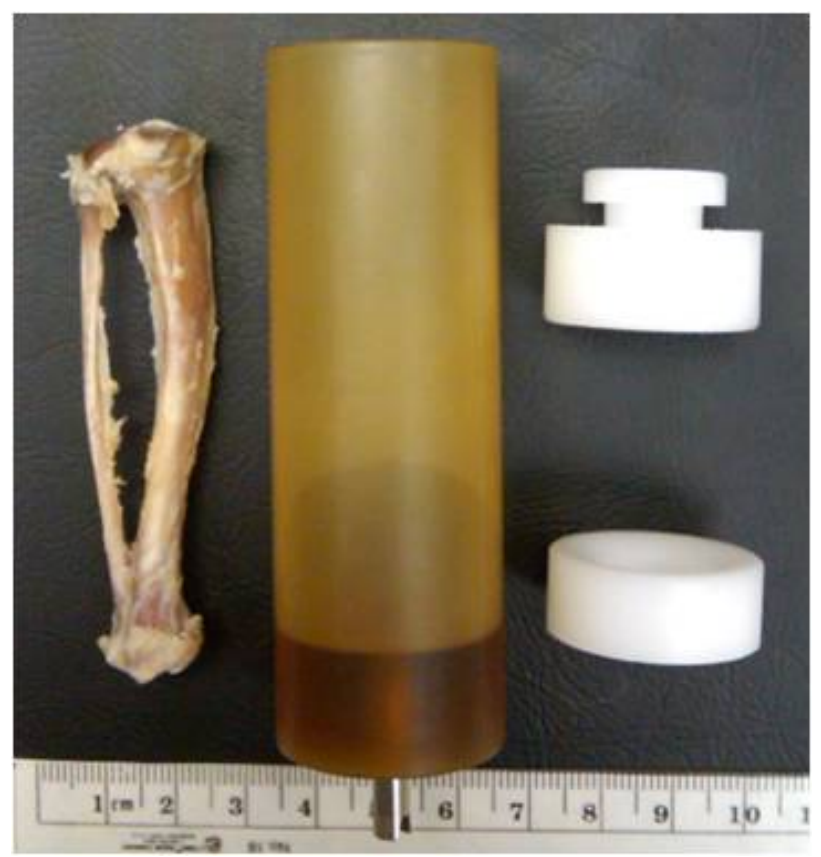

Figure 2.5: Marmot tibia next to the fixture used for micro-CT. 


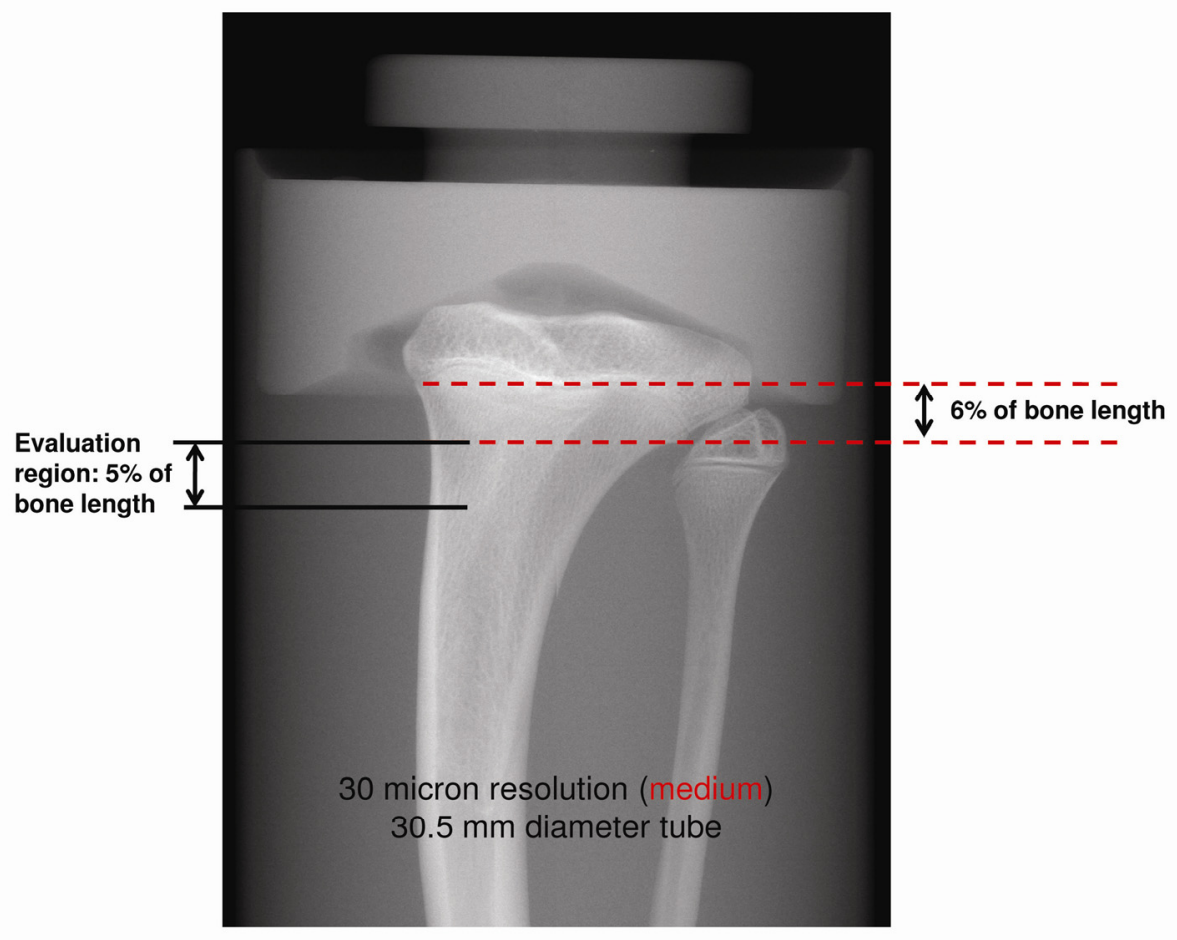

Figure 2.6: Micro-CT scout view of a marmot tibia with evaluation region highlighted.

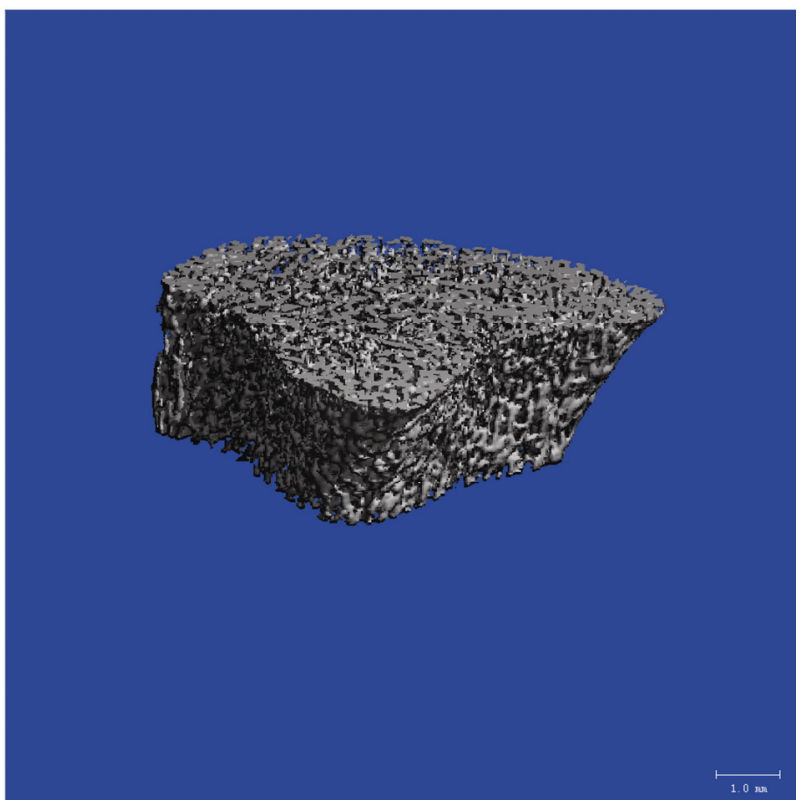

Figure 2.7: 3-D reconstruction of the region of a marmot tibia scanned with $\mu C T$. 
It is unclear whether or not trabecular bone properties scale with body weight. However, the post-hibernation samples being larger than the pre-hibernation samples could affect the outcomes. Trabecular bone morphometric parameters have been shown to vary with species size (Mullender et al. 1996). However, how trabecular bone properties scale within the size ranges of a given species is unclear. A suggested reason for changes or lack of changes of certain trabecular bone properties with body weight may be determined by requirements for maintaining sufficient surface area for calcium homeostasis (Swartz et al. 1998). Due to the decreased sample size used for $\mu \mathrm{CT}$ data could not be paired based on femur length for analysis, only two pairs could be made within the portion of the data set used for $\mu \mathrm{CT}$. Thus in attempt to account for the possibility of body weight, BV/TV data was normalized and groups were compared with a one-way ANOVA. Femur length was used for normalization instead of body weight to avoid issues with seasonal weight fluctuation, and to account for not having weight data for one season. Femur length is proportional to (Body weight) ${ }^{0.33}$ (Alexander et al. 1979; Casinos et al. 1993). This relationship was used to normalize trabecular bone properties to adjust for size differences if it is indeed a factor.

\subsection{Geometrical properties}

A cross section of the midshaft of the left femur was prepared using the same methods as described for lacunar properties. The cross section was imaged using a Nikon lens and spot digital camera. Periosteal area (Ps.Ar), cortical area (Ct.Ar), and endosteal area (Es.Ar) for each sample were calculated using image analysis software (Scion Corporation, Frederick, Maryland). A custom macro was utilized with this image analysis software to calculate the cross sectional moments of inertia for the mediolateral (bending) axis $\left(\mathrm{I}_{\mathrm{ML}}\right)$ and anteroposterior axis (IAP), product of inertia (IP), maximum moment of inertia (Imax), centroid of the cross-section, neutral axis, and the $\mathrm{x}$ and $\mathrm{y}$ distances of the cortex location furthest from the neutral axis. See Figure 2.8 for an example of a cross section used for these calculations. Cortical thickness (Ct.Th) was calculated for the cross section using Bioquant Osteo II. Polar moment of inertia (J) was calculated as the sum of IAP and IML (Vable 2002). Cross-sectional properties were compared between pre- and post-hibernation groups with a one-way ANOVA. Properties were also normalized by femur length then analyzed to account for differences in size of marmots between groups. Properties were normalized by femur length because it is well known that cross sectional

area scales with (femur length) ${ }^{2}$ and moments of inertia scale with (femur length) ${ }^{4}$ (Ruff 1984; Casinos et al. 1993; Heinrich and Biknevicius 1998). 


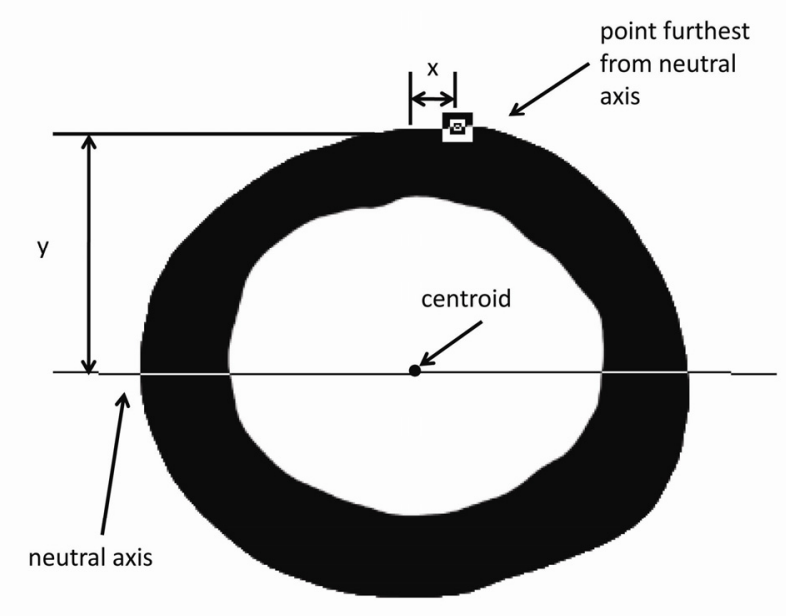

Figure 2.8: Example of a digitized femoral cross section used to calculate cross sectional properties. The neutral axis and point furthest from the neutral axis, as well as the $x$ and $y$ distances from the centroidal axis to the point furthest from the neutral axis and moments of inertia were determined by the macro.

\subsection{Whole bone bending}

The right femur of each animal was thawed and rehydrated in $0.15 \mathrm{M}$ saline solution for approximately 4.5-5 hours prior to mechanical testing. Each femur was loaded to failure in three-point bending with the anterior side of the bone in tension. Femurs were tested in bending because bending is believed to be the predominant loading type in long bones like the femur and tibia (C. T. Rubin 1984). In vivo stiffness measured by a strain gauge on the anterior surface of the femur diaphysis has been shown to correlate with results from 3-point bending (Indrekvam et al. 1991). Tests were performed on an Instron mechanical testing system (Instron Model \#8872, Canton, MA) with a crosshead speed of $10 \mathrm{~mm} / \mathrm{min}$ using an adjustable span test fixture with rounded supports $(\mathrm{r}=3.7)$. Data was collected at a sampling rate of $1.0 \mathrm{kHz}$. When placed on the test fixture bones remain more stable with the anterior surface in tension compared to other orientations. However, due to the size and geometry of the bones a small pre-load $(1-10 \mathrm{~N})$ was applied to ensure the bone remained in the desired position when testing began. No rotation of bones was noticeable once testing commenced. The adjustable span test fixture was used to maximize the span between lower supports for samples, minimizing shear effects as much as possible. Spans for test specimens ranged from $23.54 \mathrm{~mm}$ to $41-39 \mathrm{~mm}$ for pre-hibernation samples and from $25.46 \mathrm{~mm}$ to $43.9 \mathrm{~mm}$ for post-hibernation samples (Table 2.1). 
Table 2.1

Span and length-diameter (L/D) ratio information for pre- and post-hibernation samples.

\begin{tabular}{|cccccc|}
\hline & Season & Range & Mean & Median & p-value \\
\hline $\begin{array}{c}\text { Span } \\
(\mathbf{m m})\end{array}$ & pre-hibernation & $23.54-41.39$ & $30.16 \pm 4.7$ & 30.7 & $<0.0001$ \\
& post-hibernation & $25.46-43.9$ & $36.4 \pm 5.24$ & 35.1 & \\
\hline \multirow{2}{*}{ L/D ratio } & pre-hibernation & $3.8-6.9$ & $5.4 \pm 076$ & 5.76 & \multirow{2}{*}{0.0025} \\
& post-hibernation & $4.75-6.86$ & $5.96 \pm 055$ & 6.30 & \\
\hline
\end{tabular}

Whole bone mechanical properties

Whole bone mechanical properties were calculated using beam bending theory (Levenston 1995). Stress was determined as follows:

$$
\sigma=\frac{P * L *\left(I_{A P} * y-I_{P} * x\right)}{4 *\left(I_{M L} * I_{A P}-I_{P}^{2}\right)}
$$

For this equation $\mathrm{P}$ is the load and $\mathrm{L}$ is the span between lower supports. Ultimate stress $\left(\sigma_{u}\right)$ was calculated using equation 1 , where $P$ is the ultimate load $\left(P_{u}\right)$. Failure energy $\left(U_{f}\right)$ was calculated as the area under the load-deformation curve up to the failure point (Figure 2.9). Modulus of toughness $(u)$ was calculated using equation 2 (C.H. Turner and Burr 2001) where $\mathrm{c}$ is one-half the anterior-posterior diameter:

$$
u=\frac{U_{f} *\left(3 * c^{2}\right)}{I_{M L} * L}
$$

Elastic energy $\left(U_{e}\right)$ or the energy up to the yield point was also determined. Elastic energy was determined as the area under the load-deformation curve up to the value corresponding to yield stress. Yield stress was determined using the $0.2 \%$ offset method. For conversions from load to stress equation 1 was used. Deformation was converted to strain using equation 3 where $d$ is the deformation (C.H. Turner and Burr 2001).

$$
\varepsilon=\frac{12 * c * d}{L^{2}}
$$

Resilience was calculated as modulus of toughness to yield (replacing $\mathrm{U}_{\mathrm{f}}$ in equation 2 with $U_{e}$ ) Elastic modulus was calculated using equation 4 (C.H. Turner and Burr 2001). Where $(\mathrm{P} / \mathrm{d})$ is the stiffness (slope of the linear region of the load-deformation curve) and $\mathrm{L}$ is the span.

$$
E=\left(\frac{P}{d}\right) *\left(\frac{L}{48 * I_{M L}}\right)
$$




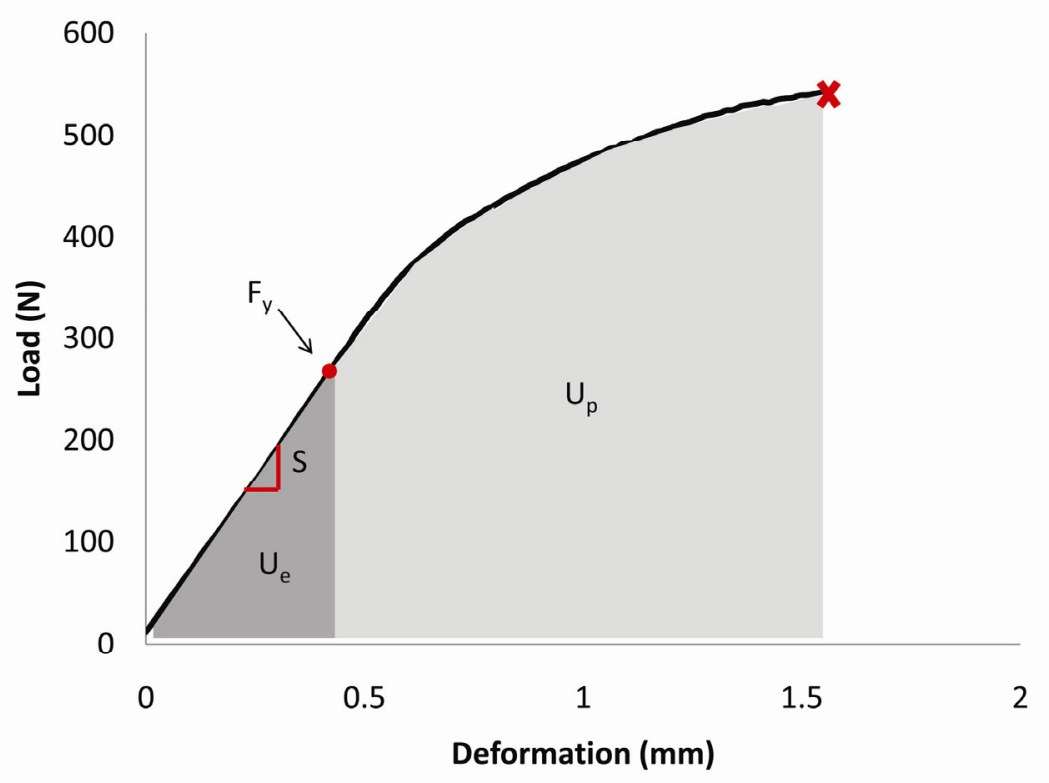

Figure 2.9: Typical load-deformation curve, red $X$ marks the failure point. Stiffness is denoted as $S$ on the curve and yield force is denoted as $F_{y}$. Yield was found by $0.2 \%$ offset method on the stress strain curve. Failure energy $\left(U_{f}\right)$ is the sum of elastic $\left(U_{e}\right)$ and plastic energy $\left(U_{p}\right)$.

Mechanical properties were compared between groups with a one-way ANOVA. To more clearly examine effects of hibernation on these properties without potential age effect paired t-test were performed also. As mentioned before sample size was decreased due to variation between groups making it necessary to omit samples that could not be paired.

\subsection{Ash Fraction}

To obtain a measure of mineral content, ash fraction for each sample was determined from the cortical bone of the proximal $1 / 2$ of the femoral diaphysis. Figure 2.10 shows the section of bone used. Each section was cleaned of marrow with a water jet and rehydrated in $0.15 \mathrm{M}$ saline for 20 minutes. Segments were weighed (wet mass) then placed in a furnace and dried at $100^{\circ} \mathrm{C}$ for 24 hours and re-weighed to obtain a dry mass. Samples were placed back in the furnace and ashed at $600^{\circ} \mathrm{C}$ for 48 hours. After 48 hours the furnace was turned down to $100^{\circ} \mathrm{C}$, after the samples reached $100^{\circ} \mathrm{C}$ they were weighed again (ash mass). The ash fraction was calculated as the ash mass divided by the dry mass. Ash fraction was compared between groups with a one-way ANOVA and also a paired t-test. 


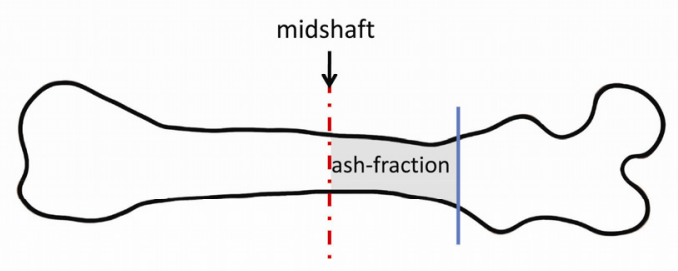

Figure 2.10: The segment of cortical bone used for determination of ash fraction is highlighted in gray.

\subsection{References}

Alcobendas M, Baud CA, Castanet J. 1991. Structural-Changes of the Periosteocytic Area in Vipera-Aspis (L) (Ophidia, Viperidae) Bone Tissue in Various Physiological Conditions. Calcified Tissue International 49(1):53-57.

Alexander RM, Jayes AS, Maloiy GMO, Wathuta EM. 1979. Allometry of the Limb Bones of Mammals from Shrews (Sorex) to Elephant (Loxodonta). Journal of Zoology 189(Nov):305-314.

Busse B, Djonic D, Milovanovic P, Hahn M, Puschel K, Ritchie RO, Djuric M, Amling M. 2010. Decrease in the osteocyte lacunar density accompanied by hypermineralized lacunar occlusion reveals failure and delay of remodeling in aged human bone. Aging Cell 9(6):1065-1075.

Casinos A, Quintana C, Viladiu C. 1993. Allometry and Adaptation in the Long Bones of a Digging Group of Rodents (Ctenomyinae). Zoological Journal of the Linnean Society 107(2):107-115.

Heinrich RE, Biknevicius AR. 1998. Skeletal allometry and interlimb scaling patterns in mustelid carnivorans. Journal of Morphology 235(2):121-34.

Indrekvam K, Husby OS, Gjerdet NR, Engester LB, Langeland N. 1991. Age-Dependent Mechanical-Properties of Rat Femur - Measured Invivo and Invitro. Acta Orthopaedica Scandinavica 62(3):248-252.

Levenston ME. 1995. Periosteal bone formation stimulated by externally induced bending strains. Journal of Bone and Mineral Research 10(4):671-2.

McGee-Lawrence ME, Stoll DM, Mantila ER, Fahrner BK, Carey HV, Donahue SW. 2011. Thirteen-lined ground squirrels (Ictidomys tridecemlineatus) show microstructural bone loss during hibernation but preserve bone macrostructural geometry and strength. Journal of Experimental Biology 214(Pt 8):1240-7. 
Mullender MG, Huiskes R, Versleyen H, Buma P. 1996. Osteocyte density and histomorphometric parameters in cancellous bone of the proximal femur in five mammalian species. J Orthop Res 14(6):972-9.

Rubin CT. 1984. Skeletal Strain and the Functional-Significance of Bone Architecture. Calcified Tissue International 36:S11-S18.

Ruff CB. 1984. Allometry between length and cross-sectional dimensions of the femur and tibia in Homo sapiens sapiens. American Journal of Physical Anthropology 65(4):347-58.

Swartz SM, Parker A, Huo C. 1998. Theoretical and empirical scaling patterns and topological homology in bone trabeculae. Journal of Experimental Biology 201(Pt 4):573-90.

Teti A, Zallone A. 2009. Do osteocytes contribute to bone mineral homeostasis? Osteocytic osteolysis revisited. Bone 44(1):11-6.

Turner CH, Burr DB. 2001. Experimental techniques for bone mechanics. In: Cowin SC, editor. Bone Mechanics Handbook. Boca Raton, FL: CRC Press. p. 7-1--7-35.

Vable M. 2002. Mechanics of Materials. Oxford University Press, Inc. p. 728. 


\section{Chapter 3 \\ Results and Conclusions}

\subsection{Samples}

Since age data was not available for any samples, femur length was used as a basis to determine if groups contained animals of similar sizes. The spring group femurs were $12.5 \%$ longer than those in the pre-hibernation group $(\mathrm{p}<0.0001)$. Similarly for those samples where weight data was available, weight was $23 \%$ higher in the posthibernation samples $(p=0.0285)$ (Table 3.1). Marmots lose $32.5 \pm 2.5 \%$ of their prehibernation boy weight (Ortmann and Heldmaier 2000; Zervanos et al. 2010). Therefore, post-hibernation animals were larger and probably older than pre-hibernation samples. When possible, and appropriate, data was normalized to account for these differences in size.

Table 3.1

Weight and femur length information for pre- and post-hibernation samples with \% differences in post hibernation samples relative to pre-hibernation samples.

\begin{tabular}{|cccccc|}
\hline Property & Units & $\begin{array}{c}\text { Pre-hibernation } \\
\text { (Fall) mean }\end{array}$ & $\begin{array}{c}\text { Post-hibernation } \\
\text { (Spring) mean }\end{array}$ & p-value & $\begin{array}{c}\text { \% } \\
\text { difference }\end{array}$ \\
\hline Weight & lbs & $4.1 \pm 1.4$ & $5.4 \pm 2.3$ & $\mathbf{0 . 0 2 8 5}$ & 23 \\
\hline $\begin{array}{l}\text { Femur } \\
\text { length }\end{array}$ & $\mathrm{mm}$ & $64.6 \pm 5.8$ & $73.8 \pm 8.1$ & $\mathbf{< . 0 0 0 1}$ & 12.5 \\
\hline
\end{tabular}

\subsection{Histology}

\section{Lacunar properties}

The three-way ANOVA was used to compare the 4 subsets of the data; taking into account all lacunae in the field of view, lacunae with a halo all the way around, lacunae with a halo or partial halo, and lacunae with no halo. However, results are reported only for the analysis of all lacunae in a field of view (halo, partial halo, and no halo). Results are only reported for this analysis because the results were the same regardless of which subset of data was analyzed. When data for all lacunae was analyzed average lacunar area was 9.3\% lower in post-hibernation samples $(\mathrm{p}<0.0001)$ (Table 3.2). Average launar area was also larger in the periosteal regions $(\mathrm{p}<0.001)$ and varied depending on which octant the lacunae were from $(\mathrm{p}<0.0001)$. Lacunar density was $10.3 \%$ lower in the posthibernation group $(\mathrm{p}<0.0001)$. Lacunar porosity was $21 \%$ lower in the post-hibernation group $(\mathrm{p}<0.0001)$ (Figure 3.1). Lacunar porosity varied by octant $(\mathrm{p}=0.0162)$ but not 
by endosteal/periosteal region $(\mathrm{p}=0.3418)$. Lacunar density was lower in the periosteal regions $(\mathrm{p}<0.0001)$ and varied by octant $(\mathrm{p}<0.0001)$. Specifics for how properties vary by octant can be seen in appendix 1. Though there was some variation of lacunar properties within a cross section, it is most important to note that lacunar area, density and porosity were all decreased $(\mathrm{p}<0.0001)$ in post-hibernation samples. This is indicative of preservation of bone, as lacunar area and porosity would be expected to be higher in post-hibernation samples if bone were being lost due through osteocytic osteolysis.

Table 3.2

Osteocyte lacunar property results for all lacunae in the field of view, with \% differences in post hibernation samples relative to pre-hibernation samples.

\begin{tabular}{|cccccc|}
\hline Property & Units & $\begin{array}{c}\text { Pre- } \\
\text { hibernation } \\
\text { (Fall) mean }\end{array}$ & $\begin{array}{c}\text { Post- } \\
\text { hibernation } \\
\text { (Spring) mean }\end{array}$ & p-value & $\begin{array}{c}\% \\
\text { difference }\end{array}$ \\
\hline $\begin{array}{c}\text { Average } \\
\text { lacunar } \\
\text { area }\end{array}$ & $\mu \mathrm{m}^{2}$ & $49.26 \pm 7.8$ & $45.08 \pm 7.8$ & $<\mathbf{0 . 0 0 0 1}$ & -9.3 \\
\hline $\begin{array}{c}\text { Lacunar } \\
\text { porosity }\end{array}$ & $\%$ & $0.95 \pm 0.3913$ & $0.79 \pm 0.26$ & $<\mathbf{0 . 0 0 0 1}$ & -21 \\
\hline $\begin{array}{c}\text { Lacunar } \\
\text { density }\end{array}$ & $\# / \mathrm{mm}^{2}$ & $193 \pm 60.9$ & $175 \pm 30.8$ & $\mathbf{< . 0 0 0 1}$ & -10.3 \\
\hline
\end{tabular}

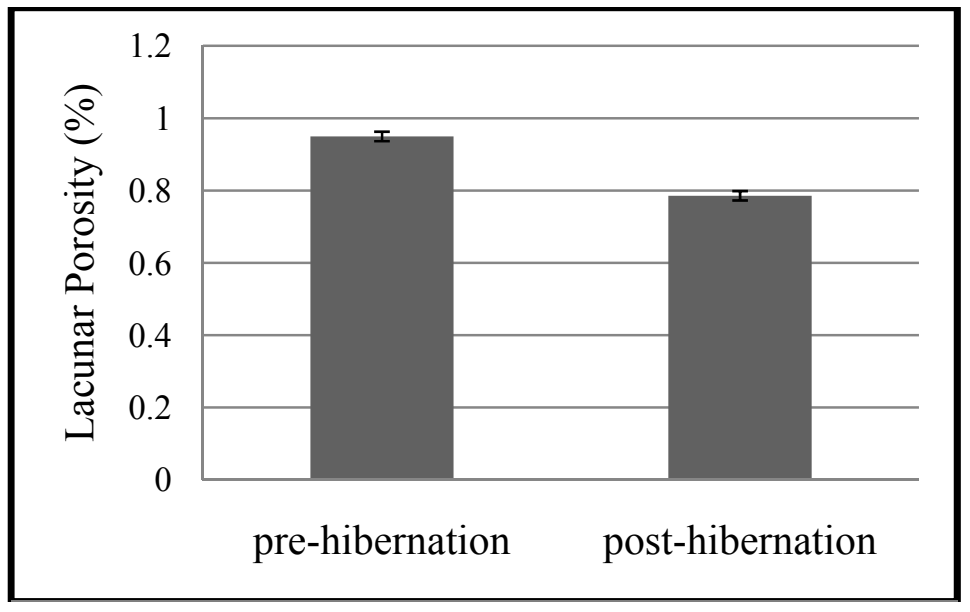

Figure 3.1: Lacunar porosity was $21 \%$ lower in post-hibernation samples $(p<0.0001)$. 
There are no known relationships between osteocyte lacunar properties and bone length. Thus in attempt to remove the potential effects of size/age differences pre- and post-hibernation samples were paired by femur length. Paired t-tests were used to determine whether or not properties were different between pre- and post-hibernation samples (Note: variation by octant and endosteal/periosteal were not looked at). Results (Table 3.3) are very similar to the results of the ANOVA used to analyze the whole data set. Average lacunar area $(p=0.0164)$ and lacunar porosity $(p=0.0067)$ were lower in post-hibernation samples. Similarly, lacunar density tended $(\mathrm{p}=0.0606)$ to be lower posthibernation.

Table 3.3

Data from paired t-test ( $n=11$ per group) of lacunar properties with $\%$ differences in post hibernation samples relative to pre-hibernation samples. Lacunar properties are lower in post hibernation samples.

\begin{tabular}{|cccccc|}
\hline Property & Units & $\begin{array}{c}\text { Pre- } \\
\text { hibernation } \\
\text { (Fall) mean }\end{array}$ & $\begin{array}{c}\text { Post- } \\
\text { hibernation } \\
\text { (Spring) mean }\end{array}$ & p-value & $\begin{array}{c}\text { \% } \\
\text { difference }\end{array}$ \\
\hline $\begin{array}{c}\text { Average } \\
\text { lacunar } \\
\text { area }\end{array}$ & $\mu \mathrm{m}^{2}$ & $48.7 \pm 5.6$ & $44.6 \pm 4.4$ & $\mathbf{0 . 0 1 6 4}$ & -9.3 \\
\hline $\begin{array}{c}\text { Lacunar } \\
\text { porosity }\end{array}$ & $\%$ & $0.975 \pm .22$ & $0.78 \pm 0.13$ & $\mathbf{0 . 0 0 6 7}$ & -24.4 \\
\hline $\begin{array}{c}\text { Lacunar } \\
\text { density }\end{array}$ & $\# / \mu \mathrm{m}^{2}$ & $0.0002 \pm$ & $0.000176 \pm$ & 0.0606 & \\
\hline
\end{tabular}

\section{Resorption and Refilling Cavities}

Remodeling cavity density was not different between pre- and post-hibernation samples (Figure 3.2) $(\mathrm{p}=0.3843)$. Similarly, when looking at resorption or refilling cavity density individually there were no differences between pre- and post-hibernation samples ( $p>0.37$ for both). Remodeling cavities were not present in all samples. However, at least one remodeling cavity was present in 25/34 pre-hibernation samples and $26 / 32$ post-hibernation samples. When data was paired by femur length to ensure age effects were not influencing the results, no difference $(p=0.9277)$ in remodeling cavity density was observed between groups. 


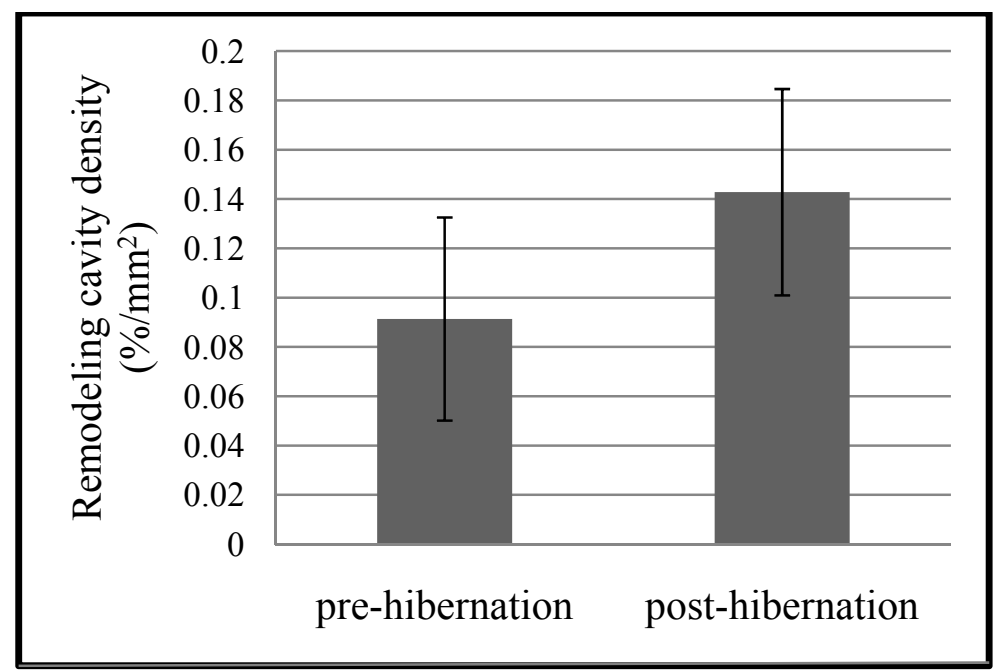

Figure 3.2: Remodeling cavity density was not different between groups $(p=0.843)$.

Because remodeling cavities were not present in all samples there was some concern over whether or not animals at the small end of the size range would demonstrate intracortical remodeling. Thus, samples were divided into 4 groups based on femur length and remodeling cavity density for each length quartile was examined to determine whether or not there was remodeling present in smaller samples (Table 3.4). These data show remodeling is occurring throughout the entire size range of samples in this study. 
Table 3.4

Samples were divided into 4 groups based on femur length and remodeling cavity density for each quartile was examined to determine whether or not there was remodeling present in smaller samples. Avg.RC.Dn stands for average remodeling cavity density.

\begin{tabular}{|c|c|c|c|c|c|}
\hline & & $\begin{array}{c}45.8-56.9 \\
\mathrm{~mm}\end{array}$ & $\begin{array}{c}57-68.5 \\
\mathrm{~mm}\end{array}$ & $\begin{array}{c}68.5-79.9 \\
\mathrm{~mm} \\
\end{array}$ & $\begin{array}{c}80-91.08 \\
\mathrm{~mm}\end{array}$ \\
\hline \multirow[t]{3}{*}{$\begin{array}{c}\text { Pre- } \\
\text { hibernation }\end{array}$} & $\begin{array}{c}\text { \# of samples } \\
\text { with remodeling } \\
\text { of total \# in size } \\
\text { range }\end{array}$ & 1 of 1 & 20 of 26 & 4 of 7 & 0 of 0 \\
\hline & $\begin{array}{l}\text { Avg. RC.Dn- } \\
\text { samples w/out } \\
\text { remodeling } \\
\text { neglected }\end{array}$ & 0.23 & 0.12 & 0.071 & N/A \\
\hline & $\begin{array}{l}\text { Avg. RC.Dn-all } \\
\text { samples in range }\end{array}$ & 0.23 & 0.096 & 0.047 & N/A \\
\hline \multirow[t]{3}{*}{$\begin{array}{c}\text { Post- } \\
\text { hibernation }\end{array}$} & $\begin{array}{c}\text { \# of samples } \\
\text { with remodeling } \\
\text { of total \# in size } \\
\text { range }\end{array}$ & 1 of 1 & 5 of 6 & 14 of 18 & 6 of 7 \\
\hline & $\begin{array}{l}\text { Avg. RC.Dn- } \\
\text { samples w/out } \\
\text { remodeling } \\
\text { neglected }\end{array}$ & 1.46 & 0.064 & 0.147 & 0.098 \\
\hline & $\begin{array}{l}\text { Avg. RC.Dn-all } \\
\text { samples in range }\end{array}$ & 1.46 & 0.053 & 0.121 & 0.084 \\
\hline \multirow[t]{3}{*}{$\begin{array}{l}\text { All samples } \\
\text { combined }\end{array}$} & $\begin{array}{c}\text { \# of samples } \\
\text { with remodeling } \\
\text { of total \# in size } \\
\text { range }\end{array}$ & 2 of 2 & 25 of 32 & 18 of 25 & 6 of 7 \\
\hline & $\begin{array}{l}\text { Avg. RC.Dn- } \\
\text { samples w/out } \\
\text { remodeling } \\
\text { neglected }\end{array}$ & 0.848 & 0.109 & 0.13 & 0.098 \\
\hline & $\begin{array}{l}\text { Avg. RC.Dn-all } \\
\text { samples in range }\end{array}$ & 0.848 & 0.088 & 0.10 & 0.084 \\
\hline
\end{tabular}




\section{Intracortical Porosity}

Intracortical porosity was not different (ANOVA $p=0.6336$, paired t-test $p=$ 0.9775 ) between pre- and post-hibernation samples. Evidence of periosteal bone formation was evident in 14 of the 34 pre-hibernation samples. The samples showing periosteal bone formation were spread throughout the size range of femurs and the collection period, there were no obvious connections to either size or collection period. During growth bone formation occurs on the periosteal surface, increasing the bone diameter. As this occurs blood vessel canals are occasionally open to the periosteal surface (Stover et al. 1992). Figure 3.3 shows the difference in what was observed in preversus post-hibernation samples in periosteal bone. This was only noticed in 3 of the 32 post-hibernation samples; however these 3 samples were collected the furthest into the active season (ie, early June). This may suggest growth is greatly reduced, if not suspended, during hibernation. This increased periosteal formation was not taken into account in quantification resorption and refilling cavities. They were not taken into account because though it was forming bone, they were not remodeling cavities.
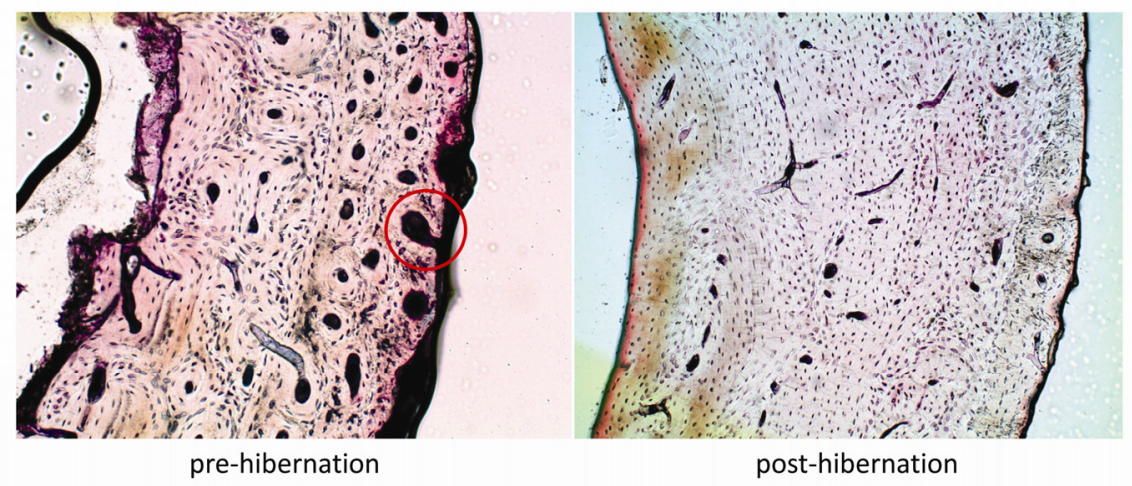

post-hibernation

Figure 3.3: Intracortical porosity was not different between pre- and post-hibernation samples. However, prehibernation samples appeared to have increased periosteal bone formation. The red circle highlights one of these forming primary osteons.

\subsection{Micro computed tomography $(\mu \mathrm{CT})$}

Micro-computed tomography of the proximal tibia showed trabecular bone volume fraction in the proximal tibia was not significantly different between groups, but approached significance $(p=0.0725)$. Bone volume fraction in the post-hibernation group tended to be higher. Trabecular number $(\mathrm{p}=0.3283)$ and trabecular separation $(\mathrm{p}=$ 0.2567 ) were not different between groups. However, trabecular thickness was $19.6 \%$ higher in post-hibernation samples $(\mathrm{p}=0.0058)$ (Figure 3.4). Material mineral density was $3.5 \%$ higher in the post-hibernation samples $(p=0.0263)$ (Figure 3.5$)$. Mean values of properties assessed by $\mu \mathrm{CT}$ as well as p-values for the one-way ANOVA can be found in Table 3.4. Based on this data it appears as though trabecular bone architectural properties are preserved. 
Table 3.5

Results of one-way ANOVA comparing pre-hibernation vs. post-hibernation samples for all properties measured by $\mu \mathrm{CT}$ with \% differences in post hibernation samples relative to pre-hibernation samples.

\begin{tabular}{|cccccc|}
\hline Property & Units & $\begin{array}{c}\text { Pre- } \\
\text { hibernation } \\
\text { (Fall) mean }\end{array}$ & $\begin{array}{c}\text { Post- } \\
\text { hibernation } \\
\text { (Spring) mean }\end{array}$ & p-value & $\begin{array}{c}\text { \% } \\
\text { difference }\end{array}$ \\
\hline BV & $\mathrm{mm}^{3}$ & $7.1 \pm 4.1$ & $10.51 \pm 5.7$ & 0.0949 & \\
\hline TV & $\mathrm{mm}^{3}$ & $82.3 \pm 15.1$ & $81.96 \pm 30.1$ & 0.9661 & \\
\hline BV/TV & $\%$ & $8.8 \pm 4.4$ & $13.7 \pm 8.5$ & 0.0725 & \\
\hline Tb.N. & $\mathrm{mm}^{-1}$ & $2.63 \pm 0.61$ & $2.34 \pm 0.78$ & 0.3283 & \\
\hline Tb.Th & $\mathrm{mm}^{3}$ & $0.074 \pm 0.013$ & $0.092 \pm 0.018$ & $\mathbf{0 . 0 0 5 8}$ & 19.6 \\
\hline Tb.Sp & $\mathrm{mm}$ & $0.401 \pm 0.108$ & $0.462 \pm 0.159$ & 0.2567 & \\
\hline App.M.Dn & $\mathrm{mgHA} / \mathrm{ccm}$ & $181 \pm 44$ & $202 \pm 78$ & 0.4003 & \\
\hline Mat.M.Dn & $\mathrm{mgHA} / \mathrm{ccm}$ & $812 \pm 31$ & $842 \pm 32$ & $\mathbf{0 . 0 2 6 3}$ & 3.5 \\
\hline
\end{tabular}

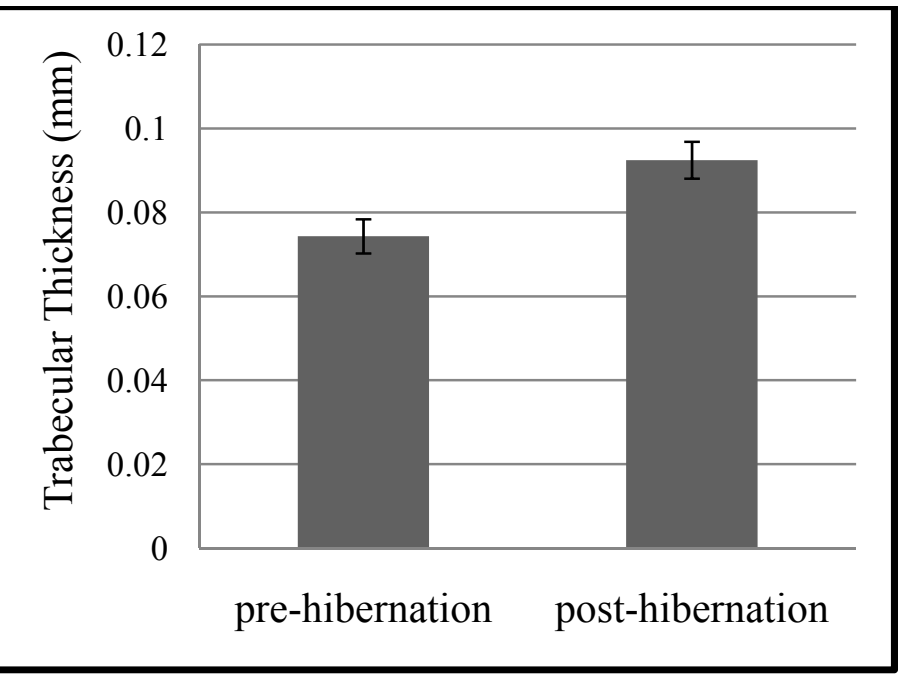

Figure 3.4: Trabecular thickness was $19.6 \%$ greater in post-hibernation samples $(p=0.0058)$. 


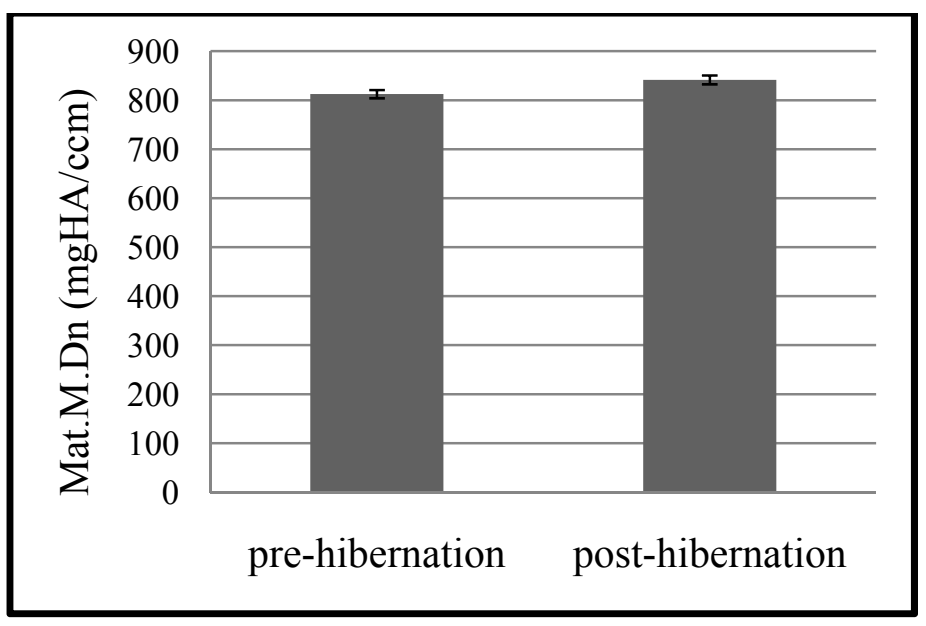

Figure 3.5: Material mineral density was 3.5\% higher in post-hibernation samples $(p=0.0263)$.

How trabecular bone properties scale with increasing body size is unclear. However, it has been shown that across species, trabecular thickness and trabecular separation may increase with increasing body size (Mullender et al. 1996). Because there is some indication of trabecular properties scaling with size, the $\mu C T$ data was normalized by (femur length) ${ }^{3}$ to examine possible effects of increasing body weight on bone properties (Table 3.5). When data was scaled, seasonal differences were only found in tissue volume and trabcular number. Tissue volume was higher $(\mathrm{p}=0.04)$ in posthibernation samples, consistent with the post-hibernation marmots being larger. Trabecular number was lower in post-hibernation samples $(\mathrm{p}=0.016)$. There was no significant difference in bone volume fraction between pre- and post-hibernation samples in either normalized $(p=0.5922)$ or un-normalized $(p=0.0725)$ data. This is of particular interest because bone volume fraction is positively correlated with bone strength (Ulrich et al. 1999; Hernandez et al. 2001). Therefore, the lack of difference in bone volume fraction between groups indicates maintained microstructural properties as well as maintenance of strength. 
Table 3.6

Trabecular bone properties normalized by (femur length) ${ }^{3}$ with $\%$ differences in post hibernation samples relative to pre-hibernation samples.

\begin{tabular}{|cccccc|}
\hline Property & Units & $\begin{array}{c}\text { Pre- } \\
\text { hibernation } \\
\text { (Fall) mean }\end{array}$ & $\begin{array}{c}\text { Post- } \\
\text { hibernation } \\
\text { (Spring) mean }\end{array}$ & p-value & $\begin{array}{c}\text { \% } \\
\text { difference }\end{array}$ \\
\hline BV & $\mathrm{mm}^{3} / \mathrm{mm}^{3}$ & $\begin{array}{c}0.000027 \pm \\
0.000012\end{array}$ & $\begin{array}{c}0.000028 \pm \\
0.000014\end{array}$ & 0.8744 & \\
\hline TV & $\mathrm{mm}^{3} / \mathrm{mm}^{3}$ & $\begin{array}{c}0.000339 \pm \\
0.000091\end{array}$ & $\begin{array}{c}0.000249 \pm \\
0.000122\end{array}$ & $\mathbf{0 . 0 4 0 5}$ & -36.1 \\
\hline BV/TV & $\% / \mathrm{mm}^{3}$ & $\begin{array}{c}3.35 \mathrm{e}-7 \pm \\
1.23 \mathrm{e}-7\end{array}$ & $\begin{array}{c}3.75 \mathrm{e}-7 \pm \\
2.4049 \mathrm{e}-7\end{array}$ & 0.5922 & \\
\hline Tb.N. & $1 / \mathrm{mm}^{3}$ & $\begin{array}{c}0.000011 \pm \\
0.0000031\end{array}$ & $\begin{array}{c}7.34 \mathrm{e}-6 \pm \\
3.81 \mathrm{e}-6\end{array}$ & $\mathbf{0 . 0 1 6 4}$ & -49.9 \\
\hline Tb.Th & $\mathrm{mm} / \mathrm{mm}^{3}$ & $\begin{array}{c}2.97 \mathrm{e}-7 \pm \\
3.56 \mathrm{e}-8\end{array}$ & $\begin{array}{c}2.77 \mathrm{e}-7 \pm \\
9.49 \mathrm{e}-8\end{array}$ & 0.4752 & \\
\hline \multirow{2}{*}{ Tb.Sp } & $\mathrm{mm} / \mathrm{mm}^{3}$ & $\begin{array}{c}1.65 \mathrm{e}-6 \pm \\
5.72 \mathrm{e}-7\end{array}$ & $\begin{array}{c}1.59 \mathrm{e}-6 \pm \\
1.51 \mathrm{e}-6\end{array}$ & 0.8951 & \\
\hline \multirow{2}{*}{ App.M.Dn } & $\mathrm{mgHA} / \mathrm{ccm}^{3}$ & $\begin{array}{c}7.32 \mathrm{e}-4 \pm \\
1.80 \mathrm{e}-4\end{array}$ & $\begin{array}{c}5.93 \mathrm{e}-4 \pm \\
0.000243\end{array}$ & 0.1093 & \\
\hline \multirow{2}{*}{ Mat.M.Dn } & $\mathrm{mgHA} / \mathrm{ccm}^{3}$ & $\begin{array}{c}3.34 \mathrm{e}-3 \pm \\
0.000717\end{array}$ & $\begin{array}{c}2.71 \mathrm{e}-3 \pm \\
0.001673\end{array}$ & 0.2171 & \\
\hline
\end{tabular}

\subsection{Geometrical properties}

Data are presented two ways; Table 3.6 shows the results of comparing geometrical properties without accounting for the post-hibernation animals being larger in size, whereas the data in Table 3.7 are normalized by functions of femur length as it is well known cross-sectional properties scale with femoral length (Ruff 1984; Heinrich and Biknevicius 1998). Un-normalized data shows no difference in endosteal area and $I_{p}$ between pre- and post-hibernation groups. However, endosteal area fraction is lower ( $\mathrm{p}<$ $0.0001)$ and cortical thickness, cortical area, periosteal area, $\mathrm{I}_{\max }, \mathrm{I}_{\mathrm{AP}}$, and $\mathrm{I}_{\mathrm{ML}}$ are higher $(\mathrm{p}<0.0002)$ in post-hibernation samples. After data was normalized (Figure 3.6), only cortical area and endosteal area were different between pre- and post-hibernation samples. 
Table 3.7

Geometrical properties compared between pre- and post-hibernation groups with \% differences in post hibernation samples relative to pre-hibernation samples.

\begin{tabular}{|cccccc|}
\hline Property & Units & $\begin{array}{c}\text { Pre- } \\
\text { hibernation } \\
\text { (Fall) mean }\end{array}$ & $\begin{array}{c}\text { Post- } \\
\text { hibernation } \\
\text { (Spring) mean }\end{array}$ & p-value & $\begin{array}{c}\text { \% } \\
\text { difference }\end{array}$ \\
\hline $\begin{array}{c}\text { Cortical } \\
\text { Thickness }\end{array}$ & $\mu \mathrm{m}$ & $803.62 \pm 162.9$ & $1120.1 \pm 291.3$ & $<\mathbf{0 . 0 0 0 1}$ & 28.3 \\
\hline $\begin{array}{c}\text { Cortical Area } \\
\mathrm{mm}^{2}\end{array}$ & $12.68 \pm 3.01$ & $19.2 \pm 6.16$ & $<\mathbf{0 . 0 0 0 1}$ & 33.9 \\
\hline Endosteal Area & $\mathrm{mm}^{2}$ & $13.16 \pm 2.58$ & $13.22 \pm 3.5$ & 0.934 & \\
\hline $\begin{array}{c}\text { Periosteal Area } \\
\text { Endosteal }\end{array} \mathrm{mm}^{2}$ & $25.84 \pm 4.37$ & $32.42 \pm 8.17$ & $\mathbf{0 . 0 0 0 2}$ & 20.3 \\
\hline $\begin{array}{c}\text { Area/Periosteal } \\
\text { Area }\end{array}$ & -- & $0.51 \pm 0.06$ & $0.42 \pm 0.09$ & $<\mathbf{0 . 0 0 0 1}$ & -22.8 \\
\hline $\mathbf{I}_{\text {max }}$ & $\mathrm{mm}^{4}$ & $46.14 \pm 16.97$ & $87.22 \pm 46.24$ & $<\mathbf{0 . 0 0 0 1}$ & 47.1 \\
\hline $\mathbf{I}_{\text {AP }}$ & $\mathrm{mm}^{4}$ & $45.93 \pm 16.87$ & $86.7 \pm 46.28$ & $<\mathbf{0 . 0 0 0 1}$ & 47 \\
\hline $\mathbf{I}_{\mathbf{M L}}$ & $\mathrm{mm}^{4}$ & $34.87 \pm 12.47$ & $62.50 \pm 32.34$ & $<\mathbf{0 . 0 0 0 1}$ & 44.2 \\
\hline $\mathbf{I}_{\mathbf{p}}$ & $\mathrm{mm}^{4}$ & $0.58 \pm 1.59$ & $1.66 \pm 3.14$ & 0.0887 & \\
\hline $\mathbf{J}$ & $\mathrm{mm}^{4}$ & $80.8 \pm 29.15$ & $149.2 \pm 77.27$ & $<\mathbf{0 . 0 0 0 1}$ & 45.8 \\
\hline & & & & & \\
\hline
\end{tabular}


Table 3.8

Normalized geometrical properties with \% differences in post hibernation samples relative to pre-hibernation samples. Cross-sectional areas were normalized by (femur length) ${ }^{2}$ and moments of inertia were normalized by (femur length) ${ }^{4}$ according to known scaling relationships (Ruff 1984; Casinos et al. 1993; Heinrich and Biknevicius 1998). Endosteal area fraction area was not normalized for this table since it is a ratio.

\begin{tabular}{|c|c|c|c|c|c|}
\hline Property & Units & $\begin{array}{l}\text { Pre-hibernation } \\
\text { (Fall) mean }\end{array}$ & $\begin{array}{l}\text { Post-hibernation } \\
\text { (Spring) mean }\end{array}$ & p-value & $\begin{array}{c}\% \\
\text { difference }\end{array}$ \\
\hline $\begin{array}{l}\text { Cortical } \\
\text { Area }\end{array}$ & $\begin{array}{l}\mathrm{mm}^{2} / \\
\mathrm{mm}^{2}\end{array}$ & $\begin{array}{c}0.00299 \pm \\
0.00042\end{array}$ & $\begin{array}{l}0.00341 \pm \\
0.000546\end{array}$ & 0.0011 & 12.3 \\
\hline $\begin{array}{c}\text { Endosteal } \\
\text { Area }\end{array}$ & $\begin{array}{l}\mathrm{mm}^{2} / \\
\mathrm{mm}^{2}\end{array}$ & $\begin{array}{c}0.003194 \pm \\
0.0008\end{array}$ & $\begin{array}{c}0.002462 \pm \\
0.0007\end{array}$ & 0.0003 & -29.7 \\
\hline $\begin{array}{l}\text { Periosteal } \\
\text { Area }\end{array}$ & $\begin{array}{l}\mathrm{mm}^{2} / \\
\mathrm{mm}^{2}\end{array}$ & $0.0062 \pm 0.001$ & $0.0059 \pm 0.0006$ & 0.1374 & \\
\hline$I_{\max }$ & $\begin{array}{c}\mathrm{mm}^{4} / \mathrm{m} \\
\mathrm{m}^{4}\end{array}$ & $\begin{array}{c}2.57 \text { E-6 } \pm 7.21 \\
\text { E-7 }\end{array}$ & $\begin{array}{c}2.62 \text { E-6 } \pm 5.25 \\
\text { E-7 }\end{array}$ & 0.6330 & \\
\hline $\mathbf{I}_{\mathrm{AP}}$ & $\begin{array}{l}\mathrm{mm}^{4} / \\
\mathrm{mm}^{4}\end{array}$ & $\begin{array}{c}2.56 \mathrm{E}-6 \pm 7.15 \\
\mathrm{E}-7\end{array}$ & $\begin{array}{c}2.62 \mathrm{E}-6 \pm 3.34 \\
\mathrm{E}-7\end{array}$ & 0.6941 & \\
\hline $\mathbf{I}_{\mathbf{M L}}$ & $\begin{array}{l}\mathrm{mm}^{4} / \\
\mathrm{mm}^{4}\end{array}$ & $\begin{array}{c}1.95 \mathrm{E}-6 \pm 5.5 \mathrm{E}- \\
7\end{array}$ & $\begin{array}{c}1.92 \mathrm{E}-6 \pm 3.97 \mathrm{E}- \\
7\end{array}$ & 0.8090 & \\
\hline $\mathbf{I}_{\mathbf{p}}$ & $\begin{array}{l}\mathrm{mm}^{4} / \\
\mathrm{mm}^{4}\end{array}$ & $\begin{array}{c}3.93 \text { E- } 8 \pm 8.39 \\
\text { E- } 8\end{array}$ & $\begin{array}{c}5.35 \mathrm{E}-8 \pm 9.47 \\
\mathrm{E}-8\end{array}$ & 0.5385 & \\
\hline $\mathbf{J}$ & $\begin{array}{l}\mathrm{mm}^{4} / \\
\mathrm{mm}^{4}\end{array}$ & $4.51 \mathrm{E}-6 \pm 1.3 \mathrm{E}-6$ & $4.54 \mathrm{E}-6 \pm 8.9 \mathrm{E}-7$ & 0.9032 & \\
\hline
\end{tabular}




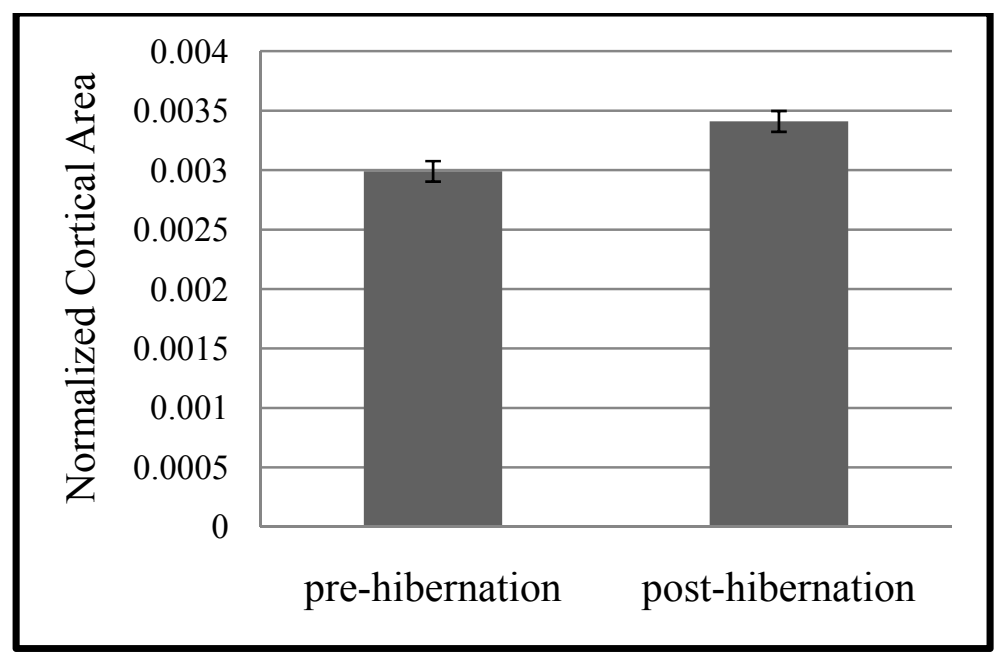

Figure 3.6: After normalization cortical area was higher in post-hibernation samples.

To verify that values taken from literature for normalization were a good assumption for this data, femur length (L) was regressed against areas and moments on a log-log plot to determine how the factors scale. For all of the marmot femurs (pre- and post-hibernation samples combined) :

- Body weight is proportional to $\mathrm{L}^{2.9}$

- Cross-sectional area is proportional to $\mathrm{L}^{2.8}$

- Medio-lateral moment of inertia is proportional to $\mathrm{L}^{3.9}$

- Antero-posterior moment of inertia is proportional to $\mathrm{L}^{4.3}$

- Max moment of inertia is proportional to $\mathrm{L}^{4.3}$

These values are similar to values found in literature. Body weight was proportional to $\mathrm{L}^{2.9}$ in digging rodents (Casinos et al. 1993). Scaling of cross-sectional properties in mustelids showed cross-sectional area proportional to $\mathrm{L}^{2}$ and moments of inertia proportional to $\mathrm{L}^{4}$ (Ruff 1984; Heinrich and Biknevicius 1998).

\subsection{Whole bone bending}

Some samples had to be excluded from the mechanical properties calculations, due to missing cross-sectional data or lack of an obvious fracture point on the stressstrain curve. Sample sizes were pre-hibernation $n=21$ and post-hibernation $n=27$ for fracture load and failure energy. Modulus of toughness sample size for pre-hibernation was $\mathrm{n}=19$ and post-hibernation $\mathrm{n}=27$. Ultimate stress sample sizes were prehibernation $n=29$ and post-hibernation $n=30$. Failure load, failure energy, elastic energy, energy to ultimate, ultimate stress, yield stress and stiffness were all higher $(\mathrm{p}<$ 0.004 ) in post-hibernation samples (Table 3.8). Modulus of toughness was lower ( $\mathrm{p}=$ $0.0431)$ in post-hibernation samples. There was no difference $(p>0.319)$ in resilience or elastic modulus or failure displacement between pre- and post-hibernation samples. 
Table 3.9

Mechanical properties calculated from three-point bending test with \% differences in post hibernation samples relative to pre-hibernation samples.

\begin{tabular}{|cccccc|}
\hline Property & Units & $\begin{array}{c}\text { Pre- } \\
\text { hibernation } \\
\text { (Fall) mean }\end{array}$ & $\begin{array}{c}\text { Post- } \\
\text { hibernation } \\
\text { (Spring) mean }\end{array}$ & p-value & $\begin{array}{c}\text { \% } \\
\text { difference }\end{array}$ \\
\hline Failure Load & $\mathrm{N}$ & $214 \pm 91$ & $403 \pm 150$ & $<\mathbf{0 . 0 0 0 1}$ & 46.9 \\
\hline $\begin{array}{c}\text { Failure } \\
\text { Displacement }\end{array}$ & $\mathrm{mm}$ & $2.27 \pm 0.81$ & $2.07 \pm 0.58$ & 0.319 & \\
\hline $\begin{array}{c}\text { Failure } \\
\text { Energy }\end{array}$ & $\mathrm{mJ}$ & $458 \pm 239$ & $673 \pm 255$ & $\mathbf{0 . 0 0 4 6}$ & 31.9 \\
\hline $\begin{array}{c}\text { Energy to } \\
\text { Ultimate }\end{array}$ & $\mathrm{mJ}$ & $281 \pm 119$ & $452 \pm 198$ & $\mathbf{0 . 0 0 0 3}$ & 37.8 \\
\hline $\begin{array}{c}\text { Elastic } \\
\text { Energy }\end{array}$ & $\mathrm{mJ}$ & $62 \pm 41$ & $105 \pm 46$ & $\mathbf{0 . 0 0 0 7}$ & 40.6 \\
\hline $\begin{array}{c}\text { Modulus of } \\
\text { Toughness }\end{array}$ & $\mathrm{mJ} / \mathrm{mm}^{3}$ & $9.92 \pm 3.52$ & $8.12 \pm 2.35$ & $\mathbf{0 . 0 4 3 1}$ & -22.2 \\
\hline $\begin{array}{c}\text { Resilience } \\
\text { Modustic }\end{array}$ & $\mathrm{mJ} / \mathrm{mm}^{3}$ & $1.3 \pm 0.68$ & $1.4 \pm 0.37$ & 0.5272 & \\
\hline $\begin{array}{c}\text { Stress } \\
\text { Yield Stress }\end{array}$ & $\mathrm{MPa}$ & $108.57 \pm 45.2$ & $143.36 \pm 28$ & $\mathbf{0 . 0 0 1 5}$ & 24.3 \\
\hline $\begin{array}{c}\text { Stiffness } \\
\text { MPa }\end{array}$ & $\mathrm{N} / \mathrm{mm}$ & $344.32 \pm 94.08$ & $486.43 \pm 127.06$ & $<\mathbf{0 . 0 0 0 1}$ & 29.2 \\
\hline
\end{tabular}


Table 3.10

Mechanical properties calculated from three-point bend tests for select samples. Twelve samples from each group were paired by femur length and compared using paired t-test to better assess the effects of hibernation on these properties by eliminating effects due to post-hibernation samples being larger than pre-hibernation samples. Data is presented with \% differences in post hibernation samples relative to pre-hibernation samples.

\begin{tabular}{|c|c|c|c|c|}
\hline Property & Units & $\begin{array}{c}\text { Pre- } \\
\text { hibernation } \\
\text { (Fall) mean }\end{array}$ & $\begin{array}{c}\text { Post- } \\
\text { hibernation } \\
\text { (Spring) mean }\end{array}$ & p-value $\begin{array}{c}\% \\
\text { difference }\end{array}$ \\
\hline Failure Load & $\mathrm{N}$ & $263.6 \pm 106$ & $313.7 \pm 106$ & 0.2824 \\
\hline $\begin{array}{c}\text { Failure } \\
\text { Displacement }\end{array}$ & $\mathrm{mm}$ & $2.36 \pm 1.06$ & $2.37 \pm 0.95$ & 0.987 \\
\hline $\begin{array}{l}\text { Failure } \\
\text { Energy }\end{array}$ & $\mathrm{mJ}$ & $612.7 \pm 256.6$ & $611.9 \pm 230.9$ & 0.9946 \\
\hline $\begin{array}{l}\text { Energy to } \\
\text { Ultimate }\end{array}$ & $\mathrm{mJ}$ & $336.6 \pm 83.8$ & $350.5 \pm 116.3$ & 0.7117 \\
\hline $\begin{array}{l}\text { Elastic } \\
\text { Energy }\end{array}$ & $\mathrm{mJ}$ & $78 \pm 41$ & $81 \pm 39$ & 0.7846 \\
\hline $\begin{array}{l}\text { Modulus of } \\
\text { Toughness }\end{array}$ & $\mathrm{mJ} / \mathrm{mm}^{3}$ & $10.07 \pm 3.67$ & $8.2 \pm 2.25$ & 0.2876 \\
\hline Resilience & $\mathrm{mJ} / \mathrm{mm}^{3}$ & $1.49 \pm 0.69$ & $1.37 \pm 0.41$ & 0.5912 \\
\hline $\begin{array}{l}\text { Ultimate } \\
\text { Stress }\end{array}$ & $\mathrm{MPa}$ & $176.15 \pm 49.6$ & $187.75 \pm 39.5$ & 0.5033 \\
\hline Yield Stress & $\mathrm{MPa}$ & $123.37 \pm 46.3$ & $134.39 \pm 33.18$ & 0.5048 \\
\hline Stiffness & $\mathrm{N} / \mathrm{mm}$ & $402.3 \pm 102.4$ & $418.5 \pm 116$ & 0.5294 \\
\hline $\begin{array}{l}\text { Elastic } \\
\text { Modulus }\end{array}$ & $\mathrm{GPa}$ & $6.35 \pm 1.72$ & $6.63 \pm 1.88$ & 0.7001 \\
\hline
\end{tabular}




\subsection{Ash Fraction}

Ash fraction was 3.3\% higher in post-hibernation samples $(\mathrm{p}=0.0003)$ (Figure 3.7). However, when data was paired by femur length there was no difference ( $p=$ 0.3874 ) in ash fraction between pre- and post-hibernation samples.

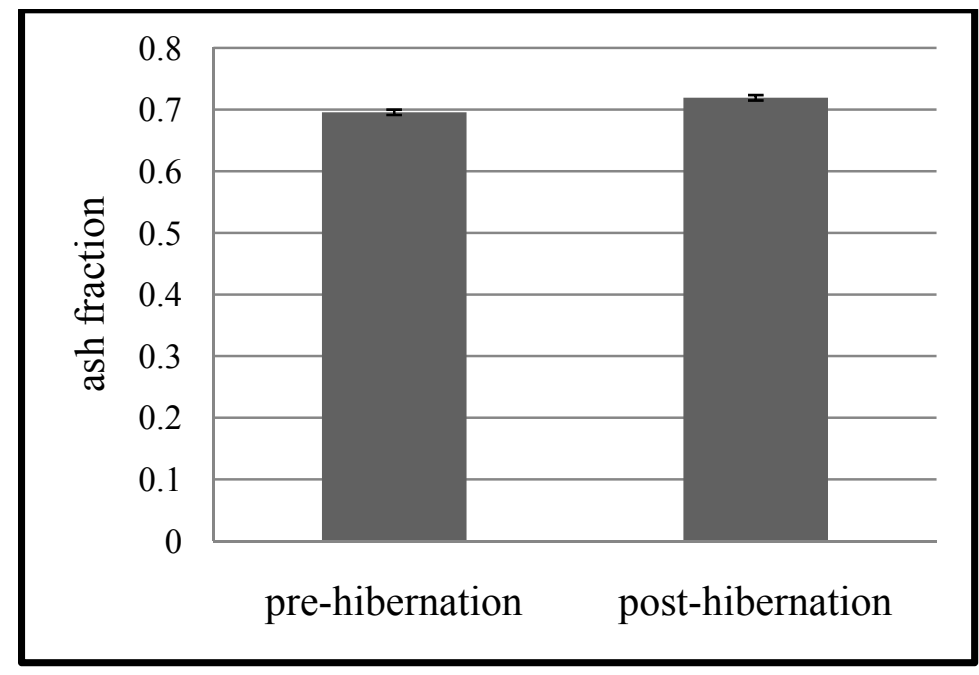

Figure 3.7: Ash fraction was higher in post-hibernation samples.

\subsection{References}

Casinos A, Quintana C, Viladiu C. 1993. Allometry and Adaptation in the Long Bones of a Digging Group of Rodents (Ctenomyinae). Zoological Journal of the Linnean Society 107(2):107-115.

Heinrich RE, Biknevicius AR. 1998. Skeletal allometry and interlimb scaling patterns in mustelid carnivorans. Journal of Morphology 235(2):121-34.

Hernandez CJ, Beaupre GS, Keller TS, Carter DR. 2001. The influence of bone volume fraction and ash fraction on bone strength and modulus. Bone 29(1):74-78.

Mullender MG, Huiskes R, Versleyen H, Buma P. 1996. Osteocyte density and histomorphometric parameters in cancellous bone of the proximal femur in five mammalian species. J Orthop Res 14(6):972-9.

Ortmann S, Heldmaier G. 2000. Regulation of body temperature and energy requirements of hibernating Alpine marmots (Marmota marmota). American Journal of Physiology-Regulatory Integrative and Comparative Physiology 278(3):R698R704. 
Ruff CB. 1984. Allometry between length and cross-sectional dimensions of the femur and tibia in Homo sapiens sapiens. American Journal of Physical Anthropology 65(4):347-58.

Stover SM, Pool RR, Martin RB, Morgan JP. 1992. Histological Features of the Dorsal Cortex of the 3rd Metacarpal Bone Mid-Diaphysis during Postnatal-Growth in Thoroughbred Horses. Journal of Anatomy 181:455-469.

Ulrich D, Van Rietbergen B, Laib A, Ruegsegger P. 1999. The ability of threedimensional structural indices to reflect mechanical aspects of trabecular bone. Bone 25(1):55-60.

Zervanos SM, Maher CR, Waldvogel JA, Florant GL. 2010. Latitudinal Differences in the Hibernation Characteristics of Woodchucks (Marmota monax). Physiological and Biochemical Zoology 83(1):135-141. 


\section{Chapter 4 \\ Discussion}

Hibernating mammals have a unique ability to reduce their energy expenditure in order to adapt to stressful conditions, like the cold temperatures and food scarcity of winter (Heldmaier et al. 2004). Animals that hibernate for the winter are inactive for up to 6-7 months of the year (Thomas et al. 1990; Salsbury and Armitage 1994; Armitage et al. 2003). If humans and many mammals were to remain inactive or significantly decrease skeletal loading for a similar period of time the musculoskeletal system would be impaired (Kaneps et al. 1997; Takata and Yasui 2001). Bears have been shown to preserve bone integrity during the inactive period of hibernation (McGee-Lawrence et al. 2009a; McGee-Lawrence et al. 2009b). Understanding the mechanism by which bears preserve bone could lead to translating the mechanism for treatment of disuse osteoporosis in humans. However, fully understanding the mechanisms which allow bears to survive hibernation and emerge skeletally intact could be difficult as they are not a practical laboratory model for many labs. Though some facilities may be equipped to house and care for bears, investigation of a smaller hibernator may be more ideal. In order to utilize small hibernators, the effect of hibernation on their skeletal system must first be understood. Small hibernators follow a different hibernation pattern than bears in that they arouse periodically and may urinate or defecate during the arousal period. Urination/defecation during hibernation could provide a method for the body to remove calcium from the system, allowing more calcium to be pulled from the skeletal system for systemic use. Early studies have indicated small hibernators like bats may lose bone during hibernation (Whalen et al. 1972; Krook et al. 1977; Kwiecinski et al. 1987). Similarly, both early and recent studies in squirrels have shown evidence of osteocytic osteolysis during hibernation (Haller and Zimny 1977; McGee-Lawrence et al. 2011). However, preservation of whole bone mechanical properties has also been demonstrated in both the golden-mantled ground squirrel and the 13-lined ground squirrel (Utz et al. 2009; McGee-Lawrence et al. 2011). Likewise, no differences were observed in ash fraction of bones from hibernating vs. active squirrels (McGee-Lawrence et al. 2011). Though there is potential for use of squirrels as a laboratory model for disuse osteoporosis, a drawback to using them as an animal model is that they are too small to utilize intracortical remodeling. Marmots, on the other hand, are large enough to have Haversian remodeling and have been used in many laboratories for hibernation physiology research (Zatzman and South 1972; Florant and Heller 1977; Ortmann and Heldmaier 2000).

The present study indicates preservation of bone during hibernation in yellowbellied marmots. Most importantly, mechanical and cross-sectional properties are not diminished in samples collected after hibernation. A decrease in modulus of toughness in post-hibernation samples was observed in the entire data set, but not in the paired t-test. It is likely that, since larger animals in the post-hibernation group indicate an older group, the decrease observed in toughness as well as the increase in energy and ultimate stress 
could be due to age-related increases in size and mineral content as opposed to being an effect of hibernation. For example, ultimate stress and ash fraction were found to increase with age in black bears (McGee-Lawrence et al. 2009a). Because age data was not available for this study, correlations between mechanical properties and age could not be made. It is important to note that samples paired by femur length showed no difference between pre- and post-hibernation samples for any mechanical property calculated. Similarly, there was no difference in ash fraction between groups when paired by femur length. Physiological loading of the femur does not simply result in bending about the medial-lateral axis but rather a combination of bending about the medial-lateral and anterior-posterior axes as well as torsional loading. When cross-sectional property data was normalized by femur length to account for size differences between groups no change in moments of inertia, anterior-posterior $(p=0.6941)$ or medial-lateral $(p=$ 0.8090) were observed between groups. This further supports the idea that resistance to bending is not diminished in the post-hibernation group. Similarly, in normalized data polar moment of inertia is not diminished $(\mathrm{p}=0.9032)$ in post-hibernation samples indicating the ability to withstand torsional loads is not diminished. It is also important to note that yield stress was higher in post-hibernation samples $(p=0.0015)$ and resilience was not different (0.5272) between groups. This indicates there is no increase in fracture risk for normal physiological loading in post-hibernation samples.

Micro-structural changes, or lack thereof, also indicate preservation of bone during the hibernation period. The pre-hibernation group provides a baseline for what properties would be present in an active marmot right before entering hibernation. The post-hibernation group was captured within a few weeks of emergence from hibernation. Though some remobilization had occurred, based on the time required for recovery of bone lost during disuse, this would not have been sufficient time to regain lost bone if marmots were following trends similar to other (non-hibernation) mammals. There were no differences, in the full data set or paired data, between remodeling cavity density or intracortical porosity between groups. If microstructural bone loss were occurring, it is likely an increased porosity would be observed after the hibernation period as seen in other disuse models (Gross and Rubin 1995; Li et al. 2005). The lack of change in Haversian porosity in marmots is similar to findings in black bears. Porosity was not different between pre- and post-hibernation black bears and was 30\% lower in hibernating compared to active grizzly bears (McGee et al. 2008b; McGee-Lawrence et al. 2009a).

Lacunar properties were lower $(\mathrm{p}<0.0001)$ in post-hibernation samples. Area was $17 \%$ lower, density $9 \%$ lower, and porosity $8.5 \%$ lower. Similarly when data was paired based on femur length average lacunar area $(\mathrm{p}=0.0164)$ and lacunar porosity $(\mathrm{p}=$ $0.0067)$ were lower in post-hibernation samples. It is noteworthy that the results of the paired data are comparable to the results from the entire data set because lacunar density has been shown to decrease with age in humans (Busse et al. 2010). The decreasing trend in properties after hibernation is similar to findings in bears. Lacunar porosity was $26 \%$ lower in hibernating bears compared to active and lacunar size was $15 \%$ lower in hibernating bears than active bears (density was not reported) (McGee-Lawrence et al. 2008). Average lacunar area did not change in active vs. hibernating 13-lined ground 
squirrels. However, lacunar porosity was $44 \%$ higher and density was $59 \%$ higher in hibernating squirrels (McGee-Lawrence et al. 2011). The differences between what is observed microscopically to lacunar properties in 13-lined ground squirrels compared to bears and marmots may be a result of how bone is remodeled. Marmots and bears can utilize Haversian remodeling as well as utilizing trabecular bone and the lacunarcanalicular system to maintain mineral homeostasis during hibernation. Whereas squirrels can utilize trabecular bone remodeling and osteocytic osteolysis, but cannot pull mineral from intracortical remodeling. Thus, is it possible that to adequately maintain mineral homeostasis, more mineral needs to be removed via osteocytic osteolysis in squirrels than in marmots or bears; resulting in a measureable increase with hibernation in squirrels. The opposite appears to be occurring in marmots and bears. Osteocyte lacunar area and porosity decrease after hibernation indicating osteocytes may actually be filling in the lacunae. Osteocytic bone formation has been demonstrated by perilacunar tetracycline labeling as well as a decrease in lacunar area (Baylink and Wergedal 1971; Zallone et al. 1983). It is possible that circulating calcium that is re-deposited in the skeletal system is deposited in the lacunar-canalicular system due to hormonal changes associated with hibernation that result in signaling osteocytes to form bone.

The post-hibernation group containing larger animals may also affect the comparison of the $\mu \mathrm{CT}$ data. It is unclear as to whether or not trabecular bone properties scale with body weight or bone length within the size ranges of a given species. Trabecular thickness, number, and separation have been shown to vary with species size (Mullender et al. 1996). Without normalization, $\mu \mathrm{CT}$ data only shows differences in Tb.Th, and Mat.M.Dn. Trabecular thickness increases, and Mat.M.Dn increases in posthibernation samples; neither of these changes indicate bone loss, in fact the increase in Tb.Th and Mat.M.Dn would suggest bone gain in the post-hibernation samples. Changes in bone volume fraction approach significance $(p=0.0725)$. However, it approaches significance of being higher post-hibernation, which would support prevention of bone loss. Trabecular bone properties have also been shown to be preserved in hibernating 13lined ground squirrels and bears (McGee-Lawrence et al. 2009b; McGee-Lawrence et al. 2010).

Overall, the results of this study indicate preservation of bone mechanical and microstructural properties in marmots during hibernation. This could be further clarified with future studies where age data were available for samples. It would be very useful to further characterize circannual skeletal and hormonal changes in marmots. For example, sampling at multiple time-points throughout hibernation and the active seasons would allow characterization of hormone fluctuations as well as what is happening with cellular activity and remodeling in bone throughout the year. Ideally, a study comparing changes in the active versus hibernation season would involve active animals collected from their natural environment for measurements as opposed to being caged. Using marmots in a natural setting would of course add a degree of difficulty; however, marmots could be tagged and tracked for measurements at different time points. If all captive animals are to be used, it is important to determine whether or not the decreased activity resulting from caging affects bone properties during the active season. Laboratory studies could potentially lead to understanding bone preservation mechanisms much more easily than 
field studies. Though it is ideal to study the animals in their natural environment it can make studies looking at blood serum or metabolic changes challenging. The marmot appears to be a promising model for disuse osteoporosis studies. Because marmots are so adorable, furry, and small they would make an exceptional laboratory model. They would provide a better model than squirrels would because not only are they cuter, they show Haversian remodeling which can be important in osteoporosis studies.

Though marmots would make a useful animal model for osteoporosis studies, studying various hibernators may be more useful in uncovering the mechanism that allows bone preservation. For example, studies like this one allow comparisons with other species to be drawn between the effects of hibernation on the skeletal system. Different species of hibernators may utilize the same or similar physiological mechanism to preserve bone during hibernation. More in depth studies looking at bone cells and endocrine changes and comparisons across species may allow further understanding of this mechanism. For example investigating seasonal fluctuations in hormones that are known to play a part in regulation of bone mass or mineral content, like parathyroid hormone or leptin, in various hibernating species and comparing results may be insightful. Leptin is a hormone that acts through the sympathetic nervous system to inhibit insulin secretion and is hypothesized to act through the osteoblast by modulating osteocalcin activity (Karsenty et al. 2008). And though leptin has a regulatory role in both bone mass and energy metabolism, these functions of leptin can occur independently of one another (Shi et al. 2008). Because studies have shown that bone has a regulatory role in glucose metabolism and fat mass (through uncarboxylated osteocalcin) (Lieben et al. 2009), the metabolic changes that occur in hibernators may be responsible for their ability to maintain bone. Serum leptin levels show little variation between hibernating and active bears (Donahue et al. 2006), however serum leptin concentrations significantly decreased from September through February in marmots (Florant et al. 2004). In marmots, serum leptin is positively correlated with increases in fat mass and fat cell size. So as expected, it increases during the active period when animals are gaining weight. However, leptin also decreases before a decrease in fat mass occurs indicating leptin levels may not be coupled to white adipose tissue leptin gene expression during hibernation (Florant et al. 2004). It is possible these changes that appear to be metabolic in nature also act to preserve the musuloskeletal system. Further understanding of skeletal and endocrine changes in hibernation could translate to an improved treatment for disuse osteoporosis in humans. 


\section{References}

Armitage KB, Blumstein DT, Woods BC. 2003. Energetics of hibernating yellow-bellied marmots (Marmota flaviventris). Comparative Biochemistry and Physiology Part A: Molecular and Integrative Physiology 134(1):101-14.

Baylink DJ, Wergedal JE. 1971. Bone formation by osteocytes. American Journal of Physiology 221(3):669-78.

Busse B, Djonic D, Milovanovic P, Hahn M, Puschel K, Ritchie RO, Djuric M, Amling M. 2010. Decrease in the osteocyte lacunar density accompanied by hypermineralized lacunar occlusion reveals failure and delay of remodeling in aged human bone. Aging Cell 9(6):1065-1075.

Donahue SW, Galley SA, Vaughan MR, Patterson-Buckendahl P, Demers LM, Vance JL, McGee ME. 2006. Parathyroid hormone may maintain bone formation in hibernating black bears (Ursus americanus) to prevent disuse osteoporosis. Journal of Experimental Biology 209(Pt 9):1630-8.

Florant GL, Heller HC. 1977. Cns Regulation of Body-Temperature in Euthermic and Hibernating Marmots (Marmota-Flaviventris). American Journal of Physiology 232(5):R203-R208.

Florant GL, Porst H, Peiffer A, Hudachek SF, Pittman C, Summers SA, Rajala MW, Scherer PE. 2004. Fat-cell mass, serum leptin and adiponectin changes during weight gain and loss in yellow-bellied marmots (Marmota flaviventris). Journal of Comparative Physiology B-Biochemical Systemic and Environmental Physiology 174(8):633-639.

Gross TS, Rubin CT. 1995. Uniformity of resorptive bone loss induced by disuse. Journal of Orthopaedic Research 13(5):708-14.

Haller AC, Zimny ML. 1977. Effects of hibernation on interradicular alveolar bone. Journal of Dental Research 56(12):1552-7.

Heldmaier G, Ortmann S, Elvert R. 2004. Natural hypometabolism during hibernation and daily torpor in mammals. Respiratory Physiology and Neurobiology 141(3):317-29.

Kaneps AJ, Stover SM, Lane NE. 1997. Changes in canine cortical and cancellous bone mechanical properties following immobilization and remobilization with exercise. Bone 21(5):419-23.

Karsenty G, Hinoi E, Gao N, Jung DY, Yadav V, Yoshizawa T, Myers MG, Chua SC, Kim JK, Kaestner KH. 2008. The sympathetic tone mediates leptin's inhibition of 
insulin secretion by modulating osteocalcin bioactivity. Journal of Cell Biology 183(7):1235-1242.

Krook L, Wimsatt WA, Whalen JP, MacIntyre I, Nunez EA. 1977. Calcitonin and hibernation bone loss in the bat (Myotis lucifugus). Cornell Vet 67(2):265-71.

Kwiecinski GG, Krook L, Wimsatt WA. 1987. Annual skeletal changes in the little brown bat, Myotis lucifugus lucifugus, with particular reference to pregnancy and lactation. American Journal of Anatomy 178(4):410-20.

Li CY, Price C, Delisser K, Nasser P, Laudier D, Clement M, Jepsen KJ, Schaffler MB. 2005. Long-term disuse osteoporosis seems less sensitive to bisphosphonate treatment than other osteoporosis. Journal of Bone and Mineral Research 20(1):117-24.

Lieben L, Callewaert F, Bouillon R. 2009. Bone and metabolism: a complex crosstalk. Hormone Research 71 Suppl 1:134-8.

McGee-Lawrence ME, Carey HV, Donahue SW. 2008. Mammalian hibernation as a model of disuse osteoporosis: the effects of physical inactivity on bone metabolism, structure, and strength. American Journal of Physiology Regulatory, Integrative and Comparative Physiology 295(6):R1999-2014.

McGee-Lawrence ME, Wojda SJ, Barlow LN, Drummer TD, Bunnell K, Auger J, Black HL, Donahue SW. 2009a. Six months of disuse during hibernation does not increase intracortical porosity or decrease cortical bone geometry, strength, or mineralization in black bear (Ursus americanus) femurs. Journal of Biomechanics 42(10):1378-83.

McGee-Lawrence ME, Wojda SJ, Barlow LN, Drummer TD, Castillo AB, Kennedy O, Condon KW, Auger J, Black HL, Nelson OL et al. . 2009b. Grizzly bears (Ursus arctos horribilis) and black bears (Ursus americanus) prevent trabecular bone loss during disuse (hibernation). Bone 45(6):1186-91.

McGee-Lawrence ME, Stoll DM, Mantila ER, Fahrner BK, Carey HV, Donahue SW. 2010. 13-lined ground squirrels (Ictidomys tridecemlineatus) show microstructural bone loss during hibernation but preserve bone macrostructural geometry and strength. Journal of Experimental Biology.

McGee-Lawrence ME, Stoll DM, Mantila ER, Fahrner BK, Carey HV, Donahue SW. 2011. Thirteen-lined ground squirrels (Ictidomys tridecemlineatus) show microstructural bone loss during hibernation but preserve bone macrostructural geometry and strength. Journal of Experimental Biology 214(Pt 8):1240-7.

McGee ME, Maki AJ, Johnson SE, Nelson OL, Robbins CT, Donahue SW. 2008 b. Decreased bone turnover with balanced resorption and formation prevent cortical 
bone loss during disuse (hibernation) in grizzly bears (Ursus arctos horribilis). Bone 42(2):396-404.

Mullender MG, Huiskes R, Versleyen H, Buma P. 1996. Osteocyte density and histomorphometric parameters in cancellous bone of the proximal femur in five mammalian species. J Orthop Res 14(6):972-9.

Ortmann S, Heldmaier G. 2000. Regulation of body temperature and energy requirements of hibernating Alpine marmots (Marmota marmota). American Journal of Physiology-Regulatory Integrative and Comparative Physiology 278(3):R698R704.

Salsbury CM, Armitage KB. 1994. Resting and field metabolic rates of adult male yellow-bellied marmots, Marmota flaviventris. Comparative Biochemistry and Physiology 108(4):579-88.

Shi Y, Yadav VK, Suda N, Liu XS, Guo XE, Myers MG, Jr., Karsenty G. 2008. Dissociation of the neuronal regulation of bone mass and energy metabolism by leptin in vivo. Proceedings of the National Academy of Sciences U S A 105(51):20529-33.

Takata S, Yasui N. 2001. Disuse osteoporosis. Journal of Medical Investigation 48(34):147-56.

Thomas DW, Dorais M, Bergeron JM. 1990. Winter Energy Budgets and Cost of Arousals for Hibernating Little Brown Bats, Myotis-Lucifugus. Journal of Mammalogy 71(3):475-479.

Utz JC, Nelson S, O'Toole BJ, van Breukelen F. 2009. Bone strength is maintained after 8 months of inactivity in hibernating golden-mantled ground squirrels, Spermophilus lateralis. Journal of Experimental Biology 212(17):2746-52.

Whalen JP, Krook L, Nunez EA. 1972. A radiographic and histologic study of bone in the active and hibernating bat (Myotis lucifugus). Anatomical Record 172(1):97108 .

Zallone AZ, Teti A, Primavera MV, Pace G. 1983. Mature osteocytes behaviour in a repletion period: the occurence of osteoplastic activity. Basic and Applied Histochemistry 27:191-204.

Zatzman ML, South FE. 1972. Renal function of the awake and hibernating marmot Marmota flaviventris. American Journal of Physiology 222(4):1035-9. 


\section{Complete List of References}

Alcobendas M, Baud CA, Castanet J. 1991. Structural-Changes of the Periosteocytic Area in Vipera-Aspis (L) (Ophidia, Viperidae) Bone Tissue in Various Physiological Conditions. Calcified Tissue International 49(1):53-57.

Alexander RM, Jayes AS, Maloiy GMO, Wathuta EM. 1979. Allometry of the Limb Bones of Mammals from Shrews (Sorex) to Elephant (Loxodonta). Journal of Zoology 189(Nov):305-314.

Anderson DC, Armitage KB, Hoffman RS. 1976. Socioecology of marmots: female reproductive strategies. Ecology 57(3):552-560.

Armitage KB, Downhower JF, Svendsen GE. 1976. Seasonal-Changes in Weights of Marmots. American Midland Naturalist 96(1):36-51.

Armitage KB, Melcher JC, Ward JM. 1990. Oxygen-Consumption and BodyTemperature in Yellow-Bellied Marmot Populations from Montane-Mesic and Lowland-Xeric Environments. Journal of Comparative Physiology B-Biochemical Systemic and Environmental Physiology 160(5):491-502.

Armitage KB, Blumstein DT, Woods BC. 2003. Energetics of hibernating yellow-bellied marmots (Marmota flaviventris). Comparative Biochemistry and Physiology Part A: Molecular and Integrative Physiology 134(1):101-14.

Bailey ED, Davis DE. 1965. The utilization of body fat during hibernation in woodchucks. Canadian Journal of Zoology 43(5):701-7.

Barboza PS, Farley SD, Robbins CT. 1997. Whole-body urea cycling and protein turnover during hyperphagia and dormancy in growing bears (Ursus americanus and U-arctos). Canadian Journal of Zoology-Revue Canadienne De Zoologie 75(12):2129-2136.

Baylink DJ, Wergedal JE. 1971. Bone formation by osteocytes. American Journal of Physiology 221(3):669-78.

Bentolila V, Boyce TM, Fyhrie DP, Drumb R, Skerry TM, Schaffler MB. 1998. Intracortical remodeling in adult rat long bones after fatigue loading. Bone 23(3):275-81.

Black DM, Delmas PD, Eastell R, Reid IR, Boonen S, Cauley JA, Cosman F, Lakatos P, Leung PC, Man Z et al. . 2007. Once-yearly zoledronic acid for treatment of postmenopausal osteoporosis. New England Journal of Medicine 356(18):180922. 
Bone HG, Hosking D, Devogelaer JP, Tucci JR, Emkey RD, Tonino RP, RodriguezPortales JA, Downs RW, Gupta J, Santora AC et al. . 2004. Ten years' experience with alendronate for osteoporosis in postmenopausal women. New England Journal of Medicine 350(12):1189-99.

Brown DC, Mulhausen RO, Andrew DJ, Seal US. 1971. Renal function in anesthetized dormant and active bears. American Journal of Physiology 220(1):293-8.

Bruce DS, Wiebers JE. 1970. Calcium and phosphate levels in bats (Myotis lucifugus) as function of season and activity. Experientia 26(6):625-7.

Busse B, Djonic D, Milovanovic P, Hahn M, Puschel K, Ritchie RO, Djuric M, Amling M. 2010. Decrease in the osteocyte lacunar density accompanied by hypermineralized lacunar occlusion reveals failure and delay of remodeling in aged human bone. Aging Cell 9(6):1065-1075.

Caillot-Augusseau A, Lafage-Proust MH, Soler C, Pernod J, Dubois F, Alexandre C. 1998. Bone formation and resorption biological markers in cosmonauts during and after a 180-day space flight (Euromir 95). Clinical Chemistry 44(3):578-85.

Casinos A, Quintana C, Viladiu C. 1993. Allometry and Adaptation in the Long Bones of a Digging Group of Rodents (Ctenomyinae). Zoological Journal of the Linnean Society 107(2):107-115.

Chesnut IC, Skag A, Christiansen C, Recker R, Stakkestad JA, Hoiseth A, Felsenberg D, Huss H, Gilbride J, Schimmer RC et al. . 2004. Effects of oral ibandronate administered daily or intermittently on fracture risk in postmenopausal osteoporosis. Journal of Bone and Mineral Research 19(8):1241-9.

Christodoulou C, Cooper C. 2003. What is osteoporosis? Postgrad Medical Journal 79(929):133-8.

Compston J. 2000. Prevention of osteoporotic fractures in post-menopausal women. Baillieres Best Practice and Research Clinical Endocrinology and Metabolism 14(2):251-64.

Davis DE. 1976. Hibernation and circannual rhythms of food consumption in marmots and ground squirrels. Quarterly Review of Biology 51(4):477-514.

Donahue SW, Galley SA, Vaughan MR, Patterson-Buckendahl P, Demers LM, Vance JL, McGee ME. 2006. Parathyroid hormone may maintain bone formation in hibernating black bears (Ursus americanus) to prevent disuse osteoporosis. Journal of Experimental Biology 209(Pt 9):1630-8.

Doty SB, Nunez EA. 1985. Activation of osteoclasts and the repopulation of bone surfaces following hibernation in the bat, Myotis lucifugus. Anatomical Record 213(4):481-95. 
Ducher G, Tournaire N, Meddahi-Pelle A, Benhamou CL, Courteix D. 2006. Short-term and long-term site-specific effects of tennis playing on trabecular and cortical bone at the distal radius. Journal of Bone and Mineral Metabolism 24(6):484-490.

Epstein S. 2006. Update of current therapeutic options for the treatment of postmenopausal osteoporosis. Clinical Therapeutics 28(2):151-73.

Eser P, Frotzler A, Zehnder Y, Wick L, Knecht H, Denoth J, Schiessl H. 2004. Relationship between the duration of paralysis and bone structure: a pQCT study of spinal cord injured individuals. Bone 34(5):869-80.

Farley SD, Robbins CT. 1995. Lactation, hibernation, and mass dynamics of American black bears and grizzly bears. Canadian Journal of Zoology-Revue Canadienne De Zoologie 73(12):2216-2222.

Florant GL, Heller HC. 1977. Cns Regulation of Body-Temperature in Euthermic and Hibernating Marmots (Marmota-Flaviventris). American Journal of Physiology 232(5):R203-R208.

Florant GL, Porst H, Peiffer A, Hudachek SF, Pittman C, Summers SA, Rajala MW, Scherer PE. 2004. Fat-cell mass, serum leptin and adiponectin changes during weight gain and loss in yellow-bellied marmots (Marmota flaviventris). Journal of Comparative Physiology B-Biochemical Systemic and Environmental Physiology 174(8):633-639.

Floyd T, Nelson RA, Wynne GF. 1990. Calcium and bone metabolic homeostasis in active and denning black bears (Ursus americanus). Clinical Orthopaedics and Related Research(255):301-9.

French AR. 1990. Age-class differences in the pattern of hibernation in yellow-bellied marmots, Marmota flaviventris. Oecologia 82(1):93-96.

Frotzler A, Berger M, Knecht H, Eser P. 2008. Bone steady-state is established at reduced bone strength after spinal cord injury: a longitudinal study using peripheral quantitative computed tomography (pQCT). Bone 43(3):549-55.

Gerdhem P, Obrant KJ. 2002. Effects of cigarette-smoking on bone mass as assessed by dual-energy X-ray absorptiometry and ultrasound. Osteoporos International 13(12):932-6.

Gross TS, Rubin CT. 1995. Uniformity of resorptive bone loss induced by disuse. Journal of Orthopaedic Research 13(5):708-14.

Haller AC, Zimny ML. 1977. Effects of hibernation on interradicular alveolar bone. Journal of Dental Research 56(12):1552-7. 
Harlow HJ, Lohuis T, Grogan RG, Beck TDI. 2002. Body mass and lipid changes by hibernating reproductive and nonreproductive black bears (Ursus americanus). Journal of Mammalogy 83(4):1020-1025.

Harvey KB, Donahue SW. 2004. Bending properties, porosity, and ash fraction of black bear (Ursus americanus) cortical bone are not compromised with aging despite annual periods of disuse. Journal of Biomechanics 37(10):1513-20.

Harvey KB, Drummer TD, Donahue SW. 2005. The tensile strength of black bear (Ursus americanus) cortical bone is not compromised with aging despite annual periods of hibernation. Journal of Biomechanics 38(11):2143-50.

Heinrich RE, Biknevicius AR. 1998. Skeletal allometry and interlimb scaling patterns in mustelid carnivorans. Journal of Morphology 235(2):121-34.

Heldmaier G, Ortmann S, Elvert R. 2004. Natural hypometabolism during hibernation and daily torpor in mammals. Respiratory Physiology and Neurobiology 141(3):317-29.

Hellgren EC, Vaughan MR, Kirkpatrick RL, Scanlon PF. 1990. Serial Changes in Metabolic Correlates of Hibernation in Female Black Bears. Journal of Mammalogy 71(3):291-300.

Hellgren EC. 1998. Physiology of Hibernation in Bears. Ursus 10:467-477.

Hernandez CJ, Beaupre GS, Keller TS, Carter DR. 2001. The influence of bone volume fraction and ash fraction on bone strength and modulus. Bone 29(1):74-78.

Indrekvam K, Husby OS, Gjerdet NR, Engester LB, Langeland N. 1991. Age-Dependent Mechanical-Properties of Rat Femur - Measured Invivo and Invitro. Acta Orthopaedica Scandinavica 62(3):248-252.

Jaworski ZF, Liskova-Kiar M, Uhthoff HK. 1980. Effect of Long-Term Immobilisation on the Pattern of Bone Loss in Older Dogs. Journal of Bone and Joint Surgery 62$\mathrm{B}(1): 104-110$.

Jaworski ZF, Uhthoff HK. 1986. Reversibility of nontraumatic disuse osteoporosis during its active phase. Bone 7(6):431-9.

Jee WS, Mori S, Li XJ, Chan S. 1990. Prostaglandin E2 enhances cortical bone mass and activates intracortical bone remodeling in intact and ovariectomized female rats. Bone 11(4):253-66.

Jorgensen L, Crabtree NJ, Reeve J, Jacobsen BK. 2000a. Ambulatory level and asymmetrical weight bearing after stroke affects bone loss in the upper and lower part of the femoral neck differently: bone adaptation after decreased mechanical loading. Bone 27(5):701-7. 
Jorgensen L, Jacobsen BK, Wilsgaard T, Magnus JH. 2000b. Walking after stroke: does it matter? Changes in bone mineral density within the first 12 months after stroke. A longitudinal study. Osteoporosis International 11(5):381-7.

Ju YI, Sone T, Okamoto T, Fukunaga M. 2008. Jump exercise during remobilization restores integrity of the trabecular architecture after tail suspension in young rats. Journal of Applied Physiology 104(6):1594-600.

Kaneps AJ, Stover SM, Lane NE. 1997. Changes in canine cortical and cancellous bone mechanical properties following immobilization and remobilization with exercise. Bone 21(5):419-23.

Kanis JA, Melton LJ, 3rd, Christiansen C, Johnston CC, Khaltaev N. 1994. The diagnosis of osteoporosis. Journal of Bone and Mineral Research 9(8):1137-41.

Karsenty G, Hinoi E, Gao N, Jung DY, Yadav V, Yoshizawa T, Myers MG, Chua SC, Kim JK, Kaestner KH. 2008. The sympathetic tone mediates leptin's inhibition of insulin secretion by modulating osteocalcin bioactivity. Journal of Cell Biology 183(7):1235-1242.

Kitao N, Fukui D, Hashimoto M, Osborne PG. 2009. Overwintering strategy of wild freeranging and enclosure-housed Japanese raccoon dogs (Nyctereutes procyonoides albus). International Journal of Biometeorology 53(2):159-165.

Krook L, Wimsatt WA, Whalen JP, MacIntyre I, Nunez EA. 1977. Calcitonin and hibernation bone loss in the bat (Myotis lucifugus). Cornell Vet 67(2):265-71.

Kwiecinski GG, Krook L, Wimsatt WA. 1987. Annual skeletal changes in the little brown bat, Myotis lucifugus lucifugus, with particular reference to pregnancy and lactation. American Journal of Anatomy 178(4):410-20.

Lang T, LeBlanc A, Evans H, Lu Y, Genant H, Yu A. 2004. Cortical and Trabecular Bone Mineral Loss From the Spine and Hip in Long-Duration Spaceflight. Journal of Bone and Mineral Research 19:1006-1012.

Law MR, Hackshaw AK. 1997. A meta-analysis of cigarette smoking, bone mineral density and risk of hip fracture: recognition of a major effect. British Medical Journal 315(7112):841-6.

Leblanc AD, Schneider VS, Evans HJ, Engelbretson DA, Krebs JM. 1990. Bone mineral loss and recovery after 17 weeks of bed rest. Journal of Bone and Mineral Research 5(8):843-50.

Lee TQ, Shapiro TA, Bell DM. 1997. Biomechanical properties of human tibias in longterm spinal cord injury. Journal of Rehabilitation Research and Development 34(3):295-302. 
Levenston ME. 1995. Periosteal bone formation stimulated by externally induced bending strains. Journal of Bone and Mineral Research 10(4):671-2.

Li CY, Price C, Delisser K, Nasser P, Laudier D, Clement M, Jepsen KJ, Schaffler MB. 2005. Long-term disuse osteoporosis seems less sensitive to bisphosphonate treatment than other osteoporosis. Journal of Bone and Mineral Research 20(1):117-24.

Lieben L, Callewaert F, Bouillon R. 2009. Bone and metabolism: a complex crosstalk. Hormone Research 71 Suppl 1:134-8.

Lohuis TD, Harlow HJ, Beck TD. 2007. Hibernating black bears (Ursus americanus) experience skeletal muscle protein balance during winter anorexia. Comparative Biochemistry and Physiology Part B Biochemistry and Molecular Biology 147(1):20-8.

Lundberg DA, Nelson RA, Wahner HW, Jones JD. 1976. Protein-Metabolism in Black Bear before and during Hibernation. Mayo Clinic Proceedings 51(11):716-722.

Mackey MS, Stevens ML, Ebert DC, Tressler DL, Combs KS, Lowry CK, Smith PN, Mcosker JE. 1995. The Ferret as a Small Animal-Model with Bmu-Based Remodeling for Skeletal Research. Bone 17(4):S191-S196.

Matson J. 1946. Notes on Dormancy in the Black Bear. Journal of Mammalogy 27(3):203-212.

McCreadie BR, Hollister SJ, Schaffler MB, Goldstein SA. 2004. Osteocyte lacuna size and shape in women with and without osteoporotic fracture. Journal of Biomechanics 37(4):563-572.

McGee-Lawrence ME, Carey HV, Donahue SW. 2008. Mammalian hibernation as a model of disuse osteoporosis: the effects of physical inactivity on bone metabolism, structure, and strength. American Journal of Physiology Regulatory, Integrative and Comparative Physiology 295(6):R1999-2014.

McGee-Lawrence ME, Wojda SJ, Barlow LN, Drummer TD, Bunnell K, Auger J, Black HL, Donahue SW. 2009a. Six months of disuse during hibernation does not increase intracortical porosity or decrease cortical bone geometry, strength, or mineralization in black bear (Ursus americanus) femurs. Journal of Biomechanics 42(10):1378-83.

McGee-Lawrence ME, Wojda SJ, Barlow LN, Drummer TD, Castillo AB, Kennedy O, Condon KW, Auger J, Black HL, Nelson OL et al. . 2009b. Grizzly bears (Ursus arctos horribilis) and black bears (Ursus americanus) prevent trabecular bone loss during disuse (hibernation). Bone 45(6):1186-91. 
McGee-Lawrence ME, Stoll DM, Mantila ER, Fahrner BK, Carey HV, Donahue SW. 2010. 13-lined ground squirrels (Ictidomys tridecemlineatus) show microstructural bone loss during hibernation but preserve bone macrostructural geometry and strength. Journal of Experimental Biology.

McGee-Lawrence ME, Stoll DM, Mantila ER, Fahrner BK, Carey HV, Donahue SW. 2011. Thirteen-lined ground squirrels (Ictidomys tridecemlineatus) show microstructural bone loss during hibernation but preserve bone macrostructural geometry and strength. Journal of Experimental Biology 214(Pt 8):1240-7.

McGee ME, Magic KW, Miller DL, Maki AJ, Donahue SW. 2007a. Black bear femoral porosity decreases and mechanical properties increase with age despite annual periods of disuse (hibernation). Engineering Fracture Mechanics 74(12):19421952.

McGee ME, Miller DL, Auger J, Black HL, Donahue SW. 2007b. Black bear femoral geometry and cortical porosity are not adversely affected by ageing despite annual periods of disuse (hibernation). Journal of Anatomy 210(2):160-9.

McGee ME, Barlow LN, Simoni KJ, Wojda SJ, Auger J, Black HL, Donahue SW. 2008a. Post-hibernation black bears (Ursus americanus) do not demonstrate cortical bone loss compared to pre-hibernation bears despite 6 months of disuse.

McGee ME, Maki AJ, Johnson SE, Nelson OL, Robbins CT, Donahue SW. 2008 b. Decreased bone turnover with balanced resorption and formation prevent cortical bone loss during disuse (hibernation) in grizzly bears (Ursus arctos horribilis). Bone 42(2):396-404.

Modlesky CM, Majumdar S, Narasimhan A, Dudley GA. 2004. Trabecular bone microarchitecture is deteriorated in men with spinal cord injury. Journal of Bone and Mineral Research 19(1):48-55.

Modlesky CM, Slade JM, Bickel CS, Meyer RA, Dudley GA. 2005. Deteriorated geometric structure and strength of the midfemur in men with complete spinal cord injury. Bone 36(2):331-9.

Mosekilde L. 1995. Assessing bone quality--animal models in preclinical osteoporosis research. Bone 17(4 Suppl):343S-352S.

Mullender MG, Huiskes R, Versleyen H, Buma P. 1996. Osteocyte density and histomorphometric parameters in cancellous bone of the proximal femur in five mammalian species. J Orthop Res 14(6):972-9.

Nelson RA. 1973. Winter sleep in the black bear. A physiologic and metabolic marvel. Mayo Clinic Proceedings 48(10):733-7. 
Nieminen P, Finnila MA, Tuukkanen J, Jamsa T, Mustonen AM. 2010. Preservation of bone mass and biomechanical properties during winter sleep-the raccoon dog (Nyctereutes procyonoides) as a novel model species. Bone.

Organization WH. 1994. Assessment of fracture risk and its application to screening for postmenopausal osteoporosis. Report of a WHO Study Group. Geneva: World Health Organization.

Ortmann S, Heldmaier G. 2000. Regulation of body temperature and energy requirements of hibernating Alpine marmots (Marmota marmota). American Journal of Physiology-Regulatory Integrative and Comparative Physiology 278(3):R698R704.

Pardy CK, Wohl GR, Ukrainetz PJ, Sawers A, Boyd SK, Zernicke RF. 2004. Maintenance of bone mass and architecture in denning black bears (ursus americanus). Journal of Zoology, London 263:359-364.

Park KJ, Jones G, Ransome RD. 2000. Torpor, arousal and activity of hibernating Greater Horseshoe Bats (Rhinolophus ferrumequinum). Functional Ecology 14(5):580588.

Ragnarsson KT, Sell GH. 1981. Lower extremity fractures after spinal cord injury: a retrospective study. Archives of Physical Medicine amd Rehabilitation 62(9):41823.

Ramnemark A, Nyberg L, Borssen B, Olsson T, Gustafson Y. 1998. Fractures after stroke. Osteoporos International 8(1):92-5.

Rauch F, Travers R, Glorieux FH. 2007. Intracortical remodeling during human bone development--a histomorphometric study. Bone 40(2):274-80.

Ray NF, Chan JK, Thamer M, Melton LJ, 3rd. 1997. Medical expenditures for the treatment of osteoporotic fractures in the United States in 1995: report from the National Osteoporosis Foundation. Journal of Bone and Mineral Research 12(1):24-35.

Reginster J, Minne HW, Sorensen OH, Hooper M, Roux C, Brandi ML, Lund B, Ethgen D, Pack S, Roumagnac I et al. . 2000. Randomized trial of the effects of risedronate on vertebral fractures in women with established postmenopausal osteoporosis. Vertebral Efficacy with Risedronate Therapy (VERT) Study Group. Osteoporos International 11(1):83-91.

Riggs BL, Melton LJ, 3rd. 1995. The worldwide problem of osteoporosis: insights afforded by epidemiology. Bone 17(5 Suppl):505S-511S. 
Rittweger J, Beller G, Armbrecht G, Mulder E, Buehring B, Gast U, Dimeo F, Schubert $\mathrm{H}$, de Haan A, Stegeman DF et al. . Prevention of bone loss during 56 days of strict bed rest by side-alternating resistive vibration exercise. Bone 46(1):137-47.

Rittweger J, Frost HM, Schiessl H, Ohshima H, Alkner B, Tesch P, Felsenberg D. 2005. Muscle atrophy and bone loss after 90 days' bed rest and the effects of flywheel resistive exercise and pamidronate: results from the LTBR study. Bone 36(6):1019-29.

Rubin C, Gross T, Qin YX, Fritton S, Guilak F, McLeod K. 1996. Differentiation of the bone-tissue remodeling response to axial and torsional loading in the turkey ulna. Journal of Bone and Joint Surgery 78(10):1523-33.

Rubin CT. 1984. Skeletal Strain and the Functional-Significance of Bone Architecture. Calcified Tissue International 36:S11-S18.

Ruff CB. 1984. Allometry between length and cross-sectional dimensions of the femur and tibia in Homo sapiens sapiens. American Journal of Physical Anthropology 65(4):347-58.

Salsbury CM, Armitage KB. 1994. Resting and field metabolic rates of adult male yellow-bellied marmots, Marmota flaviventris. Comparative Biochemistry and Physiology 108(4):579-88.

Sartorelli P, Calderola S, Sala M, Citterio C, Lanfranchi P. 2004. Seasonal changes in serum metabolites in free-ranging alpine marmots (Marmota marmota). Journal of Comparative Physiology B-Biochemical Systemic and Environmental Physiology 174(4):355-61.

Shi Y, Yadav VK, Suda N, Liu XS, Guo XE, Myers MG, Jr., Karsenty G. 2008. Dissociation of the neuronal regulation of bone mass and energy metabolism by leptin in vivo. Proceedings of the National Academy of Sciences U S A 105(51):20529-33.

Spector ER, Smith SM, Sibonga JD. 2009. Skeletal effects of long-duration head-down bed rest. Aviation Space and Environmental Medicine 80(5 Suppl):A23-8.

Steinberg B, Singh IJ, Mitchell OG. 1981. The effects of cold-stress. Hibernation, and prolonged inactivity on bone dynamics in the golden hamster, Mesocricetus auratus. Journal of Morphology 167(1):43-51.

Steinberg B, Singh IJ, Mitchell OG. 1986. An autoradiographic study of the uptake of tritiated proline by osteoblasts during hibernation. Histology and Histopathology $1(2): 155-60$. 
Stover SM, Pool RR, Martin RB, Morgan JP. 1992. Histological Features of the Dorsal Cortex of the 3rd Metacarpal Bone Mid-Diaphysis during Postnatal-Growth in Thoroughbred Horses. Journal of Anatomy 181:455-469.

Swartz SM, Parker A, Huo C. 1998. Theoretical and empirical scaling patterns and topological homology in bone trabeculae. Journal of Experimental Biology 201(Pt 4):573-90.

Takata S, Yasui N. 2001. Disuse osteoporosis. Journal of Medical Investigation 48(34):147-56.

Tazawa K, Hoshi K, Kawamoto S, Tanaka M, Ejiri S, Ozawa H. 2004. Osteocytic osteolysis observed in rats to which parathyroid hormone was continuously administered. Journal of Bone and Mineral Metabolism 22(6):524-529.

Teti A, Zallone A. 2009. Do osteocytes contribute to bone mineral homeostasis? Osteocytic osteolysis revisited. Bone 44(1):11-6.

Thomas DW, Dorais M, Bergeron JM. 1990. Winter Energy Budgets and Cost of Arousals for Hibernating Little Brown Bats, Myotis-Lucifugus. Journal of Mammalogy 71(3):475-479.

Tilton FE, Degioanni JJ, Schneider VS. 1980. Long-term follow-up of Skylab bone demineralization. Aviation Space and Environmental Medicine 51(11):1209-13.

Tinker DB, Harlow HJ, Beck TD. 1998. Protein use and muscle-fiber changes in freeranging, hibernating black bears. Physiological Zoology 71(4):414-24.

Trebacz H. 2001. Disuse-induced deterioration of bone strength is not stopped after free remobilization in young adult rats. Journal of Biomechanics 34(12):1631-1636.

Turner CH, Burr DB. 2001. Experimental techniques for bone mechanics. In: Cowin SC, editor. Bone Mechanics Handbook. Boca Raton, FL: CRC Press. p. 7-1--7-35.

Turner RT, Evans GL, Wakley GK. 1995. Spaceflight results in depressed cancellous bone formation in rat humeri. Aviation Space and Environmental Medicine 66(8):770-4.

Turner RT, Lotinun S, Hefferan TE, Morey-Holton E. 2006. Disuse in adult male rats attenuates the bone anabolic response to a therapeutic dose of parathyroid hormone. J Appl Physiol 101(3):881-6.

Ulrich D, Van Rietbergen B, Laib A, Ruegsegger P. 1999. The ability of threedimensional structural indices to reflect mechanical aspects of trabecular bone. Bone 25(1):55-60. 
Utz JC, Nelson S, O'Toole BJ, van Breukelen F. 2009. Bone strength is maintained after 8 months of inactivity in hibernating golden-mantled ground squirrels, Spermophilus lateralis. Journal of Experimental Biology 212(17):2746-52.

Vable M. 2002. Mechanics of Materials. Oxford University Press, Inc. p. 728.

Vestergaard P, Krogh K, Rejnmark L, Mosekilde L. 1998. Fracture rates and risk factors for fractures in patients with spinal cord injury. Spinal Cord 36(11):790-6.

Ward JM, Armitage KB. 1981. Circannual rhythms of food consumption, body mass, and metabolism in yellow-bellied marmots. Comparative Biochemistry and Physiology, A. Comparative Physiology 69A:621-626.

Weinreb M, Rodan GA, Thompson DD. 1989. Osteopenia in the immobilized rat hind limb is associated with increased bone resorption and decreased bone formation. Bone 10(3):187-94.

Weinreb M, Patael H, Preisler O, Ben-Shemen S. 1997. Short-term healing kinetics of cortical and cancellous bone osteopenia induced by unloading during the reloading period in young rats. Virchows Archive 431(6):449-52.

Whalen JP, Krook L, Nunez EA. 1972. A radiographic and histologic study of bone in the active and hibernating bat (Myotis lucifugus). Anatomical Record 172(1):97108 .

Wright PH, Jowsey JO, Robb RA. 1978. Osteocyte Lacunar Area in Normal Bone, Hyper-Parathyroidism, Renal-Disease, and Osteoporosis. Surgical Forum 29:558559.

Wronski TJ, Morey ER. 1983. Inhibition of cortical and trabecular bone formation in the long bones of immobilized monkeys. Clinical Orthopaedics and Related Research(181):269-76.

Wronski TJ, Moreyholton ER, Doty SB, Maese AC, Walsh CC. 1987. Histomorphometric Analysis of Rat Skeleton Following Spaceflight. American Journal of Physiology 252(2):R252-R255.

Yonezu H, Takata S, Shibata A. 2004. Effects of unilateral sciatic neurectomy on growing rat femur as assessed by peripheral quantitative computed tomography, Fourier transform infrared spectroscopy and bending test. Journal of Medical Investigation 51(1-2):96-102.

Young DR, Niklowitz WJ, Brown RJ, Jee WS. 1986. Immobilization-associated osteoporosis in primates. Bone 7(2):109-17.

Young PJ. 1990. Hibernating Patterns of Free-Ranging Columbian Ground-Squirrels. Oecologia 83(4):504-511. 
Zallone AZ, Teti A, Primavera MV, Pace G. 1983. Mature osteocytes behaviour in a repletion period: the occurence of osteoplastic activity. Basic and Applied Histochemistry 27:191-204.

Zatzman ML, South FE. 1972. Renal function of the awake and hibernating marmot Marmota flaviventris. American Journal of Physiology 222(4):1035-9.

Zatzman ML, South FE. 1975. Concentration of urine by the hibernating marmot. American Journal of Physiology 228(5):1336-40.

Zervanos SM, Maher CR, Waldvogel JA, Florant GL. 2010. Latitudinal Differences in the Hibernation Characteristics of Woodchucks (Marmota monax). Physiological and Biochemical Zoology 83(1):135-141.

Zerwekh JE, Ruml LA, Gottschalk F, Pak CY. 1998. The effects of twelve weeks of bed rest on bone histology, biochemical markers of bone turnover, and calcium homeostasis in eleven normal subjects. Journal of Bone and Mineral Research 13(10):1594-601.

Zimmerman GD, McKean TA, Hardt AB. 1976. Hibernation and disuse osteoporosis. Cryobiology 13(1):84-94. 


\section{Appendix A}

Lacunar properties are presented here for all four measurements; all lacunae in focus in the field of view, lacunae fully surrounded by a halo, lacunae with any portion of a halo, lacunae with no halo. The results previously reported in the results section were for all lacunae in the field of view, this data is repeated here in more detail (including how properties vary by octant). Overall, regardless of which set was used, seasonal changes were the similar. Lacunar area, porosity, and density are lower in posthibernation samples. However, how properties vary by octant or endosteal/periosteal location changes between measurement types. Figure A.1 shows representative images of the lacunae measured. Table A.1 is a summary of how the results from measurement types compare; subsequent tables throughout the appendix show values for properties within the different subsets of data.

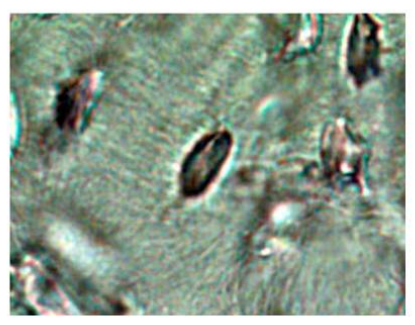

Partial Halo

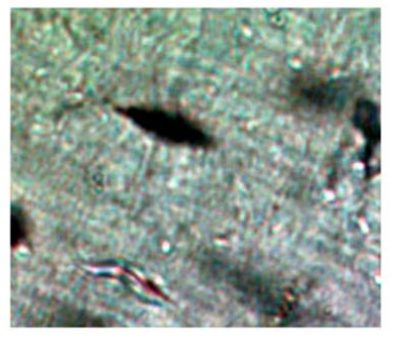

Non Halo

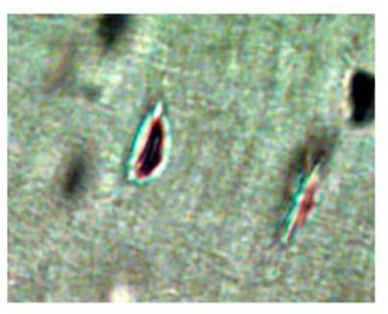

Halo

Figure A.1: Representative images of lacunae with a halo, partial halo or no halo. 
Table A.1

Summary of how results compare for each measurement type.

\begin{tabular}{|c|c|c|c|c|}
\hline & All lacunae & $\begin{array}{c}\text { Only } 100 \% \\
\text { halo }\end{array}$ & $\begin{array}{c}\text { Halo+partial } \\
\text { halo }\end{array}$ & No halo \\
\hline \multirow{4}{*}{$\begin{array}{c}\text { Average } \\
\text { lacunar } \\
\text { area }\end{array}$} & $\begin{array}{l}\text { Spring lower } \\
\text { than fall }\end{array}$ & $\begin{array}{l}\text { Spring lower } \\
\text { than fall }\end{array}$ & $\begin{array}{l}\text { Spring lower } \\
\text { than fall }\end{array}$ & $\begin{array}{l}\text { Spring lower } \\
\text { than fall }\end{array}$ \\
\hline & $\begin{array}{l}\text { Endosteal lower } \\
\text { than periosteal }\end{array}$ & $\begin{array}{l}\text { Endosteal lower } \\
\text { than periosteal }\end{array}$ & $\begin{array}{l}\text { Endosteal lower } \\
\text { than periosteal }\end{array}$ & $\begin{array}{l}\text { Endosteal lower } \\
\text { than periosteal }\end{array}$ \\
\hline & Octants differ & Octants differ & Octants differ & $\begin{array}{l}\text { Octants do not } \\
\text { differ }\end{array}$ \\
\hline & $\begin{array}{l}\text { Spring lower } \\
\text { than fall }\end{array}$ & $\begin{array}{l}\text { Spring tends to } \\
\text { be lower than } \\
\text { fall }\end{array}$ & $\begin{array}{l}\text { Spring lower } \\
\text { than fall }\end{array}$ & $\begin{array}{l}\text { Spring lower } \\
\text { than fall }\end{array}$ \\
\hline \multirow[t]{3}{*}{$\begin{array}{c}\text { Lacunar } \\
\text { density }\end{array}$} & $\begin{array}{l}\text { Endosteal } \\
\text { higher than } \\
\text { periosteal }\end{array}$ & $\begin{array}{l}\text { Endosteal } \\
\text { higher than } \\
\text { periosteal }\end{array}$ & $\begin{array}{l}\text { Endosteal } \\
\text { higher than } \\
\text { periosteal }\end{array}$ & $\begin{array}{l}\text { Endosteal } \\
\text { higher than } \\
\text { periosteal }\end{array}$ \\
\hline & Octants differ & $\begin{array}{l}\text { Octants do not } \\
\text { differ }\end{array}$ & Octants differ & Octants differ \\
\hline & $\begin{array}{l}\text { Spring lower } \\
\text { than fall }\end{array}$ & $\begin{array}{l}\text { Spring lower } \\
\text { than fall }\end{array}$ & $\begin{array}{l}\text { Spring lower } \\
\text { than fall }\end{array}$ & $\begin{array}{l}\text { Spring lower } \\
\text { than fall }\end{array}$ \\
\hline \multirow[t]{2}{*}{$\begin{array}{l}\text { Lacunar } \\
\text { porosity }\end{array}$} & $\begin{array}{l}\text { Endosteal not } \\
\text { different from } \\
\text { periosteal }\end{array}$ & $\begin{array}{l}\text { Endosteal } \\
\text { higher than } \\
\text { periosteal }\end{array}$ & $\begin{array}{c}\text { Endosteal not } \\
\text { different from } \\
\text { periosteal }\end{array}$ & $\begin{array}{c}\text { Endosteal not } \\
\text { different from } \\
\text { periosteal }\end{array}$ \\
\hline & Octants differ & $\begin{array}{l}\text { Octants do not } \\
\text { differ }\end{array}$ & $\begin{array}{l}\text { Octants do not } \\
\text { differ }\end{array}$ & Octants differ \\
\hline
\end{tabular}

\section{All lacunae in the field of view}

Lacunar properties are lower in post-hibernation samples, Table A.2. Lacunar area, porosity and density vary by octant. Specific differences of lacunar properties between octants are provided in Tables A.3-A5. Lacunar area and density are different in endosteal and periosteal regions of the cross-section as well (Table A.6). 
Table A.2

All lacunae-Average lacunar area, porosity, and density are lower in post-hibernation samples $(\mathbf{p}<0.0001)$.

\begin{tabular}{|c|c|c|c|c|}
\hline Property & Units & $\begin{array}{c}\text { Pre-hibernation } \\
\text { (Fall) mean }\end{array}$ & $\begin{array}{c}\text { Post-hibernation } \\
\text { (Spring) mean }\end{array}$ & p-value \\
\hline $\begin{array}{c}\text { Average } \\
\text { lacunar area }\end{array}$ & $\mu \mathrm{m}^{2}$ & $49.26 \pm 7.8$ & $45.08 \pm 7.8$ & $<\mathbf{0 . 0 0 0 1}$ \\
\hline $\begin{array}{c}\text { Lacunar } \\
\text { porosity }\end{array}$ & $\%$ & $0.95 \pm 0.3913$ & $0.79 \pm 0.26$ & $<\mathbf{0 . 0 0 0 1}$ \\
\hline $\begin{array}{c}\text { Lacunar } \\
\text { density }\end{array}$ & $\# / \mathrm{mm}^{2}$ & $193 \pm 60.9$ & $175 \pm 30.8$ & $<\mathbf{0 . 0 0 0 1}$ \\
\hline
\end{tabular}

Table A.3

All lacunae-Average lacunar area for each octant, area is different by octant $(p<0.0001)$. Octants with the same letters are not significantly different from each other. Data presented is for all samples (spring and fall groups combined).

\begin{tabular}{|l|c|l|}
\hline \multicolumn{3}{|c|}{ Average lacunar area $\left(\mu \mathrm{m}^{2}\right)(\mathrm{p}<0.0001)$} \\
\hline \multicolumn{1}{|c|}{ Octant } & Mean $\pm \mathrm{SD}$ & \\
\hline Anterior & $45.9 \pm 7.2$ & A,B \\
\hline Anterior-Lateral & $45.3 \pm 7.1$ & A,B \\
\hline Anterior-Medial & $46.1 \pm 6.7$ & A,B \\
\hline Lateral & $46.1 \pm 8.9$ & A,B \\
\hline Medial & $47 \pm 7.4$ & A,B \\
\hline Posterior & $49.1 \pm 8.7$ & C \\
\hline Posterior-Lateral & $48.7 \pm 8.2$ & B,C \\
\hline Posterior-Medial & $49.3 \pm 8.8$ & C \\
\hline
\end{tabular}

Table A.4

All lacunae-Lacunar porosity data for each octant, porosity is different by octant $(p=0.0162)$. Octants with the same letters are not significantly different from each other. Data presented is for all samples (spring and fall groups combined).

\begin{tabular}{|l|c|l|}
\hline \multicolumn{3}{|c|}{ Lacunar porosity $(\%)(\mathrm{p}=0.0162)$} \\
\hline \multicolumn{1}{|c|}{ Octant } & Mean $\pm \mathrm{SD}$ & \\
\hline Anterior & $0.84 \pm 0.3$ & A,B \\
\hline Anterior-Lateral & $0.86 \pm 0.3$ & A,B \\
\hline Anterior-Medial & $0.93 \pm 0.29$ &, $\mathrm{~B}$ \\
\hline Lateral & $0.87 \pm 0.3$ & A,B \\
\hline Medial & $0.9 \pm 0.34$ & A,B \\
\hline Posterior & $0.81 \pm 0.3$ & A \\
\hline Posterior-Lateral & $0.9 \pm 0.28$ & A,B \\
\hline Posterior-Medial & $0.83 \pm 0.29$ & A,B \\
\hline
\end{tabular}


Table A.5

All lacunae-Lacunar density data for each octant, lacunar density is different by octant $(p<0.0001)$. Octants with the same letters are not significantly different from each other. Data presented is for all samples (spring and fall groups combined).

\begin{tabular}{|l|c|c|}
\hline \multicolumn{3}{|c|}{ Lacunar density $\left(\# / \mathrm{mm}^{2}\right)(\mathrm{p}<0.0001)$} \\
\hline \multicolumn{1}{|c|}{ Octant } & Mean $\pm \mathrm{SD}$ & \\
\hline Anterior & $183 \pm 61.2$ & A,B,C \\
\hline Anterior-Lateral & $188 \pm 52.2$ & A,B,C \\
\hline Anterior-Medial & $203 \pm 61.3$ & B,C \\
\hline Lateral & $186 \pm 55.8$ & A,B,C \\
\hline Medial & $192 \pm 61.6$ & B,C \\
\hline Posterior & $165 \pm 50.2$ & \\
\hline Posterior-Lateral & $187 \pm 52.9$ & A,B,C \\
\hline Posterior-Medial & $169 \pm 49.8$ & A \\
\hline
\end{tabular}

Table A.6

All lacunae-Average lacunar area is lower in the endosteal region. Lacunar density is higher in endosteal regions. Lacunar porosity is not different between sampling areas. Data presented is for all samples (spring and fall groups combined).

\begin{tabular}{|c|c|c|c|c|}
\hline Property & Units & Periosteal (mean) & Endosteal (mean) & p-value \\
\hline $\begin{array}{c}\text { Average } \\
\text { lacunar area }\end{array}$ & $\mu \mathrm{m}^{2}$ & $49.48 \pm 7.45$ & $44.87 \pm 7.92$ & $<\mathbf{0 . 0 0 0 1}$ \\
\hline $\begin{array}{c}\text { Lacunar } \\
\text { porosity }\end{array}$ & $\%$ & $0.859 \pm 0.302$ & $0.876 \pm 0.303$ & 0.3418 \\
\hline $\begin{array}{c}\text { Lacunar } \\
\text { density }\end{array}$ & $\# / \mathrm{mm}^{2}$ & $173 \pm 53.5$ & $195 \pm 57.9$ & $<\mathbf{0 . 0 0 0 1}$ \\
\hline
\end{tabular}




\section{Lacunae with full halos only}

Average lacunar area $(\mathrm{p}<0.0001)$ and lacunar density $(\mathrm{p}<0.0001)$ are significantly lower in post-hibernation samples. Lacunar porosity tends to be lower $(p=0.059)$ in posthibernation samples also (Table A.7). Average lacunar area varies by octant, but porosity and lacunar density do not. Specific differences in lacunar area between octants are provided in Tables A.8-A10. Lacunar area and density are different in endosteal and periosteal regions of the cross section as well (Table A.11).

Table A.7

Lacunae with full halos-Average lacunar area and lacunar density are lower in post-hibernation samples $(p<$ $0.0001)$. Lacunar porosity tends to be lower in post-hibernation samples $(p=0.059)$.

\begin{tabular}{|c|c|c|c|c|}
\hline Property & Units & $\begin{array}{c}\text { Pre- } \\
\text { hibernation } \\
\text { (Fall) mean }\end{array}$ & $\begin{array}{c}\text { Post- } \\
\text { hibernation } \\
\text { (Spring) } \\
\text { mean }\end{array}$ & p-value \\
\hline $\begin{array}{c}\text { Average } \\
\text { lacunar area }\end{array}$ & $\mu \mathrm{m}^{2}$ & $48.25 \pm 10.53$ & $42.8 \pm 12.49$ & $<\mathbf{0 . 0 0 0 1}$ \\
\hline $\begin{array}{c}\text { Lacunar } \\
\text { porosity }\end{array}$ & $\%$ & $0.301 \pm 0.15$ & $0.257 \pm 0.13$ & 0.059 \\
\hline $\begin{array}{c}\text { Lacunar } \\
\text { density }\end{array}$ & $\# / \mathrm{mm}^{2}$ & $62.1 \pm 27$ & $58.9 \pm 27$ & $<\mathbf{0 . 0 0 0 1}$ \\
\hline
\end{tabular}

Table A.8

Lacunae with full halos-Average lacunar area is different between octants $(p<0.0001)$. Octants with the same letters are not significantly different from each other. Data presented is for all samples (spring and fall groups combined).

\begin{tabular}{|l|c|l|}
\hline \multicolumn{3}{|c|}{ Average lacunar area $\left(\mu \mathrm{m}^{2}\right)(\mathrm{p}<0.0001)$} \\
\hline \multicolumn{1}{|c|}{ Octant } & Mean $\pm \mathrm{SD}$ & \\
\hline Anterior & $42.3 \pm 12.09$ & $\mathrm{~A}$ \\
\hline Anterior-Lateral & $43.99 \pm 10.5$ & $\mathrm{~A}, \mathrm{~B}$ \\
\hline Anterior-Medial & $43.6 \pm 11.47$ & $\mathrm{~A}, \mathrm{~B}$ \\
\hline Lateral & $44.4 \pm 11.5$ & $\mathrm{~A}, \mathrm{~B}$ \\
\hline Medial & $46.1 \pm 10.23$ & $\mathrm{~A}, \mathrm{~B}, \mathrm{C}$ \\
\hline Posterior & $47.9 \pm 13.63$ & $\mathrm{~B}, \mathrm{C}$ \\
\hline Posterior-Lateral & $47.1 \pm 11.98$ & $\mathrm{~B}, \mathrm{C}$ \\
\hline Posterior-Medial & $48.9 \pm 11.94$ & $\mathrm{C}$ \\
\hline
\end{tabular}


Table A.9

Lacunae with full halos-Lacunar porosity is not different between octants $(p=0.2462)$. (Octants with the same letters are not significantly different from each other). Data presented is for all samples (spring and fall groups combined).

\begin{tabular}{|l|c|l|}
\hline \multicolumn{3}{|c|}{ Lacunar porosity $(\%)(\mathrm{p}=0.2462)$} \\
\hline \multicolumn{1}{|c|}{ Octant } & Mean \pm SD & \\
\hline Anterior & $0.262 \pm 0.143$ & A \\
\hline Anterior-Lateral & $0.268 \pm 0.134$ & A \\
\hline Anterior-Medial & $0.275 \pm 0.134$ & A \\
\hline Lateral & $0.273 \pm 0.136$ & A \\
\hline Medial & $0.281 \pm 0.129$ & A \\
\hline Posterior & $0.277 \pm 0.156$ & A \\
\hline Posterior-Lateral & $0.306 \pm 0.158$ & A \\
\hline Posterior-Medial & $0.294 \pm 0.14$ & A \\
\hline
\end{tabular}

Table A.10

Lacunae with full halos-Lacunar density is not different between octants $(p=0.358)$. (Octants with the same letters are not significantly different from each other). Data presented is for all samples (spring and fall groups combined).

\begin{tabular}{|l|c|l|}
\hline \multicolumn{3}{|c|}{ Lacunar density $\left(\# / \mathrm{mm}^{2}\right)(\mathrm{p}=0.358)$} \\
\hline \multicolumn{1}{|c|}{ Octant } & Mean $\pm \mathrm{SD}$ & \\
\hline Anterior & $59.46 \pm 30.38$ & $\mathrm{~A}$ \\
\hline Anterior-Lateral & $60.32 \pm 28.6$ & $\mathrm{~A}$ \\
\hline Anterior-Medial & $63.65 \pm 29.1$ & $\mathrm{~A}$ \\
\hline Lateral & $61.01 \pm 25.7$ & $\mathrm{~A}$ \\
\hline Medial & $60.84 \pm 24.8$ & $\mathrm{~A}$ \\
\hline Posterior & $55.65 \pm 25.5$ & $\mathrm{~A}$ \\
\hline Posterior-Lateral & $63.52 \pm 28.6$ & $\mathrm{~A}$ \\
\hline Posterior-Medial & $59.98 \pm 25$ & $\mathrm{~A}$ \\
\hline
\end{tabular}

Table A.11

Lacunae with full halos-Average lacunar area is lower in the endosteal region. Lacunar density and porosity are higher in endosteal regions. Data presented is for all samples (spring and fall groups combined).

\begin{tabular}{|c|c|c|c|c|}
\hline Property & Units & Periosteal (mean) & Endosteal (mean) & p-value \\
\hline $\begin{array}{c}\text { Average } \\
\text { lacunar area }\end{array}$ & $\mu \mathrm{m}^{2}$ & $47.42 \pm 12$ & $43.64 \pm 11.4$ & $<\mathbf{0 . 0 0 0 1}$ \\
\hline $\begin{array}{c}\text { Lacunar } \\
\text { porosity }\end{array}$ & $\%$ & $0.268 \pm 0.14$ & $0.291 \pm 0.14$ & $<\mathbf{0 . 0 0 0 1}$ \\
\hline $\begin{array}{c}\text { Lacunar } \\
\text { density }\end{array}$ & $\# / \mathrm{mm}^{2}$ & $54.8 \pm 25.3$ & $66.3 \pm 27.9$ & $\mathbf{0 . 0 0 9 4}$ \\
\hline
\end{tabular}




\section{Lacunae with any portion of halo (either a full halo or partial halo)}

Average lacunar area, lacunar density and lacunar porosity $(\mathrm{p}<0.0001)$ are significantly lower in post-hibernation samples (Table A.12). Average lacunar area and lacunar density vary by octant, but porosity does not. Specific differences in lacunar area between octants are provided in Tables A.13-A.15. Lacunar area and density are different in endosteal and periosteal regions of the cross section as well (Table A.16).

Table A.12

Lacunae with full halo or partial halo-Average lacunar area, lacunar porosity, and lacunar density are lower in post-hibernation samples $(\mathrm{p}<\mathbf{0 . 0 0 0 1})$.

\begin{tabular}{|c|c|c|c|c|}
\hline Property & Units & $\begin{array}{c}\text { Pre- } \\
\text { hibernation } \\
\text { (Fall) mean }\end{array}$ & $\begin{array}{c}\text { Post- } \\
\text { hibernation } \\
\text { (Spring) } \\
\text { mean }\end{array}$ & p-value \\
\hline $\begin{array}{c}\text { Average } \\
\text { lacunar area }\end{array}$ & $\mu \mathrm{m}^{2}$ & $35.01 \pm 9.13$ & $32.33 \pm 9.04$ & $<\mathbf{0 . 0 0 0 1}$ \\
\hline $\begin{array}{c}\text { Lacunar } \\
\text { porosity }\end{array}$ & $\%$ & $0.66 \pm 0.24$ & $0.55 \pm 0.19$ & $<\mathbf{0 . 0 0 0 1}$ \\
\hline $\begin{array}{c}\text { Lacunar } \\
\text { density }\end{array}$ & $\# / \mathrm{mm}^{2}$ & $136 \pm 44$ & $125 \pm 40$ & $<\mathbf{0 . 0 0 0 1}$ \\
\hline
\end{tabular}

Table A.13

Lacunae with full halo or partial halo-Average lacunar area is different between octants $(p<0.0001)$. Octants with the same letters are not significantly different from each other. Data presented is for all samples (spring and fall groups combined).

\begin{tabular}{|l|c|l|}
\hline \multicolumn{3}{|c|}{ Average lacunar area $\left(\mu \mathrm{m}^{2}\right)(\mathrm{p}<0.0001)$} \\
\hline \multicolumn{1}{|c|}{ Octant } & Mean $\pm \mathrm{SD}$ & \\
\hline Anterior & $32.7 \pm 8.8$ & A \\
\hline Anterior-Lateral & $31.98 \pm 7.8$ & A,B \\
\hline Anterior-Medial & $31.7 \pm 9.1$ & B \\
\hline Lateral & $32.8 \pm 9.4$ & A,B \\
\hline Medial & $33.8 \pm 9.3$ & A,B,C \\
\hline Posterior & $36.3 \pm 10$ & C \\
\hline Posterior-Lateral & $34.8 \pm 9.6$ & A,B,C \\
\hline Posterior-Medial & $35.2 \pm 8.4$ & A C C \\
\hline
\end{tabular}


Table A.14

Lacunae with full halo or partial halo-Lacunar porosity is not different between octants $(p=0.4206)$. (Octants with the same letters are not significantly different from each other). Data presented is for all samples (spring and fall groups combined).

\begin{tabular}{|l|c|l|}
\hline \multicolumn{3}{|c|}{ Lacunar porosity $(\%)(\mathrm{p}=0.4206)$} \\
\hline \multicolumn{1}{|c|}{ Octant } & Mean $\pm \mathrm{SD}$ & \\
\hline Anterior & $0.590 \pm 0.226$ & $\mathrm{~A}$ \\
\hline Anterior-Lateral & $0.596 \pm 0.204$ & $\mathrm{~A}$ \\
\hline Anterior-Medial & $0.626 \pm 0.223$ & $\mathrm{~A}$ \\
\hline Lateral & $0.601 \pm 0.209$ & $\mathrm{~A}$ \\
\hline Medial & $0.625 \pm 0.210$ & $\mathrm{~A}$ \\
\hline Posterior & $0.595 \pm 0.251$ & $\mathrm{~A}$ \\
\hline Posterior-Lateral & $0.639 \pm 0.223$ & $\mathrm{~A}$ \\
\hline Posterior-Medial & $0.589 \pm 0.206$ & $\mathrm{~A}$ \\
\hline
\end{tabular}

Table A.15

Lacunae with full halo or partial halo-Lacunar density varies between octants $(p=0.0027)$. (Octants with the same letters are not significantly different from each other). Data presented is for all samples (spring and fall groups combined).

\begin{tabular}{|l|c|l|}
\hline \multicolumn{3}{|c|}{ Lacunar density $\left(\# / \mathrm{mm}^{2}\right)(\mathrm{p}=0.0027)$} \\
\hline \multicolumn{1}{|c|}{ Octant } & Mean $\pm \mathrm{SD}$ & \\
\hline Anterior & $132 \pm 51.2$ & A,B \\
\hline Anterior-Lateral & $134 \pm 39.9$ & A,B \\
\hline Anterior-Medial & $138 \pm 45.9$ & A \\
\hline Lateral & $131 \pm 37.9$ & A,B \\
\hline Medial & $134 \pm 37.4$ & A,B \\
\hline Posterior & $12 \pm 39.2$ & B \\
\hline Posterior-Lateral & $133 \pm 41.8$ & A,B \\
\hline Posterior-Medial & $121 \pm 39$ & B \\
\hline
\end{tabular}

Table A.16

Lacunae with full halo or partial halo-Average lacunar area is lower in the endosteal region. Lacunar density is higher in endosteal regions. And there is no difference between endosteal and periosteal locations for lacunar porosity. Data presented is for all samples (spring and fall groups combined).

\begin{tabular}{|c|c|c|c|c|}
\hline Property & Units & Periosteal (mean) & Endosteal (mean) & p-value \\
\hline $\begin{array}{c}\text { Average } \\
\text { lacunar area }\end{array}$ & $\mu \mathrm{m}^{2}$ & $35.61 \pm 8.99$ & $31.73 \pm 8.96$ & $<\mathbf{0 . 0 0 0 1}$ \\
\hline $\begin{array}{c}\text { Lacunar } \\
\text { porosity }\end{array}$ & $\%$ & $0.608 \pm 0.218$ & $0.607 \pm 0.221$ & 0.9495 \\
\hline $\begin{array}{c}\text { Lacunar } \\
\text { density }\end{array}$ & $\# / \mathrm{mm}^{2}$ & $124 \pm 39.5$ & $137 \pm 43.5$ & $<\mathbf{0 . 0 0 0 1}$ \\
\hline
\end{tabular}




\section{Lacunae with no halo}

Average lacunar area $(\mathrm{p}<0.0001)$ and lacunar density $(\mathrm{p}<0.0001)$ are significantly lower in post-hibernation samples. Lacunar porosity tends to be lower $(p=0.059)$ in posthibernation samples also (Table A.17). Average lacunar area varies by octant, but porosity and lacunar density do not. Specific differences in lacunar area between octants are provided in Tables A.18-A20. Lacunar area and density are different in endosteal and periosteal regions of the cross section as well (Table A.21).

Table A.17

Lacunae with no halo-Average lacunar area, lacunar porosity, and lacunar density are lower in post-hibernation samples $(\mathbf{p}<0.0002)$.

\begin{tabular}{|c|c|c|c|c|}
\hline Property & Units & $\begin{array}{c}\text { Pre- } \\
\text { hibernation } \\
\text { (Fall) mean }\end{array}$ & $\begin{array}{c}\text { Post- } \\
\text { hibernation } \\
\text { (Spring) } \\
\text { mean }\end{array}$ & p-value \\
\hline $\begin{array}{c}\text { Average } \\
\text { lacunar area }\end{array}$ & $\mu \mathrm{m}^{2}$ & $48.16 \pm 13.22$ & $45.12 \pm 12.63$ & $\mathbf{0 . 0 0 0 2}$ \\
\hline $\begin{array}{c}\text { Lacunar } \\
\text { porosity }\end{array}$ & $\%$ & $0.285 \pm 0.18$ & $0.233 \pm 0.18$ & $<\mathbf{0 . 0 0 0 1}$ \\
\hline $\begin{array}{c}\text { Lacunar } \\
\text { density }\end{array}$ & $\# / \mathrm{mm}^{2}$ & $193 \pm 61$ & $174 \pm 51$ & $<\mathbf{0 . 0 0 0 1}$ \\
\hline
\end{tabular}

Table A.18

Lacunae with no halo-Average lacunar area is not different between octants $(p<0.3751)$. Octants with the same letters are not significantly different from each other. Data presented is for all samples (spring and fall groups combined).

\begin{tabular}{|l|c|l|}
\hline \multicolumn{3}{|c|}{ Average lacunar area $\left(\mu \mathrm{m}^{2}\right)(\mathrm{p}=0.3751)$} \\
\hline \multicolumn{1}{|c|}{ Octant } & Mean $\pm \mathrm{SD}$ & \\
\hline Anterior & $46.0 \pm 13$ & $\mathrm{~A}$ \\
\hline Anterior-Lateral & $46.1 \pm 13.17$ & $\mathrm{~A}$ \\
\hline Anterior-Medial & $46.2 \pm 11.81$ & $\mathrm{~A}$ \\
\hline Lateral & $45.6 \pm 14.32$ & $\mathrm{~A}$ \\
\hline Medial & $45.4 \pm 12.75$ & $\mathrm{~A}$ \\
\hline Posterior & $47.3 \pm 12.55$ & $\mathrm{~A}$ \\
\hline Posterior-Lateral & $47.3 \pm 12.53$ & $\mathrm{~A}$ \\
\hline Posterior-Medial & $49.0 \pm 13.78$ & $\mathrm{~A}$ \\
\hline
\end{tabular}


Table A.19

Lacunae with no halo-Lacunar porosity varies between octants $(p=0.0123)$. (Octants with the same letters are not significantly different from each other). Data presented is for all samples (spring and fall groups combined).

\begin{tabular}{|l|c|l|}
\hline \multicolumn{3}{|c|}{ Lacunar porosity $(\%)(\mathrm{p}=0.0123)$} \\
\hline \multicolumn{1}{|c|}{ Octant } & Mean $\pm \mathrm{SD}$ & \\
\hline Anterior & $0.245 \pm 0.17$ & A,B \\
\hline Anterior-Lateral & $0.262 \pm 0.17$ & A,B \\
\hline Anterior-Medial & $0.302 \pm 0.20$ & A \\
\hline Lateral & $0.263 \pm 0.19$ & A,B \\
\hline Medial & $0.279 \pm 0.23$ & A,B \\
\hline Posterior & $0.216 \pm 0.13$ & B \\
\hline Posterior-Lateral & $0.263 \pm 0.16$ & A,B \\
\hline Posterior-Medial & $0.244 \pm 0.16$ & A,B \\
\hline
\end{tabular}

Table A.20

Lacunae with no halo-Lacunar density varies between octants $(p<0.0001)$. (Octants with the same letters are not significantly different from each other). Data presented is for all samples (spring and fall groups combined).

\begin{tabular}{|l|c|c|}
\hline \multicolumn{3}{|c|}{ Lacunar density $\left(\# / \mathrm{mm}^{2}\right)(\mathrm{p}<0.0001)$} \\
\hline \multicolumn{1}{|c|}{ Octant } & Mean $\pm \mathrm{SD}$ & \multicolumn{2}{|c|}{} \\
\hline Anterior & $180 \pm 61.1$ & A,B \\
\hline Anterior-Lateral & $188 \pm 52.2$ & B,C \\
\hline Anterior-Medial & $203 \pm 61.26$ & \multicolumn{2}{c|}{ C,D } \\
\hline Lateral & $184 \pm 58$ & A,B,C \\
\hline Medial & $192 \pm 61.6$ & \multicolumn{2}{c|}{ B D } \\
\hline Posterior & $165 \pm 50.2$ & A \\
\hline Posterior-Lateral & $187 \pm 52.9$ & B,C E \\
\hline Posterior-Medial & $169 \pm 49.8$ & A $\quad$ E \\
\hline
\end{tabular}

Table A.21

Lacunae with no halo-Average lacunar area is lower in the endosteal region $(\mathbf{p}<\mathbf{0 . 0 0 0 1})$. Lacunar density is higher in endosteal regions $(p<0.0001)$. Lacunar porosity is not different between regions $(p=0.1267)$. Data presented is for all samples (spring and fall groups combined).

\begin{tabular}{|c|c|c|c|c|}
\hline Property & Units & Periosteal (mean) & Endosteal (mean) & p-value \\
\hline $\begin{array}{c}\text { Average } \\
\text { lacunar area }\end{array}$ & $\mu \mathrm{m}^{2}$ & $48.32 \pm 13.5$ & $44.96 \pm 12.3$ & $<\mathbf{0 . 0 0 0 1}$ \\
\hline $\begin{array}{c}\text { Lacunar } \\
\text { porosity }\end{array}$ & $\%$ & $0.251 \pm 0.172$ & $0.268 \pm 0.189$ & 0.1267 \\
\hline $\begin{array}{c}\text { Lacunar } \\
\text { density }\end{array}$ & $\# / \mathrm{mm}^{2}$ & $173 \pm 53.5$ & $194 \pm 58.6$ & $<\mathbf{0 . 0 0 0 1}$ \\
\hline
\end{tabular}

